\title{
Associations between the Adult ADHD Self-Report Rating Scale and the Test of Differential Inhibition and Attention
}

\author{
Andrew Benton Darling \\ West Virginia University, abdarling@mail.wvu.edu
}

Follow this and additional works at: https://researchrepository.wvu.edu/etd

Part of the Clinical Psychology Commons, and the Counseling Psychology Commons

\section{Recommended Citation \\ Darling, Andrew Benton, "Associations between the Adult ADHD Self-Report Rating Scale and the Test of Differential Inhibition and Attention" (2020). Graduate Theses, Dissertations, and Problem Reports. 7800. https://researchrepository.wvu.edu/etd/7800}

This Dissertation is protected by copyright and/or related rights. It has been brought to you by the The Research Repository @ WVU with permission from the rights-holder(s). You are free to use this Dissertation in any way that is permitted by the copyright and related rights legislation that applies to your use. For other uses you must obtain permission from the rights-holder(s) directly, unless additional rights are indicated by a Creative Commons license in the record and/ or on the work itself. This Dissertation has been accepted for inclusion in WVU Graduate Theses, Dissertations, and Problem Reports collection by an authorized administrator of The Research Repository @ WVU. For more information, please contact researchrepository@mail.wvu.edu. 
Associations between the Adult ADHD Self-Report Rating Scale and the Test of Differential Inhibition and Attention

Andrew Benton Darling

Follow this and additional works at: https://researchrepository.wvu.edu/etd

Part of the Clinical Psychology Commons, and the Counseling Psychology Commons 


\title{
Associations between the Adult ADHD Self-Report Rating Scale and the Test of Differential Inhibition and Attention
}

\section{A. Benton Darling, M.A.}

\author{
Dissertation submitted to the \\ College of Education and Human Services \\ at West Virginia University \\ in partial fulfillment of the requirements for the degree of \\ Doctor of Philosophy in \\ Counseling Psychology
}
Monica Leppma, Ph.D., Chair James Bartee, Ph.D. Jeffrey Daniels, Ph.D. Daniel Long, Ph.D.
Christine Schimmel, Ed.D.

Department of Counseling, Rehabilitation Counseling, and Counseling Psychology

\section{Morgantown, West Virginia 2019}

Keywords: attention deficit hyperactivity disorder, adult ADHD, continuous performance test, response control, motor response inhibition, stop signal task, assessment

Copyright 2019 A. Benton Darling, M.A. 


\begin{abstract}
Associations between the Adult ADHD Self-Report Rating Scale (ASRS) and the Test of Differential Inhibition and Attention (TDIA)
\end{abstract}

\title{
A. Benton Darling, M.A.
}

Attention-Deficit/Hyperactivity Disorder (ADHD) ranks among the most common mental health disorders in adults (APA, 2013). ADHD assessment is complicated by heterogenous symptoms, gender and age differences in diagnosis, variability in symptom manifestation across the lifespan, and comorbidity with other psychiatric disorders and medical conditions (Asherson, 2016; Willcut, 2012; Williamson \& Johnston, 2015). The stop-signal task (SST) identifies ADHD clinical groups in children and adults (Lifffijt et al., 2005), yet it remains unclear whether SST performance reflects general deficits in attention (Alderson et al., 2007) or a selective deficit in motor response inhibition (Aron \& Poldrack, 2005). Studies of SST often involve lower cognitive complexity without the additional inhibitory load produced by interference control (Uno et al., 2006). Currently, there is no research on SST with interference control in the adult population. The aim of this study was to assess the diagnostic utility of response inhibition metrics in the adult population on tasks with greater central processing demands. Forty-nine adults completed the Adult ADHD Self-Report Scale - V1.1 Symptoms Checklist and the Test of Differential Inhibition and Attention (TDIA). Results from hierarchical multiple linear regression analyses showed that TDIA metrics associated with motor response inhibition significantly predicted self-reported symptoms of inattention, hyperactivity-impulsivity, and combined ADHD, over and above metrics representing general attention. This study supports the clinical utility of SST with interference control in identifying ADHD in adults. Furthermore, the results support a conceptual model of ADHD wherein response control deficits are primary to the executive dysfunction associated with the disorder. Possible explanations for these results, limitations of the study, and future directions are explored. 


\section{ACKNOWLEDGEMENTS}

I would like to acknowledge the members of my dissertation committee for their guidance and encouragement during this process. Without you, this study would not have succeeded. To my clinical supervisors, especially Dr. Daniel Long and Dr. Narayan Gold, thank you for your support and inspiration. I am forever grateful for your mentorship. To West Virginia University's College of Education and Human Services, thank you for believing in me and providing me with the opportunity to pursue my dream. To the Carruth Center, with your support I discovered my passion as a psychologist. I will forever cherish the memories of our time together.

I would also like to thank my cohort - Adri, Chelsea, Connor, Tim, and Sarah - whose friendship made these past five years one of the greatest joys of my lifetime. You are special people whom I am lucky to consider colleagues and dear friends. May these Country Roads always take us home, to the place where we belong.

Finally, I would like to express my love and gratitude to my family, whose unwavering support over the years made this possible. I dedicate my work to you for all that you have contributed to this occasion. To Alex and my new family, the Kinders, you are a blessing. I am excited for the future we will share together. I love and thank you all for the joy you bring to my life. 
TABLE OF CONTENTS

CHAPTER 1: INTRODUCTION AND REVIEW OF SELECTED LITERATURE ............. 1

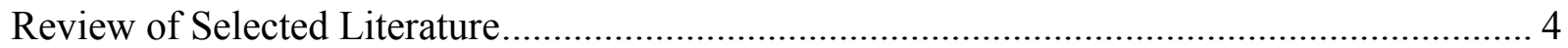

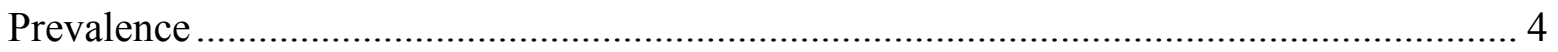

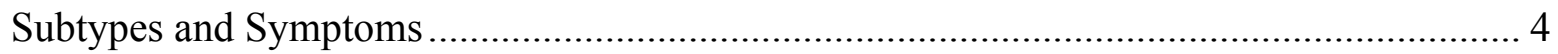

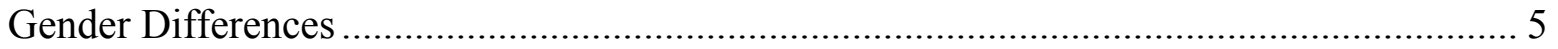

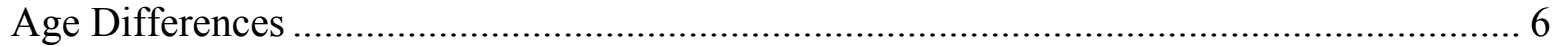

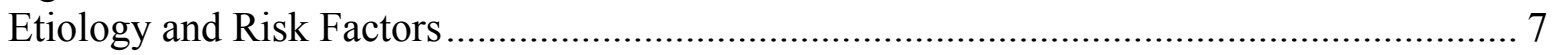

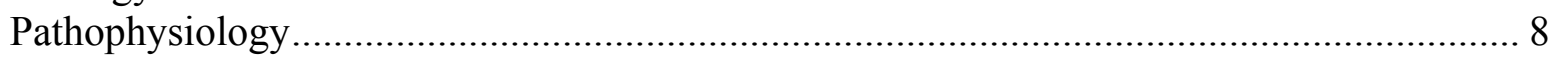

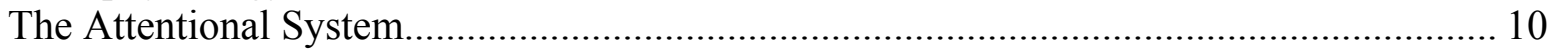

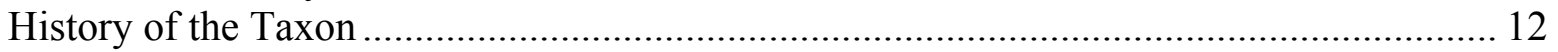

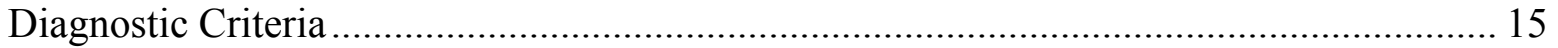

ADHD in Adolescence and Adulthood...................................................................... 16

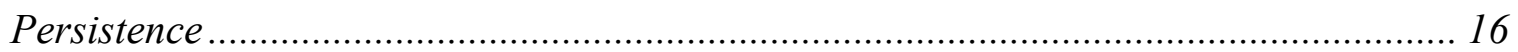

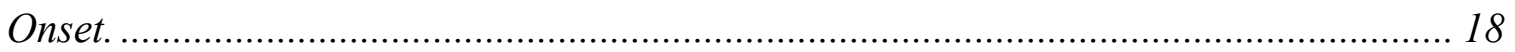

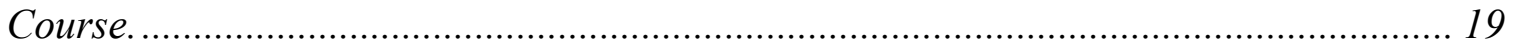

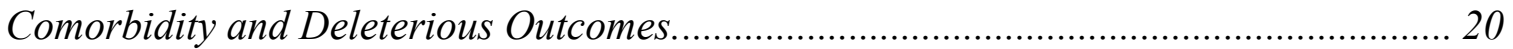

Assessment and Diagnosis of Adult ADHD ................................................................ 23

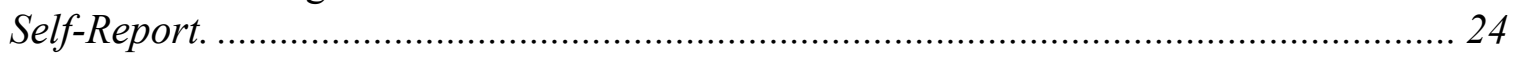

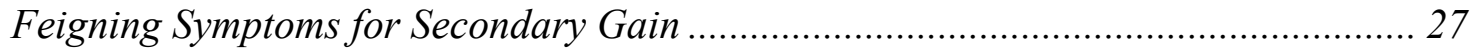

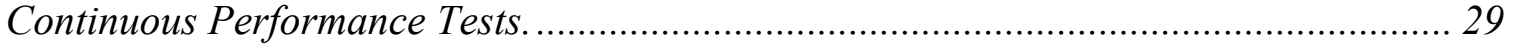

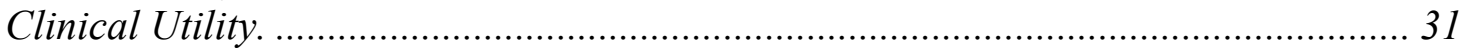

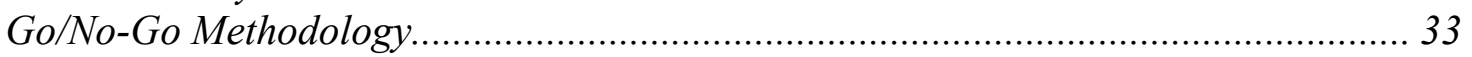

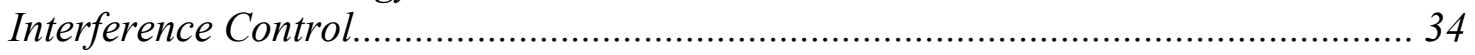

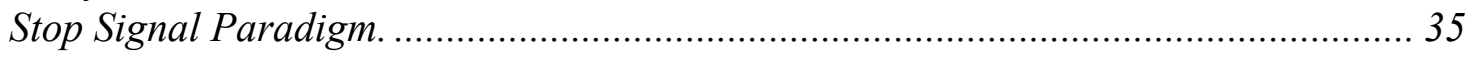

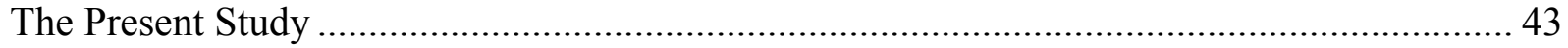

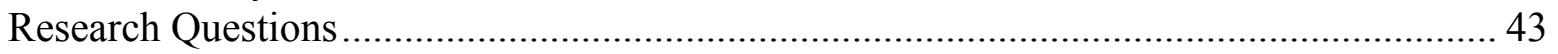

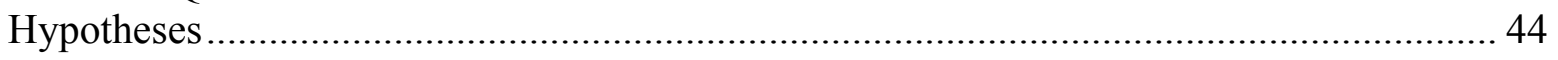

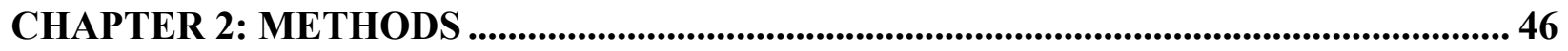

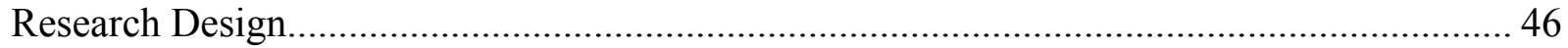

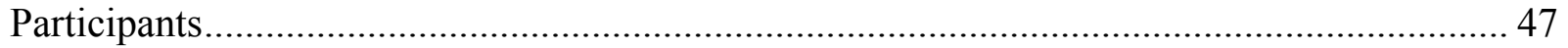

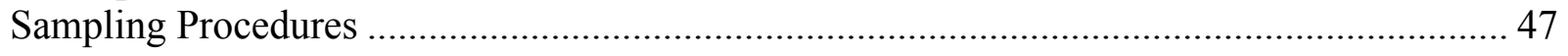

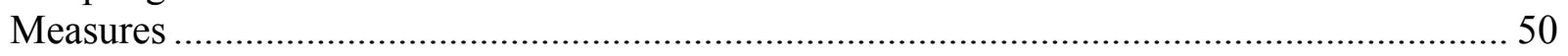

World Health Organization Adult ADHD Self-Report Scale - V1.1 Symptoms Checklist

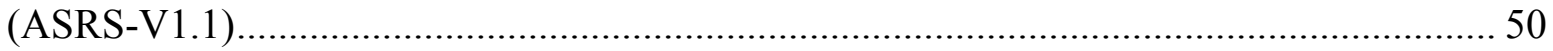

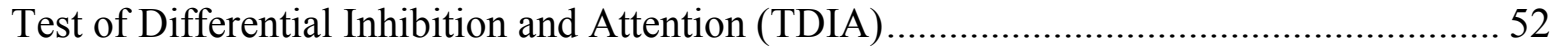

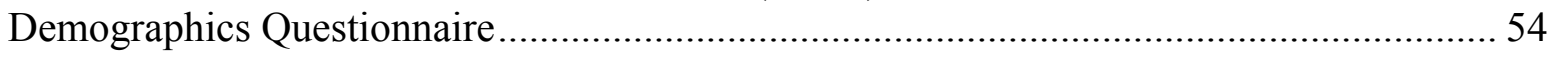

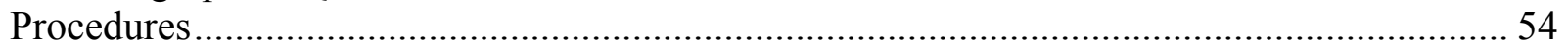

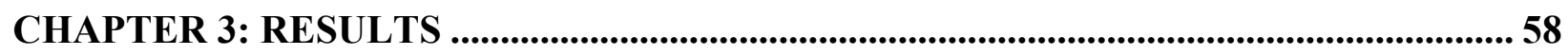

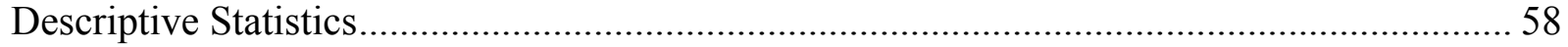

Assumptions and Reliability of the Measures ........................................................... 59

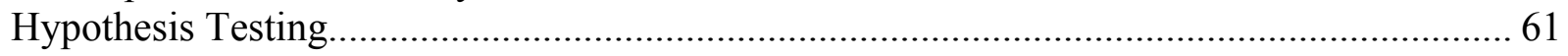

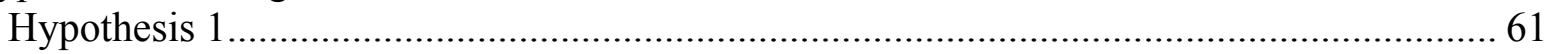

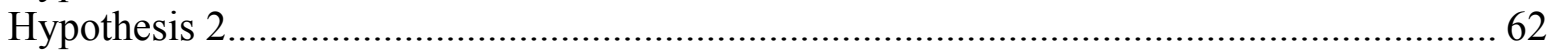

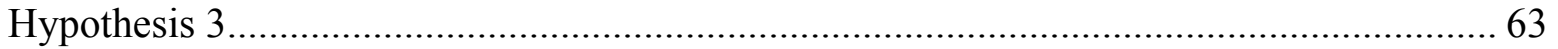




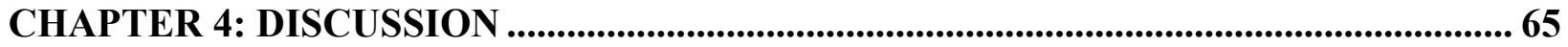

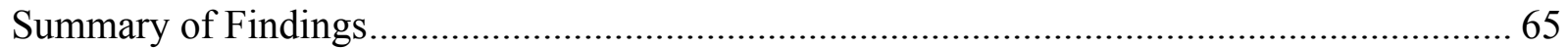

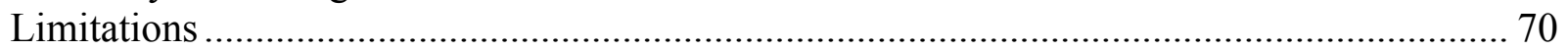

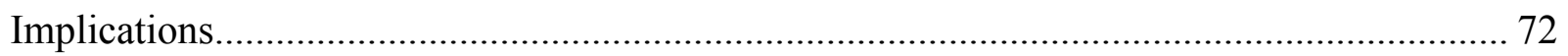

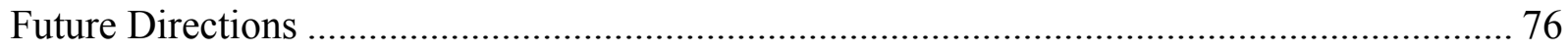

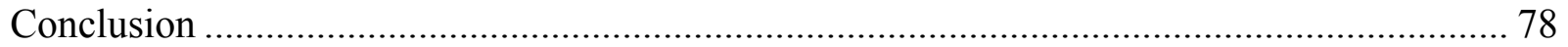

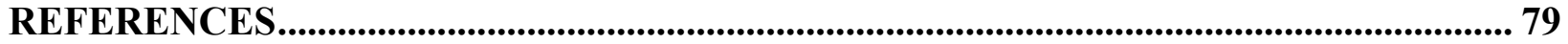

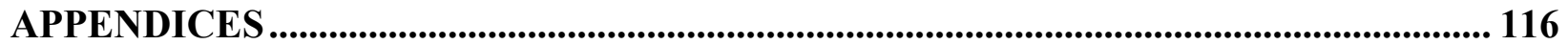

Appendix A: Informational Cover Letter - Form A ....................................................... 116

Appendix B: Informational Cover Letter - Form B ..................................................... 117

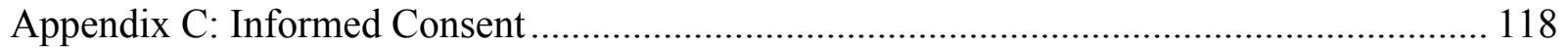

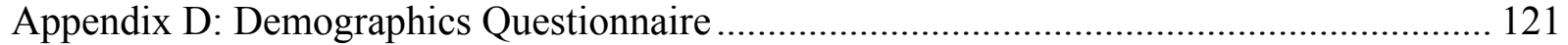

Appendix E: Adult ADHD Self-Report Scale (ASRS-V1.1) Symptom Checklist............... 122

Appendix F: Closing Statement and Resources.............................................................. 124

Appendix G: IRB Acknowledgement of Exemption ..................................................... 125 


\section{TABLE OF ACRONYMS}

\begin{tabular}{|l|l|}
\hline Acronym & Term(s) \\
\hline ADHD & Attention-Deficit/Hyperactivity Disorder \\
\hline PFC & Prefrontal cortex \\
\hline DA & Dopamine \\
\hline NE & Norepinephrine \\
\hline DAT & Dopamine transporter protein \\
\hline NET & Norepinephrine transport protein \\
\hline VAN & Ventral attention network \\
\hline DAN & Dorsal attention network \\
\hline FPN & Frontoparietal network \\
\hline CO & Cingulo-opercular network \\
\hline CPT & Continuous Performance Test \\
\hline G/NG & "Go / No-Go" tasks \\
\hline SST & Stop-signal task \\
\hline MRT & Mean reaction time to targets \\
\hline SSD & Stop-signal delay \\
\hline SDRT & Reaction time variability \\
\hline SSRT & Stop-signal reaction time \\
\hline SONA & University research participation system \\
\hline $\begin{array}{l}\text { ASRS- } \\
\text { V1.1 }\end{array}$ & $\begin{array}{l}\text { World Health Organization Adult ADHD Self-Report Scale - V1.1 Symptoms } \\
\text { Checklist }\end{array}$ \\
\hline TDIA & Test of Differential Inhibition and Attention \\
\hline
\end{tabular}




\section{CHAPTER 1: INTRODUCTION AND REVIEW OF SELECTED LITERATURE}

Attention-Deficit/Hyperactivity Disorder (ADHD) is a neurodevelopmental disorder characterized by developmentally inappropriate symptoms of inattention, hyperactivity and impulsivity. Symptoms of ADHD are pervasive across multiple settings with functional and developmental impairment in academic, occupational, and social domains (American Psychiatric Association [APA], 2013). ADHD symptoms may present in childhood, adolescence, or adulthood and early impairment may persist across the lifespan (APA, 2013; Biederman et al., 2012).

ADHD was once considered to be solely a childhood disorder with symptoms that attenuated prior to adulthood (Efron, 2015). Research has since clearly demonstrated that ADHD symptoms may persist beyond childhood (Biederman, Petty, Evans, Small, \& Faraone, 2010; Guelzow, Loya, \& Hinshaw, 2017; Langley et al., 2010). Moreover, there is increasing evidence for symptom onset during adolescence and adulthood (i.e., after age 12 years), thereby challenging the notion that ADHD is a childhood disorder (Moffitt et al., 2015). Indeed, ADHD now ranks among the most common mental health disorders in adults (APA, 2013) with clinically significant impairment in social, academic, vocational, and neuropsychological functioning (Klein et al., 2012). ADHD was also once considered to be a disorder of emotional and behavioral immaturity among prepubescent children (APA, 1968). This antiquated model has since been supplanted by a modern conceptualization based on cognitive and executive dysfunction (Barkley, 1997; Douglas, 1972).

As our understanding of the etiology and pathology of ADHD continues to evolve, there is increasing need for diagnostic tools that reflect these scientific advancements. ADHD assessment is complicated by a variety of factors including heterogeneity in symptoms, gender 
and age differences in rates of diagnosis, variability in symptom manifestation across the lifespan, and high comorbidity with other psychiatric disorders and medical conditions (Asherson, 2016; Willcut, 2012; Williamson \& Johnston, 2015). Additionally, ADHD is associated with deficits in academic, social, occupational, and emotional functioning, making it difficult to differentiate ADHD from other psychiatric disorders (Bruner, Kuryluk, \& Whitton, 2015; Klein et al., 2012; Prevatt \& Young, 2014; Skirrow \& Asherson, 2013).

Identifying ADHD in adults is a particularly challenging clinical endeavor, especially with individuals whose symptoms present during adolescence or adulthood (Agnew-Blais et al., 2016; Caye et al., 2016; Moffitt et al., 2015). Because current diagnostic criteria require a history of childhood onset and impairment (APA, 2013), assessment methods with adult patients often involve retrospective self- and collateral-report of symptoms, which are known to have limited validity and reliability (Sibley et al., 2012). Furthermore, there may be no childhood impairment for individuals whose symptoms first present in adulthood (Moffitt et al., 2015), thus our current diagnostic criteria may be too restrictive to accurately capture the nature of ADHD in some cases. Potential secondary gains such as access to ADHD medication and eligibility for social and academic services for individuals diagnosed with ADHD add complexity to the assessment process (Leppma, Long, Smith, \& Lassiter, 2017). Finally, symptom manifestation may vary in adulthood as a function of self-selected environments, thereby creating context-specific impairment (Lasky et al., 2016). Individuals may pursue activities and environments that minimize their perceptions of impairment, thereby masking more global deficits associated with ADHD (Mordre, Groholt, Sandstad, \& Myhre, 2012).

Because of these challenges, it behooves diagnosticians to develop instruments that can validly and reliably identify ADHD while differentiating affected individuals from other clinical 
and non-clinical populations. The stop-signal task (SST) is useful in identifying ADHD and nonADHD groups (Alderson, Rapport, \& Kofler, 2007; Aron, Dowson, Sahakian, \& Robbins, 2003; Lijffijt, Kenemans, Verbaten, \& van Engeland, 2005; Oosterlaan, Logan, \& Sergeant, 1998; Wodushek \& Neumann, 2003), and yet the reason for its utility remains an area of scholarly debate. A segment of the cognitive psychology community points to inefficient processing due to generalized attention deficit as the predominate feature of individuals with ADHD compared to controls (Alderson et al., 2007; Castellanos \& Tannock, 2002; Epstein et al., 2010; Lifffijt et al., 2005; Oosterlaan et al., 1998). Conversely, many researchers have highlighted cognitive control deficits associated with motor response inhibition as a core feature of ADHD, with stop-signal inhibition being proposed as a key endophenotype (Aron et al., 2003; Aron \& Poldrack, 2005; Berger \& Cassuto, 2014; Hart et al., 2014; Kofler et al., 2013; McAuley, Crosbie, Charach, \& Schachar, 2013; Schachar et al., 2005; Wodushek \& Neumann, 2003). The emphasis on a general deficit in cognitive control versus a selective deficit in response inhibition varies across studies of SST, the majority of which involve tasks of lower cognitive complexity without the additional inhibitory load introduced by interference control (Uno et al., 2006; van Velzen, Vriend, de Witt, \& van den Heuvel, 2014). Absent from the SST literature is assessment of the diagnostic utility of response inhibition metrics in the adult population on tasks with greater central processing demands produced by interference control.

In this study, I take an initial step toward clarifying the clinical utility of response inhibition metrics in the assessment of ADHD in adulthood. I preliminarily assessed the clinical utility of a newly developed measure of attentional processing and response control by examining performances in a sample of clinical and non-clinical adults (i.e., 18 years of age or older). The purpose of the study is to advance the development of a new diagnostic tool while 
evidencing response inhibition deficits in individuals with ADHD based on stopping latencies in the stop-signal paradigm.

\section{Review of Selected Literature}

\section{Prevalence}

ADHD is generally considered a disorder of childhood with prepubescent onset (APA, 2013). A report by the National Institute of Mental Health (NIMH; 2017) showed that the median age of symptom onset for children was six years. ADHD ranks among the most prevalent mental health disorders in children and adolescents in the United States (NIMH, 2010) and is associated with national economic costs estimated between $\$ 143$ and $\$ 676$ billion (Doshi et al., 2012). The average cost of raising a child with $\mathrm{ADHD}$ is estimated at $\$ 15,000$ (before treatment expenses), more than five times the average amount spent by neurotypical families (Zhao et al., 2019). In the study, parents and caregivers of participants with ADHD often experienced indirect costs related to inconsistent employment and lower work efficiency.

Assessments of national trends revealed increases in diagnoses by $66 \%$ from 2000 to 2010 (Garfield et al., 2012), by 42\% from 2003 to 2011 (NIMH, 2017), and by 31\% between 2010 and 2017 (Blue Cross Blue Shield Association, 2019). It is estimated that the current worldwide prevalence of ADHD in childhood ranges from 5\% (Asherson, 2016) to 7.2\% (Thomas, Sanders, Doust, Beller, \& Glasziou, 2015) and from 2.5-4.4\% in adulthood (APA, 2013; NIMH, 2017), ranking it among the most common psychiatric conditions among children (NIMH, 2010) and adults (APA, 2013).

\section{Subtypes and Symptoms}

ADHD is heterogeneous in clinical presentation as evidenced by three subsyndromal types:

predominantly inattentive, predominantly hyperactive/impulsive, and combined presentation 
(APA, 2013). The predominantly inattentive presentation is characterized by difficulty with sustained attention, task completion, and organization, as well as forgetfulness and distractibility. The predominantly hyperactive/impulsive type is marked by excessive motor activity or talking, action without forethought, restlessness, difficulty with turn-taking, and interruption of or intrusion on others. The combined designation is reserved for individuals who exhibit symptoms of both inattention and hyperactivity/impulsivity. Data drawn from meta-analytic studies show that the predominantly inattentive presentation is most common in the general population; however, individuals with the combined presentation are most likely to be referred for clinical services (Willcutt, 2012).

\section{Gender Differences}

Males are diagnosed with ADHD at a higher rate than females for all disorder subtypes (Willcut, 2012). Estimates range from 3-4:1 (Magnin \& Maurs, 2017) to 9:1 (Bruchmuller, Margaf, \& Schneider, 2012) in the clinical population, including 10:1 among children, specifically (Williamson \& Johnston, 2015). Scholars have attributed this discrepancy to social processes such as methodological inconsistency (Williamson \& Johnston, 2015) and systematic referral bias related to social expectations for behavior in boys and girls (Biederman et al., 2005). In one study, a sample of 1,000 mental health professionals read male and female versions of an otherwise identical case vignette and were asked to render or withhold a diagnosis. The male version resulted in a diagnosis of ADHD in about twice the number of cases compared to the female vignette (Bruchmuller et al., 2012). The authors posited that a representative heuristic led participants to view the male subjects as more prototypical of ADHD children. Other scholars have disagreed with this conclusion, suggesting that the discrepancy is due to genuine etiological 
differences in genetic and cognitive liabilities that persist after controlling for selection bias (Arnett, Pennington, Willcutt, DeFries, \& Olson, 2015).

\section{Age Differences}

Age differences may also be emblematic of subjectivity in diagnosis. Elder (2010)

demonstrated that ADHD diagnoses were not based solely on underlying neurological

conditions; instead, rates of diagnosis varied systematically depending on children's ages relative to eligibility cutoffs for admittance to kindergarten in their states. Elder (2010) found that the youngest children were more than twice as likely to be diagnosed with ADHD compared to the oldest children in each grade. Younger children were also more than twice as likely to be treated using psychostimulant medication. These results suggest that the relative immaturity of younger schoolchildren may lead to disproportionately higher rates of ADHD diagnoses and subsequent pharmacological intervention.

Evans, Morrill, and Parente (2010) replicated Elder's (2010) findings using data collected from 1996 through 2006 by three national health organizations. Their results indicated that children who were older for their grade were less frequently diagnosed with and treated for ADHD compared to younger children. Both Elder (2010) and Evans et al. (2010) attributed their results, in part, to differences in maturity levels between younger and older children. Data collected from 2007 through 2015 showed similar trends, with significantly higher rates of diagnosis and treatment of ADHD among children born in August than among children born in September in U.S. states with a September 1 cutoff date for kindergarten admission (Layton, Barnett, Hicks, \& Jena, 2018).

Elder and Lubotsky (2009) suggested that younger children are more likely to exhibit emotional, educational, and behavioral deficits that are characteristic of ADHD endophenotypes 
compared to older children in the same grade. APA (2013) noted that symptom identification in young children is complicated by high variability in normative behavior. Elder and Lubotsky (2009) added that developmental discrepancies may contribute to over-diagnosis of ADHD among young children whose symptoms are conflated by relative immaturity in comparison with same-grade peers. Meanwhile, older children may be underdiagnosed because their symptoms may be less obvious amid their younger, possibly less mature classmates. Elder and Lubotsky (2009) concluded that diagnosticians must consider symptom profiles relative to same-age rather than same-grade peers.

\section{Etiology and Risk Factors}

Presently there is no known single etiology for ADHD (Magnin \& Maurs, 2017), though biological and environmental determinants have been implicated. Twin studies suggest that genetic heritability is between $60 \%$ and $90 \%$ (Faraone \& Mick, 2010; Spencer, Biederman, Wilens, \& Faraone, 2002; Waldman \& Gizer, 2006), with a mean heritability estimated at 75\% worldwide (Beiderman \& Faraone, 2005; Faraone et al., 2005). A recent genome-wide association meta-analysis of 20,183 individuals diagnosed with ADHD revealed 12 genomic regions where people with ADHD differed from controls (Demontis et al., 2019). The researchers suggested that this genetic profile contributes about $22 \%$ of the risk of developing ADHD.

Contributions from social or environmental factors are also implicated, with estimates ranging from $10 \%$ to $40 \%$ (Waldman \& Gizer, 2006). For example, the basal ganglia are linked to ADHD for their role in motor response inhibition (Guo, Schmitz, Mur, Ferreir, \& Anderson, 2018; Shaw et al., 2014). The basal ganglia are a collection of subcortical structures in the telencephalon that includes the caudate nucleus, the putamen, and the globus pallidus. These 
structures collectively facilitate or inhibit movement through interaction with the motor cortex.

The basal ganglia are known to be particularly vulnerable to hypoxia (Froehlich et al., 2011). Additionally, early exposure to technologies (e.g., television) is associated with deficits in attentional functioning among children (Christakis, Zimmerman, DiGiuseppe, \& McCarty, 2004; Tamama et al., 2019). Thus, the combination of biological and environmental determinants is cause for scholarly consensus that the etiology of ADHD is polygenetic and multifactorial (Magnin \& Maurs, 2017; van Ewijk \& Oosterlaan, 2015; Waldman \& Gizer, 2006).

\section{Pathophysiology}

The prefrontal cortex (PFC) has consistently been the predominant focus in ADHD research given its association with executive functions (Arnsten, 2009). The PFC is critical in regulating and sustaining attention, screening distractions, inhibiting emotional and behavioral impulses, planning, organizing, and facilitating working memory (Arnsten, 2009; Spencer, Biederman, \& Mick, 2007). Specific regions within the PFC are linked to particular executive functions. The dorsolateral PFC is associated with organization, planning, working memory, and attention (Bush, Valera, \& Seidman, 2005). The inferior frontal gyrus of the ventrolateral PFC is associated with response inhibition as damage to this region was shown to elicit delays in response suppression on measures of attention and response control (Aron, Fletcher, Bullmore, Sahakian, \& Robbins, 2003). Dysfunction in the orbitofrontal cortex is also indicated in ADHD research for its association with behavioral inhibition and impulse control (Seidman, Valera, \& Makris, 2005).

PFC functioning is contingent on the concentration of two primary catecholamines, dopamine (DA) and norepinephrine (NE), and small changes in the levels of these neurotransmitters have immense effects on executive functioning (Arnsten, 2009). The dopamine 
hypothesis of ADHD suggests that deficits in tonic DA in the synaptic cleft are responsible for ADHD symptoms (Levy, 1991). Because the PFC is especially rich in DA (Spencer et al., 2007), dysfunction of the DA system in the nigrostriatal, mesolimbic, and mesocortical pathways is believed to account, at least partially, for PFC underactivity that underlies ADHD (Genro, Kieling, Rohde, \& Hutz, 2010). These pathways connect the PFC to midbrain structures including the hippocampus, amygdala, substantia nigra, ventral tegmental area, striatum, and nucleus accumbens (Meyer \& Quenzer, 2013). NE at high levels is also associated with PFC dysfunction. Stimulation of NE receptors enhances and prolongs the functioning of neural connections responsible for attention, behavior, and emotion regulation. Blocking NE receptors is associated with hyperactivity and impulsivity (Arnsten, 2009; Arnsten \& Li, 2005).

Associations between DA, NE, and ADHD have led to the development of pharmacotherapies that specifically target DA and NE systems in the PFC (Genro et al., 2010). Two common psychostimulants, methylphenidate and amphetamine, enhance neurotransmission of DA and NE by inhibiting reuptake of DA and NE through inhibition of dopamine transporter proteins (DAT) and norepinephrine transporters proteins (NET), respectively. Amphetamine exerts an additional effect by stimulating the release of DA and NE at the synapse (Pliszka, 2005). When uninhibited, DAT and NET function to inactivate DA and NE through reuptake by moving the neurotransmitters from the synaptic cleft into nerve terminals. By inhibiting the membrane transporter proteins responsible for reuptake, synaptic neurotransmitter levels increase. Once amphetamine enters the nerve terminal, it stimulates endogenous DA release into the extracellular fluid, resulting in an increase in synaptic DA levels (Meyer \& Quenzer, 2013).

The etiological role of candidate genes within these neurotransmitter systems has been examined in molecular genetics and functional imaging studies of ADHD (Arnsten, 2009; Genro 
et al., 2010). Genes within the dopaminergic pathway are robustly implicated as primary contributors to the etiology and pathophysiology of ADHD due to their important role in regulating attention (Ptacek, Kuzelova, \& Stefano, 2011). These include the dopamine transporter gene (DAT1; chromosomal location 5p15.33) and receptor genes (DRD3, DRD4, and DRD5; chromosomal location 3q13.31, 11p15.5, and 4p16.1, respectively) (Gizer, Ficks, \& Waldman, 2009; Waldman \& Gizer, 2006). The candidate gene most widely connected with disorders of attention is the 7-repeat allele of the DRD4 receptor gene (Spencer et al., 2002).

\section{The Attentional System}

In their seminal article, Posner and Petersen (1990) identified three separable, yet integrated networks within the attentional system of the human brain: alerting, orienting, and executive control. Exploration of these networks has proven useful in identifying motor response inhibition as a prominent ADHD endophenotype (Hart et al., 2014; McAuley et al., 2013). Peterson and Posner (2012) later updated this model considering 20 years of subsequent cognitive neuroscience research using brain imaging technology. The following is an overview of their updated model of the attentional system of the human brain.

First, the alerting network is involved in shifting between states of tonic and phasic alertness. Tonic alertness refers to an idle or "ready state" of intrinsic arousal. In contrast, phasic alertness refers to a rapid shift in arousal triggered by an environmental event that, like a warning signal, prepares the attentional system for signal detection and response execution (DeGutis \& Van Vleet, 2010). The mediation of arousal involves the ascending reticular activating system, which is initiated by NE release in midbrain structures such as locus coeruleus projections and superior colliculus (Aston-Jones \& Cohen, 2005). Activation of this system occurs in response to a cue that indicates an upcoming target stimulus (Peterson \& Posner, 2012). 
Second, signal detection is performed by the orienting system wherein sensory input, such as spatial cues, are processed. The orienting system is comprised of two sensory processing networks, the ventral attention network (VAN) and dorsal attention network (DAN). VAN is a bottom-up processing network used to orient to sensory stimuli outside of direct attention, or exogenous attention. Bottom-up processing refers to perceiving exogenous sensory information, allowing the stimulus to influence our perceptions or cognitive awareness in a data-driven manner. VAN is right lateralized in the temporoparietal junction and the ventral frontal cortex. Conversely, DAN uses top-down visuospatial processing to orient to expected presentations of stimuli based on a given task or event. Top-down processing involves the use of background or contextual knowledge to inform our perception of a stimulus. DAN involves exogenous and endogenous attention and is comprised of the frontal eye fields and the intraparietal sulcus/superior parietal lobe (Davidson \& Marrocco, 2000).

Finally, the executive control system involves two control networks, the frontoparietal network (FPN) and cingulo-opercular network (CO) (Dosenbach, Fair, Cohen, Schlaggar, \& Petersen, 2008). The FPN includes the dorsal frontal cortex, dorsolateral prefrontal cortex, inferior parietal lobule, and inferior parietal sulcus. It is associated with cognitive flexibility required to switch between cognitive tasks (Rossi, Bichot, Desimone, \& Ungerleider, 2007). The $\mathrm{CO}$ is comprised of the anterior prefrontal cortex, anterior insula/operculum, dorsal anterior cingulate cortex, and thalamus. It is associated with set maintenance across task trials (Dosenbach et al., 2008).

Our efforts to understand the characteristics of ADHD are inextricably linked to the work of Posner and Petersen (1990). Identification of the networks within the human attentional system has resulted in advanced understanding of the neural components involved in motor 
response inhibition. The right and left frontal gyri have been identified as key structures in successful inhibitory control (Aron et al., 2003; Swick, Ashley, \& Turken, 2008). Functional connectivity research by Dambacher et al. (2013) suggests that specific response inhibition networks may be activated in a task-dependent manner. Their analysis revealed that tasks involving action restraint resulted in activation of the right superior frontal gyrus, left middle frontal gyrus, and the bilateral anterior cingulate cortex, while action cancellation tasks yielded activation of the right middle frontal gyrus, posterior cingulate cortex, and parietal regions.

Cognitive flexibility, also known as task-switching or alternating attention, has also been predicted by activation of specific brain regions using fMRI. Pretrial neural activity in the basal ganglia, anterior cingulate cortex, prefrontal cortex, and posterior parietal cortex predicted subsequent cognitive flexibility during a task-switching procedure (Leber, Turk-Browne, \& Chun, 2008).

Taken together, the human attentional system involves multiple components (i.e., the alerting, orienting, and executive control systems), thus attention does not represent a single, unitary construct. Rather, it is a process in which each individual network plays a unique role in identifying when, where, and how the attentional system will function. Additionally, advancements in cognitive neuroscience research have revealed distinct neural mechanisms underlying the cognitive control deficits that are associated with ADHD, highlighted by activation of multiple structures within the cortico-striatal-thalamic-cortical loop (Castellanos, Sonuga-Barke, Milham, \& Tannock, 2006). These advancements prompted efforts among scholars to develop and evaluate measures of motor response inhibition, such as SST.

\section{History of the Taxon}


The current understanding of ADHD as a childhood disorder is rooted in clinical nomenclature from the $20^{\text {th }}$ century (Efron, 2015). Labels used to describe the disorder now called ADHD have undergone multiple iterations, all of which emphasize childhood impairment. The taxonomy evolved from hyperkinetic reaction of childhood (APA, 1968), hyperactive child syndrome (Wood, Reimherr, Wender, \& Johnson, 1976), and attention deficit disorder (APA, 1980) to the current classification introduced by the APA in 1994 (APA, 1994).

Hyperkinetic reaction of childhood (APA, 1968) attributed children's symptoms to stress reactions to stimuli within the family environment (Mallet, Natarajan, \& Hoy, 2014; McGough \& McCracken, 2006). This attribution yielded a conceptualization of ADHD as a childhood disorder with hyperactivity caused by emotionally or behaviorally immature reactions to stressors. Impairment was therefore expected to diminish concurrent with normative maturation during puberty.

Scholars soon challenged the notion that children outgrow hyperactivity with greater emotional or behavioral maturity. For instance, Wood et al. (1976) acknowledged that hyperactive child syndrome presents in childhood yet disagreed that impairment attenuates in adolescence. Instead, they suggested symptoms are transformed in adolescence and adulthood with impairment marked by greater inattention and impulsivity in addition to continued hyperactivity. Asherson (2016) added that emotional instability remains a core presentation for individuals with ADHD, though it is possibly a product of other impairments. Wood and colleagues (1976) posited that the emergence of inattentiveness does not necessarily supplant hyperactivity nor signify the conclusion of a childhood disorder. They added that other diagnostic labels (e.g., hysteria) may conceal what is more accurately conceptualized as persistent symptoms of childhood hyperkinesis in adulthood. 
Our understanding of etiology changed most markedly with the work of Douglas (1972) and Barkley (1997) who shifted the conversation away from emotional and behavioral immaturity in the direction of executive dysfunction. First, Douglas (1972) emphasized attentional and impulse control deficits as core features of ADHD. Barkley (1997) later proposed a self-regulation model with five major executive impairments that contribute to the deficits associated with ADHD: response inhibition, working memory, self-regulation of emotion and motivation, and reconstitution. At the core of Barkley’s (1997) model was impairment in response inhibition that was unique to ADHD. All other impairments were secondary as their function was contingent on effective and efficient response inhibition. Barkley's (1997) model was a catalyst for viewing ADHD as a disorder of executive functioning, which is known to play an important role in self-regulatory and goal-directed behavior (Pennington \& Ozonoff, 1996). Barkley's (1997) model postulates that the behavior of individuals with ADHD is highly regulated by their immediate environment compared to healthy controls.

The APA (1980) paralleled this advancement by introducing the term, attention deficit disorder, to classify a profile of symptoms which emphasized deficits in executive control in accordance with Douglas's (1972) and Barkley's (1997) models. Indeed, numerous studies have since identified a variety of executive functioning deficits in ADHD such as behavioral inhibition (Alderson et al., 2007; Nigg, 2001; Van Mourik, Oosterlaan, \& Sergeant, 2005), working memory (Martinussen, Hayden, Hogg-Johnson, \& Tannock, 2005; Rapport, Chung, Shore, \& Isaacs, 2001), strategic planning (Kofman, Larson, \& Mstofsky, 2008), and sustained attention and vigilance (Egeland, Johansen, \& Ueland, 2009).

Subsequently, clinical research evidenced symptom onset and persistence in adolescence (Biederman et al., 2012), which prompted the APA to revise its diagnostic criteria in response to 
burgeoning support for greater longevity of the disorder (APA, 1987). Still, APA (1987; 1994) included an age-of-onset criterion of seven years, signifying developmental onset. Barkley and Biederman (1997) contended that the arbitrary selection of seven years did not withstand empirical nor conceptual scrutiny either for onset of symptoms or impairment. These scholars articulated their rationale, noting that the criterion was "scientifically indefensible, poses unwarranted practical problems for the study of older adolescents and adults, and may be arbitrarily discriminatory" (p. 1204). Most recently, the age of onset criterion was revised from seven to 12 years with the publication of the Diagnostic and Statistical Manual of Mental Disorders - Fifth Edition (DSM-5; APA, 2013), extending the period during which symptom impairment may present by five years.

\section{Diagnostic Criteria}

The DSM-5 (APA, 2013) enumerates diagnostic criteria for ADHD consisting of 18 symptoms of inattention, hyperactivity, and impulsivity. Diagnostic thresholds are determined by the severity of clinical impairment as symptoms of ADHD are continuously distributed throughout the population (Asherson, 2016). A diagnosis under the current system requires the presence of several symptoms of inattention and/or hyperactivity/impulsivity before the age of 12 years (APA, 2013). Examples include "has difficulty remaining focused during lectures, conversations, or lengthy reading" and "often forgetful in daily activities [such as] running errands...returning calls, paying bills, keeping appointments” (APA, 2013, p. 59). The age-ofonset criterion of 12 years exemplifies a present understanding of ADHD as a neurodevelopmental disorder with symptom onset in childhood. The DSM-5 states, "ADHD begins in childhood" (APA, 2013, p. 61); therefore, there is no recognition of ADHD onset 
beyond age 12 years. Without a history of impairment in childhood, there can be no diagnosis of ADHD (Craig, 2011).

Scholars debate the validity of the age criterion citing symptom onset versus persistence in adolescence and adulthood (Agnew-Blais et al., 2016; Caye et al., 2016; Moffitt et al., 2015). To some, ADHD is a lifelong condition (Magnin \& Maurs, 2017); to others, ADHD can be a disorder solely of adulthood for some patients (Moffitt et al., 2015).

\section{ADHD in Adolescence and Adulthood}

Persistence. Although the prevailing notion for several decades was that ADHD was a neurodevelopmental disorder solely of childhood (Spencer et al., 2007), it is now estimated that about 2.5-4\% of adults meet diagnostic criteria for ADHD (APA, 2013; Fayad et al., 2007), ranking it among the most common psychiatric conditions in adulthood (APA, 2013). The possibility that childhood ADHD symptoms may persist into adolescence and adulthood was first questioned by Wood et al. (1976) and officially recognized for the first time by the APA in 1987 (APA, 1987).

Research on ADHD in adults is relatively new, with greater than $75 \%$ of the literature published within the past 10 years (Williamson \& Johnson, 2015). Though still in its infancy, a burgeoning literature supports the potential for symptom persistence beyond childhood (Biederman et al., 2010; Biederman et al., 2012; Klein et al., 2012; Langley et al., 2010). While ADHD is known to affect adult patients (Balint, Czobor, Komlosi, \& Meszaros, 2009; Wilens et al., 2009), inconsistent research findings make it difficult to achieve consensus regarding persistence rates. One explanation for the variability is methodological and definitional inconsistency across studies, particularly the diagnostic criteria used in assessment (Magnin \& Maurs, 2017; Spencer et al., 2007). For example, comparing rates of diagnosis among adults 
using former (APA, 1994) and current (APA, 2013) criteria resulted in a $27 \%$ increase in prevalence estimates in one study (Matte et al., 2015) and 65\% in another (Rigler et al., 2016). These figures may be associated with a more inclusive age-of-onset criterion of 12 years. Rigler et al. (2016) also noted that fewer symptoms are required for a diagnosis of ADHD under the current system, thereby lowering the diagnostic threshold.

Some studies have reported relatively low persistence rates ranging from $4 \%$ (Mannuzza, Klein, Bessler, Malloy, \& LaPadula, 1998) to $22 \%$ (Klein et al., 2012). Comparatively, a longitudinal study revealed that clinically significant childhood symptoms were retained in young adulthood in 58\% of cases (Barkley, Fischer, Smallish, \& Fletcher, 2004). Subsequent research showed that $70 \%$ of diagnosed children (mean age of 9.4 years) continued to meet full criteria for ADHD five years later in adolescence (Langley et al., 2010). Similar results were reported by Biederman et al. (2012) who observed either full or subthreshold symptom persistence in $77 \%$ of childhood cases at 10 - to 16-year follow-up during adolescence.

The persistence of symptoms beyond childhood occurs at comparable rates for boys and girls. Results of a 10 -year longitudinal study demonstrated that about $35 \%$ of diagnosed boys continued to meet diagnostic criteria in adulthood (Biederman et al., 2010). Likewise, a 10-year follow-up study of girls revealed that 44\% met full criteria as adults (Guelzow et al., 2017). Although boys are diagnosed with ADHD at a higher rate than girls (Magnin \& Maurs, 2017), based on these findings, both are comparably susceptible to persistent functional impairment throughout the lifespan. The degree of impairment has been shown to vary by gender, however, with males displaying a higher level of neurocognitive deficits as adults compared to females (Balint et al., 2009). 
Data from meta-analytic studies suggest that an estimated $50 \%$ of adults remain impaired by persistent childhood symptoms that are detrimental to daily functioning, even when their symptoms are in partial remission or are subthreshold diagnostically (Faraone, Biederman, \& Mick, 2006). A 16-year controlled, longitudinal study by Biederman et al. (2012) showed that adult ADHD is associated with greater psychosocial, educational, and neuropsychological impairment compared to age- and sex-matched controls. Symptom persistence has been associated with a greater number of childhood symptoms and lower childhood IQ (Agnew-Blais et al., 2016), as well as childhood symptom severity and treatment history (Caye et al., 2016). Despite overall variability in persistence rates, the potential for ADHD symptoms to be retained in adolescence and adulthood is well-established in the literature.

Onset. Research is also increasingly supporting the possibility of symptom onset beyond childhood, at ages ranging from 13 to 38 years (Agnew-Blais et al., 2016; Caye et al., 2016; Moffitt et al., 2015). In a nationally representative four-decade longitudinal cohort study, Moffitt et al. (2015) found that $90 \%$ of adults with diagnosable ADHD did not experience clinically significant impairment in childhood; importantly, all DSM-5 (APA, 2013) criteria were met except for onset-age prior to 12 years. Based on this sample, Moffitt and colleagues (2015) questioned whether ADHD is in fact a childhood-onset neurodevelopmental disorder. Their data suggest that ADHD symptom onset may also occur after the age of 12 years. Another study found that adults with ADHD symptoms experience comparable levels of impairment, regardless of age-of-onset (Agnew-Blais et al., 2016). The researchers found few discernable differences between individuals with persistent and late-onset ADHD, suggesting that adult impairment is similar for individuals whose symptoms presented before or after age 12 years. This literature 
provides initial support for continued revision, if not elimination, of the onset-age criterion of 12 years in the DSM-5 (APA, 2013).

Not all studies report equally high prevalence rates for adult-onset ADHD, however, nor do they report equal levels of impairment between childhood- and adult-onset ADHD. For example, in a sample of 388 adult outpatients, only $6.9 \%$ were classified as having adult-onset ADHD with symptoms that were less severe than patients with childhood-onset (Lopez, Micoulaud-Franchi, Galera, \& Dauvilliers, 2017). Despite some evidence to the contrary, overall the literature suggests that clinically significant symptoms may not present until adolescence or young adulthood for some individuals.

Course. Current and recent literature suggests a high degree of variability in symptom manifestation across the lifespan (Biederman, Faraone, Monuteaux, Bober, \& Cadogen, 2004; Williamson \& Johnston, 2015). Early childhood symptoms often manifest as excessive motor activity, such as running and climbing, yet children often experience a marked decline in motor hyperactivity during adolescence. Hyperactive symptoms often remit earlier in the lifespan than do inattentional effects, which become more prominent during adolescence and early adulthood (APA, 2013; Asherson, 2016; Biederman, Mick, \& Faraone, 2000). Adults may still experience hyperactivity or impulsivity, but what previously manifested as excessive running and climbing, for example, may later present as fidgeting, impatience, or restlessness (Craig, 2011).

Differences in symptom manifestation between children and adults may not be fully attributable to epidemiological factors. Manifestations of adult ADHD may be subjectively and contextually influenced by sociocultural variables such as academic or occupational activities that emphasize certain functional capacities more than others (Sibley, Mitchell, \& Becker, 2016). Some adults with ADHD describe their impairment as context-specific, citing symptoms that are 
strengths in one setting and liabilities in another (Lasky et al., 2016). Selection of environments that magnify attentional deficits and minimize hyperactivity or impulsivity, for example, may lead to an erroneous conclusion that inattention remits more slowly. It is also possible that hyperactive symptoms are equally present but do not produce the same level of functional impairment in their respective contexts due to specific environmental demands (Lasky et al., 2016) or increased use of adaptive coping mechanisms (Jensen et al., 1997). There is therefore an interaction effect between individuals and their environments that contributes to variability in impairment across the lifespan (Lasky et al., 2016).

Comorbidity and Deleterious Outcomes. Diagnosing ADHD is complicated by a high degree of overlap in functional impairment with a variety of neurodevelopmental and psychiatric disorders (Anastopolous et al., 2018; Asherson, 2016; Cadman et al., 2016). A four-year followup study of diagnosed children found elevated risk for other mental health conditions including anxiety and mood disorders, deficient intellectual and academic functioning, and conduct problems (Biederman et al., 1996). A second longitudinal study followed diagnosed children into adulthood and found that hyperactive youth were at greater risk for conduct problems (e.g., property theft, assault) and illegal drug-related activity than community controls (Barkley et al., 2004). Oppositional Defiant Disorder (ODD) and Conduct Disorder (CD) are often comorbid with ADHD, with estimates of dual diagnoses around $60 \%$ and $40 \%$, respectively (Connor, Steeber, \& McBurnett, 2010). Several studies have also reported increased risk of substance use disorders among ADHD patients (Estevez et al., 2016; Young et al., 2015) with twice the population rate among clinical samples (Asherson, 2016). Children with ADHD were found to be three times more likely to use nicotine or marijuana in their lifetime than individuals without ADHD (Lee, Humphreys, Flory, Liu, \& Glass, 2011). Childhood ADHD has also been shown to 
predict earlier onset and higher rates of risky sexual behavior in young adulthood (Flory, Molina, Pelham, Gnagy, \& Smith, 2006).

ADHD is also related to greater emotional dysregulation (Lenzi, Cortese, Harris, \& Masi, 2018; Skirrow \& Asherson, 2013), feelings of loneliness (Stickley, Koyanagi, Takahashi, Ruchkin, \& Kamio, 2017), depression (Bron et al., 2016; Michielsen et al., 2013; Simon, Czobor, \& Bitter, 2013), and suicidality (Stickley, Koyanagi, Ruchkin, \& Kamio, 2016). Individuals with ADHD may be at greater risk for prolonged mood dysregulation as evidenced by findings that ADHD is associated with increased treatment resistance to antidepressant medication (Chen et al., 2016).

Higher rates of antisocial personality disorder have been reported for samples of ADHD patients (Biederman et al., 2004; Klein et al., 2012). Research has also associated ADHD with medical conditions including obesity (Nigg et al., 2016), bulimia nervosa (Ziobrowski, Brewerton, \& Duncan, 2018) and other disordered eating behaviors (Bleck \& DeBate, 2013; Kaisari, Dourish, \& Higgs, 2017; Levin \& Rawana, 2016), celiac disease (Instanes, Klungsoyr, Halmou, Fasmer, \& Haavik, 2018), and premature death (Dalsagaard, Ostergaard, Leckman, Mortensen, \& Pedersen, 2015; London \& Landes, 2016). ADHD has been associated with neurodevelopmental disorders including autism spectrum disorder (Gillberg et al., 2004) and specific learning disorder (Sexton, Gelhorn, Bell, \& Classi, 2012).

In addition to comorbid medical and mental health concerns, individuals with ADHD often experience greater social, occupational, and vocational dysfunction (Spencer et al., 2002). ADHD is associated with a variety of poorer outcomes in academic, emotional, social, and legal domains among adolescents (Spencer et al., 2007). Symptoms in adulthood have been associated with lower socioeconomic status (Borland \& Heckman, 1976), as well as greater prevalence of 
psychological maladjustment, traffic offenses, disruptions in employment, and divorce (Murphy \& Barkley, 1996).

In a 33-year longitudinal assessment of clinical and functional outcomes of childhood ADHD, Klein et al. (2012) reported relative dysfunction among probands in educational, occupational, economic, and social domains compared to unaffected peers. The clinical sample had 2.5 fewer years of education on average with significantly lower occupational attainment and median annual salary, and significantly higher rates of divorce. Individuals with ADHD also showed higher rates of incarceration, psychiatric hospitalization, and mortality. Bruner and colleagues (2015) corroborated these results by finding diminished social functioning via impaired relationship quality in young adults with ADHD.

Kessler et al. (2006) demonstrated that adult ADHD was associated with greater rates of disability on all three dimensions of basic functioning as assessed by the World Health Organization's Disability Schedule: self-care, mobility, and cognition. They also noted deficits in instrumental functioning including days out of role, productive role functioning, and social role functioning. Finally, research has also indicated poorer academic performance (Prevatt \& Young, 2014) and higher prevalence of learning disorders (DuPaul, Gormley, \& Laracy, 2013) among individuals with ADHD.

The literature is clear that persistent childhood ADHD symptoms are associated with a myriad of far-reaching and deleterious outcomes. Comorbidity among ADHD and other psychiatric or medical conditions presents a formidable challenge to diagnosticians. For instruments to be effective, they must aid clinicians in differentiating ADHD from other disorders. Importantly, functional impairment associated with ADHD has been shown to exert itself independently from concurrent mental health problems. The neuropsychological (Faraone 
et al., 2000), psychosocial, educational, occupational, and cognitive impairment (Biederman et al., 2012) linked to ADHD symptoms have been shown to persist after statistically controlling for comorbid psychiatric conditions. Comprehensive and accurate assessment is therefore critical for identifying ADHD in clinical presentations with high comorbidity.

\section{Assessment and Diagnosis of Adult ADHD}

Accurate assessment and diagnosis of ADHD in adulthood is a challenging clinical endeavor due to heterogeneous and ambiguous symptoms (Uno et al., 2006), variability in functional impairment (Spencer et al., 2007), presence of comorbid disorders (Faraone et al., 2000), and use of instruments that were intended to diagnose ADHD in children and adolescents (Simon, Czobor, Balint, Meszaros, \& Bitter, 2009). Scholars debate whether ADHD can be validly and reliably diagnosed, citing patterns of over-diagnosis and under-diagnosis in children and adults (Bruchmuller et al., 2012; Cuffe, Moore, \& McKeown, 2005; Ginsberg, Quintero, Anand, Casillas, \& Upadhyaya, 2014; Sibley et al., 2016; Young \& Goodman, 2016). Wakefield (2015) claimed that there is "overwhelming evidence" that ADHD is highly over-diagnosed leading to a "massive false-positives problem" (p. 193). Such a trend risks pathologizing normative behavior, which Frances and Widiger (2012) cautioned could result in largescale consequences in medication side effects, stigma, and insurance problems. Elder (2010) estimated that between $\$ 320$ and $\$ 500$ million is spent annually on pharmacological treatment for individuals with invalid diagnoses of ADHD.

Other scholars have contended that ADHD is not itself a distinct entity, but rather a constellation of symptoms from multiple disorders (Weinberg \& Brumback, 1992). This position is supported by research that suggests that each subtype originates in distinctive brain regions (Stevens, Pearlson, Calhoun, \& Bessette, 2018). fMRI scans revealed that children with 
impairment in executive functions and reward management demonstrated separate brain abnormality through individual, functionally specialized neurobiological pathways. Mallett et al. (2014) argued that recent changes to the diagnostic criteria for ADHD "are supported by limited and, at times, contradictory validity evidence" (p. 46). These authors added that "there simply is not sufficient empirical evidence to have confidence that the mental health field in the United States has ADHD diagnosis correct" (p. 46). What these and other critics may point to is ambiguity in our understanding of the etiology, pathophysiology, and epidemiology of ADHD. Our ability to accurately assess and diagnose ADHD is limited by an incomplete, albeit evolving explanatory model of the disorder.

Presently there is no single diagnostic tool that represents the "gold standard" for identifying ADHD. Current assessment methods involve a combination of measures including a structured diagnostic interview, current and retrospective self-report, collateral reports from multiple sources intended to verify impairment history (e.g., parent and teacher rating forms), a computer-based continuous performance test (CPT), and a symptom validity measure. Although a plethora of diagnostic instruments are currently available, there remains no clear agreement on the most appropriate composition of a test battery (Fuermaier, Fricke, de Vries, Tucha, \& Tucha, 2018; Huang-Pollock, Karalunas, Tam, \& Moore, 2012).

Self-Report. Self-report measures of current and past functioning are often a core feature in ADHD evaluations (Taylor, Deb, \& Unwin, 2011). Retrospective assessment is especially critical with adult patients to establish or rule-out a childhood impairment history. This is however a difficult task as patients often serve as the primary informants regarding their childhood experiences. Inclusion of retrospective versus prospective data is important based on evidence from Moffitt and colleagues (2009) that lifetime prevalence rates of mental disorders 
are doubled when prospective methods are used. Additionally, reliance on self-report in the form of retrospective recall to establish childhood symptoms is known to be inaccurate and unreliable (Miller, Newcorn, \& Halperin, 2010; Sibley et al., 2012), and vulnerable to feigned symptomatology (Bryant et al., 2018).

Accurate recall is crucial because childhood impairment is a prerequisite for an ADHD diagnosis in adulthood based on the current criterion set (APA, 2013). Inaccurate recall can lead to difficulties in determining the development and trajectory of the disorder. One longitudinal study with young adults highlighted low to barely moderate correspondence $(r=.16-.32)$ between retrospective and prospective self-reported measures of childhood hyperactivity (Henry, Moffitt, Caspi, Langley, \& Silva, 1994). Based on relatively low agreement on a variety of psychosocial variables, the authors concluded that retrospective self-report measures in social science research should be used with caution. Continuing this line of inquiry, an ADHD diagnosis was shown to be at least 9-11 times more likely using parent-report than with selfreport at follow-up in young adulthood (Barkley, Fischer, Smallish, \& Fletcher, 2002). Participants tended to retrospectively underreport their childhood symptoms, rendering them increasingly ineligible for a diagnosis.

In contrast, Murphy and Schachar (2000) found significant positive correlations between adults' self-reports of childhood symptoms and retrospective ratings of childhood symptoms provided by parents. With a second sample, Murphy and Schachar (2000) reported significant positive correlations between adult self-reports of current symptoms with ratings provided simultaneously by partners. Favorably, the revised age-of-onset criterion (APA, 2013) may be advantageous in that it minimizes error in retrospective report by reducing the necessary 
recollection period and emphasizes middle rather than early childhood. Both may enhance predictive validity.

The use of self-report measures in social science research leads to internal validity concerns based on potential confounding variables such as self-deceptive enhancement (Pauls \& Crost, 2004), positive impression management (Bolino, Kacmar, Turnley, \& Gilstrap, 2008), and social desirability (Crowne \& Marlowe, 1960). Self-deceptive enhancement refers to an unwitting response style characterized by inflated or overly favorable self-report (Pauls \& Crost, 2004). Positive impression management refers to a method of self-presentation wherein a response pattern reflects intentional effort to present oneself in a favorable manner (Weiss, Weiss, Cain, \& Manley, 2009). Social desirability refers to biased responding based on social norms whereby responses represent social artifacts rather than raters' pure relationships to or perceptions of the variable(s) of interest (King \& Bruner, 2000). Social desirability is considered a robust threat to the validity of self-report measures, likely to result in underreporting of negative experiences (Ben-Porath, 2013; Huang, Liao, \& Chang, 1998). Meta-analytic data showed that only 31 of over 14,000 health-related research studies (i.e., $0.22 \%$ ) accounted for social desirability response bias (van de Mortel, 2008). Under these circumstances, self-report is likely to be inaccurate in that impairment is underreported and presentations are overly favorable.

Recall bias represents a major threat to internal validity in retrospective research using self-reported data (Hassan, 2006). Research has shown that self-evaluation among children and adults with ADHD is prone to underreporting of symptoms and impairment on performance related measures (Hoza, Vaughn, Waschbusch, Murray-Close, \& McCabe, 2012; Knouse, Bagwell, Barkley, \& Murphy, 2005; Kooji et al., 2008; Owens, Goldfine, Evangelista, Hoza, \& 
Kaiser, 2007; Owens \& Hoza, 2003). Across these studies, self-ratings of performance were consistently higher than those of collateral informants. Diener and Milich (1997) point to positive illusory bias as an explanation for this pattern, which they described as a self-protective mechanism whereby children with ADHD enhance their self-view in areas of deficit to mitigate the impact of underperformance. Generally, a tendency to underreport symptom severity on selfreport measures may result in misdiagnosis or prohibition from appropriate services. Despite threats to validity associated with self-report measures, clinicians have historically used them to assess symptom presence, severity, and history (Harrison, Edwards, \& Parker, 2007).

Feigning Symptoms for Secondary Gain. Another threat to the validity of self-report measures is impression management in the opposite direction, or over-reporting symptoms. Selfreport ADHD measures have shown minimal test specificity to feigned impairment resulting in false positives (Fisher \& Watkins, 2008; Jachimowicz \& Geiselman, 2004). Symptom exaggeration may be especially likely in the presence of secondary gain (Bryant et al., 2018; Leppma et al., 2017), and especially feasible as information about ADHD symptoms and diagnostic procedures is readily accessible on the internet (Sollman, Ranseen, \& Berry, 2010).

One incentive for feigning ADHD symptoms is potential access to medication (Leppma et al., 2017), including those classified as psychostimulants (e.g., Adderall) and non-stimulants (e.g., Straterra). Such medications are generally regarded as a first-line therapy for adults with ADHD (Asherson, 2016; Cubillo \& Rubia, 2010). Additionally, a diagnosed disability such as ADHD renders one potentially eligible for tax benefits and government funded programs, or to have student loan repayments waived (Harrison et al., 2007). For university students, a diagnosis of ADHD may result in eligibility for accessibility services and academic accommodations (Leppma et al., 2017). 
Recently, there has been an increase in stimulant medication prescriptions in the U.S. (Sollman et al., 2010) and a 35\% increase annually outside of the U.S. (Zetterqvist, Asherson, Halldner, Langstrom, \& Larsson, 2013). In a U.S. database for outpatient physician visits, 87\% of children and adolescents diagnosed with ADHD were treated with psychostimulants (Garfield et al., 2012). With a nationwide increase in stimulant medication prescriptions comes greater need for assessment methods that are sensitive to symptom over-reporting. Research has shown that $25-48 \%$ of adults may perform sub-optimally and exaggerate their symptoms on ADHD assessments when motivated by secondary gain (Constantinou, Bauer, Ashendorf, Fisher, \& McCaffrey, 2005; Sullivan, May, \& Galbally, 2007).

One incentive to receive a diagnosis of ADHD is to gain access to stimulants to then divert the medication for profit (Schultz, Silvestri, \& Correia, 2017). Diversion of medication was found to occur in $58.9 \%$ of university students with stimulant prescriptions (Galluci, Martin, \& Usdan, 2015). Non-medical use of prescription stimulants has increased from $5.3 \%$ in 2008 (DuPont, Coleman, Bucher, \& Wilford, 2008) to 17\% of students according to recent metaanalytic data (Benson, Flory, Humphreys, \& Lee, 2015). Individual studies have found that as many as $43 \%$ of undergraduates reported misusing their medication (Advokat, Guidry, \& Martino, 2008). Students may be willing to pay more than $\$ 10$ per pill (Cruz, Sumstine, Mendez, \& Bavarian, 2017), which may explain why young adults are increasingly presenting at university counseling centers with ADHD symptoms (Harrison et al., 2007; Benson et al., 2015). As stimulant prescription misuse has been associated with a variety of poor medical and academic outcomes (Benotsch, Koester, Luckman, Martin, \& Cejka, 2011; Egan, Reboussin, Blocker, Wolfson, \& Sutfin, 2013; Reid et al., 2015; Westover \& Halm, 2012), it is critical that assessment tools are sensitive to feigned ADHD symptomatology. 
Leppma and colleagues (2017) recommended including a performance validity measure in ADHD assessments to detect deliberate underperformance or effort to feign or exaggerate symptoms. One such measure is the Non-Verbal Medical Symptom Validity Test (NVMSVT; Green, 2008). The NVMST was found to discriminate between test-takers with suboptimal effort and control groups comprised of adults with dementia and youth with fetal alcohol syndrome. Examinees' performances are compared to these control groups to determine the likelihood of suboptimal performance. Green (2008) noted that patients with dementia almost never fail all four validity criteria and seldom fail even two, whereas malingerers often fail all four criteria. Such a measure can aid diagnosticians in detecting deliberate underperformance.

Continuous Performance Tests. Continuous Performance Tests (CPT) are currently among the most frequently employed instruments in ADHD evaluations (Munkvold, Manger, \& Lundervold, 2014; Sollman et al., 2010). CPT methodology was introduced in a study of the effects of brain damage on sustained attention and impulsivity (Rosvold, Mirsky, Sarason, Bransome, \& Beck, 1956). Inferior performance by patients with brain damage was attributed to deficits in neuropsychological functioning, including diminished capacity for sustained attention. CPT was later used to assess signal detection, vigilance, and arousal among radar operators (Mackworth \& Taylor, 1963). Results from these early studies prompted subsequent clinical research using CPT with psychiatric populations to measure neuropsychological impairment in individuals with attention deficits (Epstein et al., 2003).

CPT is a neuropsychological instrument intended to objectively and quantitatively measure sustained attention and response control, also known as inhibitory motor control and motor response inhibition (Alderson et al., 2007). Sustained attention refers to the ability to maintain a state of alertness over an extended period (Huang-Pollock et al., 2012), which is a 
capacity thought to be compromised in individuals with ADHD (Adler et al., 2017). Motor response inhibition is defined as the "ability to withhold a speeded motor response prior to its initiation or the ability to cancel a response after it has been initiated" (Wright, Lipszyc, Dupuis, Thayapararajah, \& Schachar, 2014, p. 429). Deficits in these two processes, action restraint and action cancellation, respectively, were evidenced by poorer performance among ADHD children on such measures compared to healthy controls (Schachar et al., 2007). Response inhibition is also considered a reflection of aspects of impulsivity (Bari \& Robbins, 2013), playing a critical role in supporting flexible, goal-directed behavior amid environmental changes (Verbruggen \& Logan, 2008).

CPT quantifies performance on measures of attention and response control based on patterns of omission and commission errors, respectively (Uno et al., 2006). Omission errors refer to missed responses, or failure to respond to target stimuli, which is traditionally considered to reflect inattention (Berger \& Cassuto, 2014). Commission errors refer to incorrect responses to non-target stimuli, or failure to inhibit a response, which is believed to reflect impulsivity. CPT provides a more objective alternative to reliance on subjective and retrospective recall, thereby countering the validity concerns that are traditionally associated with self-report measures.

Today, some of the most widely used CPTs include the Conners' CPT $-2^{\text {nd }}$ Edition $(\mathrm{C}$ CPT-II; Conners, 2000), the Tests of Variables of Attention (TOVA; Greenberg \& Waldman, 1993), and the Integrated Visual and Auditory Continuous Performance Test (IVA; Sandford \& Turner, 1995). The C-CPT-II and the TOVA measure sustained attention and response inhibition in the visual domain. The C-CPT-II presents a predetermined series of stimuli, $90 \%$ of which are targets and $10 \%$ are non-targets. Conversely, the TOVA presents a different ratio of targets to non-targets between the two halves of the test (Greenberg \& Waldman, 1993). The IVA 
combines aspects of both tests into a dual stimulus model in which stimuli are presented in the visual and auditory domains. Examinees are presented with a pseudorandom series of auditory and visual targets (" $1 ")$ and non-targets ("2"). Performance is assessed based on omission and commission errors, response times to targets, and response accuracy. Research has shown adequate convergence across commonly used CPTs ( $r=.42$; Borgaro et al., 2003) based on the multitrait-multimethod matrix for convergent and discriminant validation (Campbell \& Fiske, 1959).

Clinical Utility. The use of continuous performance tests in clinical assessment of ADHD is well-supported in the literature. Numerous studies have shown that CPT can be useful in differentiating between ADHD and non-ADHD groups (Losier, McGrath, \& Klein, 1996; Epstein et al., 2003; O’Dougherty, Neuchterlein, \& Drew, 1984; Sonuga-Barke, Sergeant, Nigg, \& Willcutt, 2008; Willcutt, Doyle, Nigg, Faraone, \& Pennington, 2005). In a meta-analytic review of 26 studies of CPT performance, children with ADHD were found to make significantly more errors of omission and commission compared to controls (Losier et al., 1996). Results indicated that children with ADHD, on average, make about twice as many errors of omission and commission compared to non-ADHD children. CPT performance has also been used to differentiate ADHD subtypes (Marks, Himelstein, Newcorn, \& Halperin, 1999).

A study by Quinn (2003) provided support for the inclusion of the IVA in ADHD evaluations. The study examined three randomly assigned groups of undergraduate students: (1) students with valid ADHD diagnoses, (2) simulated malingerers, and (3) healthy controls. Data was collected using a self-report ADHD checklist and the IVA CPT. Quinn (2003) hypothesized that simulated malingerers could successfully feign ADHD on the self-report checklist, but that they would be unsuccessful on the IVA due to overcompensation and lower scores than the 
clinical group. As hypothesized, results showed that the self-report checklist lacked specificity and could be successfully feigned, whereas malingerers scored significantly below students with ADHD on $81 \%$ of subscales. The findings supported a tendency to overcompensate among malingerers in attempting to feign ADHD. Quinn (2003) concluded that a self-report measure by itself is neither sensitive nor specific enough for clinical use. ADHD evaluations may also include a CPT as a supplemental diagnostic tool to improve test sensitivity and specificity.

Not all studies report favorable results, however. In one study of 201 adults diagnosed with and treated for ADHD, only $51.7 \%$ of the participants were classified as having the disorder based on their CPT performance (Baggio et al., 2019). In a study of the original Conners' CPT (Conners, 1995), researchers found no significant differences in performance between children referred for learning disorder and/or ADHD assessment and controls (McGee, Clark, \& Symons, 2000). The instrument was deemed to be of minimal clinical utility for differential diagnosis based on this sample. A subsequent study corroborated the finding that differential diagnoses between ADHD and learning/cognitive disorders in adults could not be determined based on CPT performance (Advokat, Martino, Hill, \& Gouvier, 2007).

Likewise, Tollander (2011) called into question the ability of the IVA to differentiate between ADHD and non-ADHD groups. The study focused specifically on the Comprehension subscale, which measures atypical error patterns thought to reflect random or impulsive responding, carelessness, and inattention. Developers of the IVA claimed that Comprehension is the "single most sensitive subscale in discriminating ADHD” (Sandford \& Turner, 2004, p. 10). Based on this assertion, Tollander (2011) expected Comprehension scores to differ significantly between ADHD participants and controls. Instead, the subscale correctly identified participants in each group only at chance levels. Additionally, CPT scores have been shown to be unrelated 
to parent and teacher ratings of ADHD symptoms among clinically referred children (Edwards et al., 2007).

Another concern is the ability of CPT to reliably differentiate between ADHD and other disorders. Mood and anxiety disorders often result in false positives on CPT (APA, 2013), perhaps due to known associations between anxiety disorders and response inhibition (Quay, 1988). Low specificity for individuals with other psychiatric conditions means that low CPT performance may not be specific to ADHD (Fuermaier et al., 2018), but may represent neuropsychological deficits associated with other psychiatric disorders.

Epstein et al. (2003) added that relationships between CPT variables and ADHD symptoms have not been equivocally and consistently demonstrated. Researchers pointed to commission errors as an example, citing an assumed connection between commission errors and impulsivity based on incorrect or inappropriate responding. However, in their study, four of five CPT parameters were related to all three ADHD symptom domains, making it difficult to determine which variables map onto which symptoms. Mean reaction time was the only variable to be significantly related with one symptom domain (i.e., hyperactivity); however, it was correlated with only one of the 18 ADHD symptoms. Generally, research has not yet definitively demonstrated which CPT parameters measure which ADHD symptoms. More research is needed to advance our understanding of the ADHD endophenotype to develop instruments that address the limitations of existing CPT.

Go/No-Go Methodology. CPT involves detecting and responding to visual or auditory target stimuli amid a continuous and rapid stream of distractors for a period of 10-30 minutes. Examinees are instructed to respond when presented with target stimuli and to inhibit a response to non-targets. Different versions of CPT have been developed. For example, in the "X version" 
(Ogundele, Ayyash, \& Banerjee, 2011), a common CPT format, examinees are presented with a series of stimuli and are instructed to respond only to the single target stimulus, the letter "X." All other stimuli are non-targets to be resisted. Variations of this format exist in which the examinee is instructed to respond to all stimuli except the letter "X." The frequency of targets may vary across CPTs and/or conditions from about $90 \%$ to $10 \%$; the former measures response inhibition to seldom presented non-targets and the latter measures sustained attention for infrequent targets.

Generally, these CPTs are referred to as "Go/No-Go" tasks (G/NG; Donders, 1969) due to the need to initiate a response (Go) or inhibit a response (No-Go) depending on stimulus presentation. The "go" response is proposed to be initiated within the brain's Behavioral Activation System, whereas the "no-go" response originates in the Behavioral Inhibition System (Gray, 1987). G/NG tasks are designed to measure the action restraint component of response control in the "no-go" condition (van Velzen et al., 2014).

Interference Control. G/NG tasks are made more difficult by including visual or auditory distractors within test stimuli, thereby invoking interference control (Uno et al., 2006; van Velzen et al., 2014). Recall that Schachar et al. (2007) assessed performance on two primary components of response control: action restraint and action cancellation. A third process, interference control, is required when stimuli are presented alongside environmental distractors. Examinees must resist attending to the distractors and attend only to task-relevant stimuli, thereby increasing the demand for sustained attention (Shalev, Ben-Simon, Mevorach, Cohen, \& Tsal, 2011). Research suggests that CPT with environmental distractors is useful in identifying ADHD among adolescents (Berger \& Cassuto, 2014). The ADHD group was identified based on 
a significantly greater number of omission errors compared to the non-ADHD group, which provides evidence for deficient sustained attention among members of the clinical sample.

Interference control can be measured by a variety of tasks including the Flanker task (Eriksen \& Eriksen, 1974), the Simon task (Rubia, Cubillo, Woolley, Brammer, \& Smith, 2011) and the Stroop task (Stroop, 1935; MacLeod, 1992). The Flanker task presents a target stimulus, typically an arrow pointing in one direction or another. Subjects are to push a button corresponding to the direction of the target arrow; however, the target arrow is flanked by nontarget distractors that point either in the same direction (in congruent trials) or the opposite direction (in incongruent trials) as the target. Subjects therefore must ignore the flankers, or control the interference they present, and maintain their attention on target stimuli.

The Simon task presents an arrow pointing left or right on either the left or right side of the screen. In congruent trials, the left and right pointing arrows appear on the left and right side of the screen, respectively. In incongruent trials, the target arrow is pointing in the opposition direction of its location on the screen. Subjects push a left/right button depending on whether the arrow points left or right while ignoring the position of the target arrow on the screen.

The Stroop task involves naming colors that appear as written words either in the same color ink (in congruent trials) or different color ink (in incongruent trials). A congruent trial would present the word red written in red ink, whereas an incongruent trial would present the word blue written in red ink. Responders are asked to read aloud a set of written words that are either congruent or incongruent with respect to ink color. Each of these three tasks involve interference control in the presence of non-target distractor stimuli (van Velzen et al., 2014).

Stop Signal Paradigm. At a higher level of inhibitory demand is a G/NG task that includes the stop-signal task (SST; Logan, 1981; Logan \& Cowan, 1984). SST adds a layer of 
cognitive complexity by presenting a stop-signal immediately following a target stimulus, typically within 50-500 milliseconds. The stop-signal is commonly presented as an auditory tone that indicates to subjects to withhold a pre-trained target response. Pairing a target stimulus with a stop-signal forces subjects to cancel an already initiated response, or to apply the "mental breaks," which increases the demand for inhibitory control (Schachar et al., 2007). Whereas basic G/NG tasks are intended to measure action initiation in "go" conditions and action restraint in "no-go" conditions, SST measures an additional and more complex process in action cancellation. It is the task with the greatest inhibitory load because the "go" process must be quickly overridden by the "stop" process in response to stop-signals (Schachar et al., 2007; van Velzen et al., 2014).

The G/NG task is based on a theoretical model wherein the "go" and "no-go" processes function independently (Logan \& Cowan, 1984). Known as the race model (Logan, 1994), it refers to the competition between two opposing processes, the response initiation and response inhibition processes. Whichever process wins the "race" determines the behavioral outcome. In support of Logan's (1994) model, Dambacher et al. (2013) used fMRI to show that action restraint and action cancellation occupy distinct neural networks. Motor response inhibition is therefore not a unitary construct and is instead multifaceted consisting of action restraint, action cancellation, and interference control (van Velzen et al., 2014). Sebastian et al. (2013) proposed that interference control, action restraint, and action cancellation involve early, intermediate, and late response inhibitory processes, respectively. Barkley (1997) had previously used alternative labels to describe the same three processes: (1) inhibiting interference, (2) inhibiting prepotent responses, and (3) stopping an ongoing response. 
The SST paradigm quantifies inhibitory control processes using the following metrics: mean reaction time to targets (MRT), stop-signal delay (SSD), reaction time variability (SDRT), and stop-signal reaction time (SSRT) (Alderson et al., 2007). MRT measures latency of the response execution process. It represents the average time required to perceive target stimuli and execute responses across a designated number of trials. SDRT supplements MRT by providing the standard deviation of reaction times to targets across trials. SSD is the average time between presentations of the target and stop-signals (i.e., SSD $=$ MRT - SSRT). SSRT measures latency of the response inhibitory process and is normally distributed (Teichert \& Ferrera, 2015; Verbruggen \& Logan, 2008). SSRT is a function of the relationship between MRT and SSD (i.e., $\mathrm{SSRT}=\mathrm{MRT}-\mathrm{SSD}$ ) and reflects the speed of the action cancellation process.

The SSD may use a fixed, variable, or tracking go-stop method for determining the frequency and timing of stop-signals (Lijffijt et al., 2005). A fixed method uses a predetermined interval to establish the ratio of go stimuli to stop-signals. A variable method uses an interval that varies as a function of MRT. The tracking method was developed to counter subjects who may compromise speed to enhance accuracy, or engage in a speed-accuracy trade-off, whereby MRT increases as subjects delay responses to targets in anticipation of a stop-signal (Logan, Schachar, \& Tannock, 1997). Schachar et al. (2004) provided evidence for error monitoring or "detection of errors and subsequent adjustment of performance" (p. 285). The results demonstrated that children with ADHD artificially and differentially slowed their reaction time to targets following unsuccessful performance compared to controls. To address this effect, some measures now employ a tracking algorithm for SSD in which the stop-signal delay is increased by $50 \mathrm{~ms}$ following successful response inhibition and decreased by $50 \mathrm{~ms}$ following unsuccessful response 
inhibition. This algorithm produces a desired success rate of about 50\% across all trials (Alderson et al., 2007).

A meta-analysis of eight studies $(n=456)$ of SST provided support for MRT and SSRT in differentiating children with ADHD from controls (Oosterlaan et al., 1998). Regarding MRT, latency for responding was significantly slower for ADHD children compared to controls, suggesting deficits in action initiation associated with inattention. Regarding SSRT, children with ADHD exhibited deficits in action cancellation by taking significantly longer (i.e., 103ms, on average) to respond to stop signals compared to controls, indicating relatively poor response control. These results support the use of MRT and SSRT in differentiating children with ADHD from non-ADHD controls.

A subsequent meta-analysis by Lijffijt and colleagues (2005) replicated and extended the work of Oosterlaan et al. (1998) by including 29 articles published in the seven years between studies. The review also included studies of adults with ADHD, whereas the original analysis examined only children. The purpose was to investigate whether ADHD is primarily characterized by response control deficits or impaired attention. The results corroborated previous findings of a significant difference in SSRT between ADHD children and adults compared to matched controls, suggesting deficient response control in this clinical population. Additionally, MRT differentiated ADHD from control groups in children, but not in adults, providing partial support for the use of this metric to identify young patients with ADHD. Taking both reviews together, MRT and SSRT were successfully used to differentiate between clinical and non-clinical groups among children, while SSRT was the metric that differentiated groups in the adult sample. 
Among children with ADHD, Lijffijt et al. (2005) found no significant differences between MRT and SSRT, which the authors concluded was possibly indicative of underlying cognitive impairment (e.g., inattention) rather than deficits in response control. For SSRT to reflect deficient response control, SSRT values must be disproportionately larger compared to MRT or there is no way to rule-out confounding variables such as impaired attention. An insignificant difference between MRT and SSRT suggests possible deficits in attention based on MRT as well as in response control based on SSRT. However, significant variability in SDRT (a function of MRT) was found among children with ADHD, which provides additional evidence for lapses of attention based on high variability in response latency to targets. This conclusion was supported by Epstein et al. (2010) who demonstrated that reaction time was slower for trials before and after errors of omission. Insignificant differences between MRT and SSRT, and significant variability in SDRT both point to impaired attention as a primary characteristic of ADHD over and above response control deficits.

Although no differences in MRT were observed between the adult clinical and control groups, SSRT was significantly different between groups. Additionally, unlike in children, significant differences between MRT and SSRT in adults suggested deficient response control independent of other potential cognitive impairment, such as inattention.

Results from these two meta-analyses are mixed regarding the utility of each metric to differentiate between ADHD and control groups. It appears that the composition of the sample may be an important factor, as different results are reported for child and adult samples. Oosterlaan et al. (1998) showed that both MRT and SSRT are clinically useful with children. Lijffijt et al. (2005) pointed specifically to MRT as the key metric among children. Their analysis also provided initial support for the use of SSRT with adults to differentiate between 
groups based on impaired response control. Considering these initial findings, it remains to be investigated whether ADHD is characterized primarily by deficient response control or by inattention, and whether this primary deficit may differ across age groups. It is also important to consider the extent to which impairment is attributable to cross-circuit interactions.

A subsequent meta-analytic review replicated the Oosterlaan et al. (1998) and Lijffijt et al. (2005) findings of significantly slower MRT among ADHD children relative to controls (Alderson et al., 2007), indicating impairment in action initiation. Moreover, significant differences in SDRT and insignificant differences in between-group SSD (i.e., MRT - SSRT) both replicated the Lijffijt et al. (2005) results and further supported a potential generalized attention deficit based on differences in MRT rather than impairment in response control based on SSRT.

Overall, these meta-analyses provide a valuable, yet preliminary contribution to our understanding of ADHD by highlighting deficient response control and inattention as core features of the disorder. The results support the use of MRT and SSRT in differentiating between ADHD and non-ADHD groups, especially among children. Oosterlaan et al. (1998) found medium combined estimated effect sizes for MRT $(d=0.40)$ and SSRT $(d=0.64)$ using Cohen's standards (Cohen, 1988). Using Lipsey and Wilson's (2000) procedures, Lijffijt et al. (2005) found a significant medium effect size using MRT (0.52) and SSRT (0.58) among children. A medium, almost large, effect size (0.79) was also significant for SSRT among adults. Alderson et al. (2007) found significant medium mean effect sizes for MRT (0.45) and SSRT (0.63) among children using Hedges' standards (Hedges, 1982). The analysis of adult patients (Lijffijt et al., 2005 ) found a significant effect size for SSRT, which is medium (0.79) but close to the threshold 
for a large effect (Lipsey \& Wilson, 2000). At least two additional studies have found significant large effect sizes for SSRT in adult samples (Aron et al., 2003; Wodushek \& Neumann, 2003).

More research is needed to corroborate and clarify whether metrics associated with inattention (i.e., MRT) and/or response control (i.e., SSRT) are clinically useful in evaluating ADHD in child and adult patients. Inattention is highlighted as a predominate deficit in studies involving children (Alderson et al., 2007; Lijffijt et al., 2005; Oosterlaan et al., 1998), whereas deficient inhibitory control has been proposed as the major feature of adult ADHD (Bekker et al., 2005; Lijffijt et al., 2005). SSRT was significantly more prolonged than MRT among adults, which supports Barkley's (1997) theoretical model in which response inhibitory deficits are primary in ADHD. All other impairments are proposedly secondary as their function is contingent on effective and efficient response inhibition. Evidence of deficient inhibitory control may also illuminate key neuroanatomical structures involved in ADHD based on their association with motor response inhibition including the basal ganglia (Guo et al., 2018; Shaw et al., 2014), frontal gyrus, posterior cingulate cortex, and parietal regions (Dambacher et al., 2013).

Support for Barkley's (1997) model is limited based on results from these meta-analyses for the following reasons. First, due to significant differences in SDRT and insignificant differences in SSD among children, both Lijffijt et al. (2005) and Alderson et al. (2007) concluded that clinical and non-clinical groups may differ based on action initiation (i.e., inattention) rather than on action cancellation (i.e., response control). When no difference exists between MRT and SSRT, the between-group variability may be attributable to a general deficit in cognitive control rather than a selective deficit in inhibition (Verbruggen \& Logan, 2008). Second, the meta-analyses included only studies of CPT performance in the basic G-NG format 
without non-target distractor stimuli. There was therefore no analysis of CPT performance with greater cognitive processing demands. The studies merely addressed response inhibition on a task of lower cognitive complexity without the additional inhibitory load introduced by interference control (Uno et al., 2006; van Velzen et al., 2014). Third, only one of the reviews included an adult sample, thus the conclusions made about SSRT among adult ADHD patients remain limited and warrant further exploration.

Based on these limitations and mixed results, further investigation is needed to determine the clinical utility of SSRT relative to MRT in differentiating between groups amid higher cognitive processing demands. Significant differences between SSRT and MRT under these conditions may provide evidence for a selective deficit in response control among individuals with ADHD (Verbruggen \& Logan, 2008). Moreover, this finding would provide contrary evidence for the conclusions of Lijffijt et al. (2005) and Alderson et al. (2007) that periodic lapses in attention are primarily responsible for between-group variation. Indeed, in a more recent meta-analysis of reaction time variability among children, adolescents, and adults with ADHD, Kofler et al. (2013) found that what accounted for group variation was SDRT, not MRT. Participants demonstrated significantly greater reaction time variability relative to controls, even after controlling for MRT.

In sum, ADHD is a complex neurodevelopmental disorder. Accurate assessment is complicated by a variety of factors including symptom heterogeneity (Uno et al., 2006), variability in functional impairment (Spencer et al., 2007), comorbid disorders (Faraone et al., 2000), and potentially insufficient or inadequate measures. While CPT is prevalent in ADHD evaluations (Munkvold, Manger, \& Lundervold, 2014; Sollman et al., 2010), different versions have shown mixed utility in identifying ADHD and non-clinical groups, as well as differentiating 
ADHD from other psychiatric disorders (Advokat et al., 2007; Fuermaier et al., 2018; McGee, Clark, \& Symons, 2000; Tollander, 2011). As our understanding of ADHD genotypes, phenotypes, and endophenotypes evolves, we must advance our assessment tools to increase instrument specificity and sensitivity.

Cognitive control deficits associated with motor response inhibition have been identified as a core feature of ADHD (Hart et al., 2014; McAuley et al., 2013). Specifically, stop-signal inhibition has been proposed as a key endophenotype (Aron \& Poldrack, 2005; Schachar et al., 2005) and research has demonstrated the clinical utility of SST in identifying ADHD and control groups on G/NG tasks (Alderson et al., 2007; Lijffijt et al., 2005; Oosterlaan et al., 1998). Absent from this literature is assessment of the diagnostic utility of stop-signal tasks in the adult population on tasks with greater central processing demands produced by interference control.

\section{The Present Study}

\section{Research Questions}

CPT has evolved from $\mathrm{G} / \mathrm{NG}$ tasks intended to measure action initiation and action restraint to central processing tasks involving higher cognitive demands associated with action cancellation and interference control. Previous research has identified MRT (i.e., inattention) as the primary metric that differentiates ADHD patients from non-clinical controls (Alderson et al., 2007; Lijffijt et al., 2005). Between-group variability was attributed to inattention based on insignificant differences between MRT and SSRT, as well as significant differences between groups on SDRT. Both results suggest that an underlying factor other than inhibitory control, such as inattention, may account for the variability. These findings are consistent with the position of Castellanos and Tannock (2002) that "perhaps that most striking clinical 
characteristics of ADHD include the transient but frequent lapses of attention, and the momentto-moment variability and inconsistency in performance" (p. 624).

In contrast, when SSRT is impaired but MRT is not, the results may suggest a selective deficit in the action cancellation facet of motor response inhibition (Verbruggen \& Logan, 2008). The purpose of the present study was to examine the relationships between scores on a selfreport measure of adult ADHD symptoms and CPT performance. The primary aim was to determine whether SSRT may predict levels of self-reported impairment from ADHD symptoms among adults on a CPT with greater central processing demands. This study addressed the following three research questions:

1. Does SSRT, as measured by the TDIA (Long, 2018), significantly predict selfreported symptoms of inattention, as measured by the Inattention subscale of the ASRS-V1.1 (Kessler et al., 2005), over and above MRT alone, as measured by the TDIA (Long, 2018)?

2. Does SSRT, as measured by the TDIA (Long, 2018), significantly predict selfreported symptoms of hyperactivity/impulsivity, as measured by the HyperactivityImpulsivity subscale of the ASRS-V1.1 (Kessler et al., 2005), over and above MRT alone, as measured by the TDIA (Long, 2018)?

3. Does SSRT, as measured by the TDIA (Long, 2018), significantly predict selfreported symptoms of combined inattention and hyperactivity/impulsivity, as measured by the ASRS-V1.1 total score (Kessler et al., 2005), over and above MRT alone, as measured by the TDIA (Long, 2018)?

\section{Hypotheses}

In light of previous literature and based on the aforementioned research questions, the 
following three hypotheses were established for the current study:

$\mathbf{H}_{1}$. SSRT will significantly predict self-reported symptoms of inattention, over and above MRT alone.

$\mathbf{H}_{2}$. SSRT will significantly predict self-reported symptoms of hyperactivity/impulsivity, over and above MRT alone.

$\mathbf{H}_{3}$. SSRT will significantly predict self-reported symptoms of combined inattention and hyperactivity/impulsivity, over and above MRT alone. 


\section{CHAPTER 2: METHODS}

I designed this study to replicate and extend previous research on stop-signal tasks (SST) that identified stop-signal reaction time (SSRT) as the primary parameter that differentiates adults with ADHD from non-clinical controls (Lijffijt et al., 2005). Whereas the analysis by Lijffift and colleagues (2005) included only basic "Go / No-Go" tasks (G/NG), I examined the performances of adults on a continuous performance test (CPT) with interference control conditions. I also extended previous research showing that a CPT with distractor stimuli aided in identifying ADHD among adolescents (Berger \& Cassuto, 2014), by replicating this result in an adult sample. While the CPT with distractors differentiated between clinical and non-clinical groups, the sample did not include adults and SST was not involved. Scholars have not yet examined the performances of adults on a CPT that includes both SST and distractor stimuli.

In this study I examined the relationships between scores on a self-report measure of adult ADHD symptoms and performances on a CPT with SST and interference conditions. My primary aim was to preliminarily assess the clinical utility of SSRT in distinguishing between adults with greater self-reported ADHD symptoms and those with lesser impairment based on CPT performance with central processing demands. Research has shown that SSRT is useful in identifying individuals with self-reported, clinically significant ADHD symptoms and individuals with self-reported subthreshold impairment (Aron et al., 2003; Berger \& Cassuto, 2014; Kofler et al., 2013; Wodushek \& Neumann, 2003).

\section{Research Design}

In this study I employed a between-subjects, quantitative-descriptive, cross-sectional, correlational design to define and describe the nature of the relationships between two continuous predictor variables (i.e., MRT and SSRT) and the single continuous criterion variable 
(i.e., self-report ratings of adult ADHD symptoms). Two measures plus a demographic questionnaire were administered to all participants. All participants received identical material, and measures were counterbalanced to account for order effects.

\section{Participants}

All participants were required to be, and reported being, at least 18 years of age. An a priori power analysis was calculated using G*Power software (Faul, Erdfelder, Buchner, \& Lang, 2009) to estimate the necessary sample size. A hierarchical multiple linear regression was the primary statistical analysis selected, which included two continuous predictor variables (i.e., MRT and SSRT) and one continuous criterion variable (i.e., ASRS-V1.1 score). Based on an alpha $(\alpha)$ level of .05 , the power analysis estimated that a minimum of 31 participants was necessary to obtain adequate statistical power (.80) to determine a large effect size using Cohen's $f^{2}=0.35$ standards (Cohen, 1988). At least two studies have found significant large effect sizes for SSRT in adult samples (Aron et al., 2003; Wodushek \& Neumann, 2003).

\section{Sampling Procedures}

The study protocol was acknowledged by the WVU Office of Research Integrity and Compliance's Institutional Review Board (IRB). Initial recruitment of undergraduate and graduate students at WVU was attempted using the online University Research Participation System, SONA, managed by the WVU Department of Psychology. SONA provides WVU psychology students with opportunity to participate in research to earn course credit. Alternative assignments are typically available for students who choose not to participate in SONA research. Students who register with SONA are provided a SONA ID number, which is used by SONA administrators to track participation. Representatives of SONA distributed information about this study to potentially eligible individuals within the SONA system via their webpage (see 
Appendix A). The study's purpose and rationale were available to potential participants including a detailed description of the eligibility requirements, anticipated completion time, participation incentive, and the researcher's contact information. Interested and eligible individuals were invited to contact the researcher to obtain additional information about the study or to express their desire to participate. However, this recruitment strategy was unsuccessful in obtaining any participants.

The recruitment letter in Appendix A was also distributed via email to graduate students and faculty in the Department of Counseling, Rehabilitation Counseling, and Counseling Psychology at WVU, as well as alumni and associates of Kalamazoo College's and Western Michigan University's Departments of Intercollegiate Athletics. The lead researcher also personally recruited students from the Master of Arts in Counseling program at WVU during a seminar on psychological assessment.

Participants were also recruited in the MindFit Clinic (MindFit) at the WVU Carruth Center for Psychological and Psychiatric Services (Carruth). MindFit provides comprehensive psychoeducational assessment, as well as cognitive and academic enhancement services in a multidisciplinary program intended to improve students' success in college. The staff is comprised of approximately two doctoral practicum trainees in psychology, three pre-doctoral psychology interns, and two licensed psychologists. All staff were trained on administration and data collection procedures for all measures involved in this study. Specifically, staff received training on procedures for recruiting participants, obtaining informed consent, maintaining privacy and confidentiality, securely storing participants' data, and referring students to resources should they experience distress associated with participation in this study. All 
individuals who presented for testing at MindFit and met the inclusion criterion were invited to participate in this study. Individuals were provided with a recruitment letter (see Appendix B).

MindFit provides approximately 50 comprehensive Learning Disorder and ADHD evaluations annually. The standard battery includes a semi-structured diagnostic interview and measures of intellectual functioning, academic functioning, executive functioning, attentional processing and response control, sleep hygiene, and performance validity. Testing typically occurs across two, three-hour appointments on separate days. Results are integrated in a written report containing diagnostic impressions and treatment recommendations. Pending a request for further action, evaluations conclude with a review of assessment findings and the provision of a report to each client. Participants were informed that the measures involved in this study are not used in any manner nor at any time during the assessment process. Information obtained for the purposes of this study was not used in any manner for clinical or diagnostic purposes.

All interested and eligible individuals were directed to a paper-form, informed consent document (see Appendix C) where they provided informed consent to participate. Survey material was identical in form across all sampling procedures. For participants associated with MindFit, administration of survey material occurred during either the first or second testing appointment at the discretion of MindFit staff; however, participants were administered only one CPT per appointment.

The sampling method used in this study is called convenience sampling (Heppner, Wampold, \& Kivlighan, 2008). Convenience sampling is a commonly used nonrandom sampling method wherein participants are recruited for practical reasons such as proximity, accessibility, and availability to the researcher (Bornstein, Jager, \& Putnick, 2013; Etikan, Musa, \& Alkassim, 
2016). The use of student volunteers as research participants is a common example of convenience sampling (Bornstein et al., 2013).

\section{Measures}

\section{World Health Organization Adult ADHD Self-Report Scale - V1.1 Symptoms Checklist}

\section{(ASRS-V1.1)}

The World Health Organization Adult ADHD Self-Report Scale - V1.1 Symptoms

Checklist (ASRS-V1.1; Kessler et al., 2005) is a measure of self-reported symptoms of ADHD in adulthood. The ASRS-V1.1 consists of 18 items that correspond to diagnostic criteria for ADHD. The response format involves five frequency ratings on a five-point Likert-type scale: 0 (never), 1 (rarely), 2 (sometimes), 3 (often) and 4 (very often). None of the items are reverse scored, meaning that higher ratings indicate greater frequency of impairment from ADHD symptoms for all items. The ASRS-V1.1 total score is derived by summing points across all 18 items, with possible scores ranging from 0 to 72 . Higher total scores indicate greater frequency of symptom impairment. Clinically significant symptom levels are defined as ASRS-V1.1 total score of 47 or greater. ASRS-V1.1 total score of 46 or less indicate subthreshold impairment. This measure takes approximately 5-10 minutes to complete (Gray, Woltering, Mawjee, \& Tannock, 2014).

The ASRS-V1.1 consists of two subscales, Inattention and Hyperactivity-Impulsivity, with nine items that correspond to each subscale and a range of possible scores from 0 to 36 . Higher total subscale scores indicate greater frequency of impairment for each symptom type. Example items that load on the Inattention subscale include, "How often are you distracted by activity or noise around you?" and "How often do you make careless mistakes when you have to work on a boring or difficult project?” Example items from the Hyperactivity-Impulsivity subscale include, "How often do you leave your seat in meetings or other situations in which you 
are expected to remain seated?" and "How often do you have difficulty waiting your turn in situations when turn-taking is required?" Items $1,2,3,4,7,8,9$, 10, and 11 correspond to the Inattention subscale. Inattention subscale total scores of 23 or greater indicate clinically significant impairment. Items $5,6,12,13,14,15,16,17$, and 18 correspond to the Hyperactivity/Impulsivity subscale. Hyperactivity/Impulsivity subscale total scores of 24 or greater indicate clinically significant impairment.

The ASRS-V1.1 demonstrated adequate psychometric quality in comparison to blind clinical assessment of adult ADHD in a community sample of 154 individuals (Kessler et al., 2005). Participants completed a semi-structured clinical ADHD Rating Scale (ADHD-RS; DuPaul, Power, Anastopoulos, \& Reid, 1998), a semi-structured diagnostic interview for symptoms of adult ADHD, and the ASRS-V1.1. Interviews were conducted by doctoral-level clinical psychologists with a minimum five years of clinical experience. All 18 ASRS-V1.1 symptom measures were significantly related to their corresponding symptom rating during clinical assessment. Cohen's kappa values ranged from .16 to .81, indicating slight to substantial concordance across all items using standards for assessing the strength of kappa coefficients (Landis \& Koch, 1977).

A second study of the ASRS-V1.1 yielded satisfactory ratings of internal consistency reliability (Adler et al., 2006). Responses on the self-report ASRS-V1.1 were compared to clinicians' ratings on the ADHD-RS (DuPaul et al., 1998) for 60 adult patients diagnosed with childhood onset adult ADHD. Internal consistency was assessed using Cronbach's alpha. The patient and clinician versions yielded Cronbach's alpha coefficients of .88 and .89 , respectively.

The ASRS-V1.1 also demonstrated sound psychometric properties in a sample of 135 English-speaking university students with a previous ADHD diagnosis (Gray et al., 2014). 
Responses on the self-report ASRS-V1.1 were compared to collateral reports of ADHD symptoms using a modified version of the ASRS-V1.1, the ASRS-V1.1 for Other developed for use in this study. Results indicated moderate congruence between self- and collateral-report versions $(r=0.46, p<0.001)$.

As discussed above, although self-report measures can be unreliable and of questionable validity (Miller, Newcorn, \& Halperin, 2010; Sibley et al., 2012), and vulnerable to feigned symptomatology (Bryant et al., 2018), self-report measures are often a core feature of adult ADHD evaluations (Taylor, Deb, \& Unwin, 2011). Clinicians have historically used these measures to assess symptom presence, severity, and history (Harrison, Edwards, \& Parker, 2007).

\section{Test of Differential Inhibition and Attention (TDIA)}

The Test of Differential Inhibition and Attention (TDIA; Long, 2018) is a computerized, 20-minute CPT designed to assess differential contributions of various attention networks and response inhibitory processes that may account for the variance in ADHD endophenotypes. CPT is among the most frequently employed instruments in ADHD evaluations (Munkvold et al., 2014; Sollman et al., 2010). The TDIA combines three different cognitive tasks: a modified Posner cuing task (Posner, 1980) that incorporates an Eriksen Flanker design (Eriksen \& Eriksen, 1974) and the classic stop signal paradigm (Logan, 1981; Logan \& Cowan, 1984).

The TDIA has three sequential conditions, each involving cuing (Posner, 1980) and flanker tasks (Eriksen \& Eriksen, 1974). Participants see a series of target arrows flanked by other arrows and are instructed to press the left or right key that matches the direction of the center, target arrow. In the flanker task, subjects are presented with a target stimulus, typically an arrow pointing in one direction or another. Subjects are to push a button corresponding to the 
direction of the target arrow; however, the target arrow is flanked by non-target distractors that point either in the same direction (in congruent trials) or the opposite direction (in incongruent trials) as the target. Subjects therefore must ignore the flankers, or control the interference they present, and maintain their attention on target stimuli. A sample is presented below.

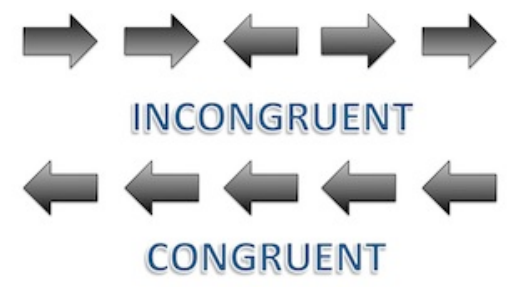

Figure 1. Congruent and incongruent trials in the Eriksen Flanker design (Eriksen \& Eriksen, 1974).

The Posner cuing task (Posner, 1980) measures the orienting network of the human attentional system by presenting a visual cue prior to test stimuli. A percentage of trials has no visual cue preceding the target and distractor stimuli, while other trials consist of either a center cue, spatial cue, or invalid cue. A center cue trial involves an asterisk in the center of the computer screen intended to alert and orient participants that a target stimulus is upcoming; however, the stimulus may then appear anywhere on the screen. A spatial cue designates that the target and distractor stimuli appear in the same location as the preceding visual cue (i.e., top, center, or bottom). An invalid cue indicates that the visual cue and subsequent stimuli appear in different locations on the screen. The target stimulus for each trial is either congruent or incongruent with respect to its flanker stimuli, meaning that the target arrow points in the same or opposing direction as the distractor arrows, respectively.

Condition two builds on condition one by introducing the stop-signal task (Logan, 1981; Logan \& Cowan, 1984). In this task subjects are presented with a stop-signal (i.e., auditory tone) immediately following a target stimulus, typically within 50-500 milliseconds, signaling to 
subjects to withhold a pre-trained target response. Pairing a target stimulus with a stop-signal increases the demand for inhibitory control (Schachar et al., 2007). On a percentage of trials, the tone will sound to signal that the participant should refrain from pressing either arrow keys. Mean values for MRT and SSRT are calculated for each respondent. MRT represents the mean reaction time to target stimuli across a designated number of trials and appears as "GO RT MEAN" in row six of the output spreadsheet. SSRT is calculated by subtracting the ending audio stop delay from the go reaction time (i.e., MRT - SSD) and appears in row 30 of the output. Finally, condition three is identical to condition two except that participants are instructed to ignore the stop-signal and respond to target stimuli as in condition one. Data generated in condition three were not included in the analysis.

TDIA employs a tracking go-stop method whereby SSD increases by 50ms following successful response inhibition and decreases by 50ms following unsuccessful response inhibition. This method produces a desired success rate of about 50\% across all trials (Alderson et al., 2007). After condition three, output is generated using Microsoft Excel software.

\section{Demographics Questionnaire}

An English version of a five-item self-report, forced-choice demographics questionnaire was used to collect clients' demographic information including their age, sex, psychodiagnostic history of ADHD, age at time of diagnosis (if applicable), and to ascertain whether they: (1) are currently prescribed, (2) were previously prescribed, or (3) have never been prescribed psychostimulant medication.

\section{Procedures}

Interested and eligible individuals were recruited using the sampling procedures and recruitment letters described above (see Appendices A and B). Participants were required to 
appear in-person to complete all measures. For individuals whose participation did not occur in conjunction with an evaluation in MindFit, 30-minute laboratory sessions were held in preapproved campus locations. Participants were directed to a computer where they were again presented with the recruitment letter (see Appendix A). As stated in Appendix A, individuals whose participation did not occur in conjunction with a MindFit evaluation were invited to enter into an anonymous, random drawing to win one of ten $\$ 10$ Amazon gift cards. Interested participants were asked to provide their email addresses for the drawing, and they were informed that their addresses were not linked to their responses to maintain the anonymity of their data.

Following review of the recruitment letter, participants were directed to an informed consent document (see Appendix C) where they confirmed their informed consent prior to accessing the measures. Responses to the demographic questionnaire and ASRS-V1.1 were stored in a locked filing cabinet maintained by Carruth personnel. Data from the TDIA were recorded and secured on an external hard drive accessible only to researchers. Participants who inquired about their performance on any of the measures were advised that no such information could be provided for the following two reasons: (1) no norms for the TDIA currently exist, and (2) the study is solely for experimental purposes and is not intended to be clinically informative. In this case, the examiner was prepared to provide participants with referrals to Carruth for a clinical assessment of cognitive and/or academic functioning.

Procedures were modified for individuals whose participation occurred concurrent with a LD/ADHD evaluation in MindFit, in accordance with all agency policies and procedures. Individuals who were eligible and wished to participate in this study were presented with a recruitment letter (see Appendix B) and asked to provide their informed consent (see Appendix C) should they be eligible and wish to participate in this study. Participants were offered a $\$ 10$ 
Amazon gift card in exchange for completing all measures. Responses to the demographic questionnaire and ASRS-V1.1 were stored in a locked filing cabinet maintained by Carruth personnel. Data from the TDIA were recorded and secured on an external hard drive accessible only to researchers.

If a participant in MindFit inquired about their performance on any of the measures, they were advised that no such information can be provided for the following two reasons: (1) no norms for the TDIA currently exist, and (2) the study is solely for experimental purposes and is not intended to be clinically informative. In this case, the examiner was prepared to inform students that their participation in this study occurred in conjunction with a clinical assessment of their cognitive and/or academic functioning. Moreover, the examiner informed participants that their results from study materials were not to be used in any manner nor at any time to make clinical decisions during their formal evaluation in MindFit.

To identify participants' datasets and protect their privacy, each participant was assigned a unique code known only to their attending researcher or MindFit clinician. The coding system consisted of the examiner's first and last initial followed by the numerical order in which study materials were administered to participants (e.g., the fifth participant of examiner "John Smith" would receive the following code: "JS05"). This code served as each participant's identification number and was used to link demographic information to the corresponding dataset.

Finally, all participants were thanked for their time and in cases where participants experienced any form or level of distress or discomfort related to study participation, they were referred to professional mental health services. Resources provided included the WVU Carruth Center for Psychological and Psychiatric Services, the WVU Quin Curtis Center and the WVU 
Student Health Center. Participants were provided with contact information for each resource (see Appendix F). 


\section{CHAPTER 3: RESULTS}

\section{Descriptive Statistics}

Data were collected from 49 participants. Technological issues resulted in one participant's dataset being deleted; therefore, 48 participants were included in the final sample. The sample consisted of four participants from the MindFit Clinic at Carruth, seven participants associated with Kalamazoo College and Western Michigan University, 17 participants from the Master of Arts in Counseling program at WVU, and 20 participants from WVU's doctoral program in Counseling Psychology.

The average age of the sample was 29.75 years, ranging from 19 to 68 . Fourteen participants self-identified as male (29.2\%), 32 self-identified as female (66.7\%) and two selfidentified as non-binary (4.2\%). Five participants (10.4\%) had a previous diagnosis of ADHD; three were diagnosed between the ages of $0-12$ years $(6.3 \%)$, one was diagnosed between 12 and 18 years $(2.1 \%)$, and one was diagnosed at age 18 years or older $(2.1 \%)$. Forty-three participants $(89.6 \%)$ endorsed never being diagnosed with ADHD. Finally, one participant $(2.1 \%)$ reported a current prescription for psychostimulant medication, five participants (10.4\%) reported previous prescriptions, and 42 participants $(87.5 \%)$ denied a prescription history for psychostimulants.

Descriptive statistics for the measures are provided in Table 1.

Table 1

Descriptive of Measures

\begin{tabular}{rcccccc}
\hline \multicolumn{1}{c}{ Measure } & Min. & Max. & Mean & Std. Error & Std. Deviation & Variance \\
\hline ASRS-V1.1 Total & 9 & 53 & 26.35 & 1.49 & 10.33 & 106.78 \\
ASRS-V1.1 (I) & 5 & 28 & 14.46 & .77 & 5.37 & 28.93 \\
ASRS-V1.1 (H/I) & 2 & 28 & 11.90 & .89 & 6.18 & 38.22 \\
TDIA MRT & .56332 & 1.15270 & .78711 & .02241 & .15530 & .024 \\
TDIA SSRT & .33374 & .67446 & .44997 & .01201 & .08326 & .007 \\
\hline
\end{tabular}


A correlation table for the variables is presented in Table 2. The table displays a twotailed probability for each correlation coefficient to identify significant relationships between the predictor variables. As shown, there is a statistically significant correlation between the two predictor variables, TDIA MRT and TDIA SSRT; however, a correlation of .499 is below the threshold for multicollinearity (Laerd Statistics, 2015). Multicollinearity is discussed further in the section below on assumptions for hierarchical multiple linear regression.

Table 2

Correlations

\begin{tabular}{|c|c|c|c|c|c|}
\hline & $\begin{array}{c}\text { ASRS-V1.1 } \\
\text { Total }\end{array}$ & $\begin{array}{c}\text { ASRS-V1.1 } \\
\text { Inattention (I) }\end{array}$ & $\begin{array}{c}\text { ASRS-V1.1 } \\
(\mathrm{H} / \mathrm{I})\end{array}$ & $\begin{array}{l}\text { TDIA } \\
\text { MRT }\end{array}$ & $\begin{array}{l}\text { TDIA } \\
\text { SSRT }\end{array}$ \\
\hline \multicolumn{6}{|l|}{ Pearson Correlation } \\
\hline ASRS-V1.1 Total & 1.000 & $.877 * *$ & $.908 * *$ & -.274 & .194 \\
\hline ASRS-V1.1 (I) & $.877 * *$ & 1.000 & $.596 * *$ & -.207 & $.300 *$ \\
\hline ASRS-V1.1 (H/I) & $.908 * *$ & $.596^{* *}$ & 1.000 & -.278 & .063 \\
\hline TDIA MRT & -.274 & -.207 & -.278 & 1.000 & $.499 * *$ \\
\hline TDIA SSRT & .194 & $.300 *$ & .063 & $.499 * *$ & 1.000 \\
\hline \multicolumn{6}{|l|}{ Sig. (2-tailed) } \\
\hline ASRS-V1.1 Total & & .000 & .000 & .059 & .186 \\
\hline ASRS-V1.1 (I) & .000 & & .000 & .157 & .038 \\
\hline ASRS-V1.1 (H/I) & .000 & .000 & & .056 & .669 \\
\hline TDIA MRT & .059 & .157 & .056 & & .000 \\
\hline TDIA SSRT & .186 & .038 & .669 & .000 & \\
\hline
\end{tabular}

Assumptions and Reliability of the Measures

Collected data were analyzed to ensure they met six statistical assumptions for hierarchical multiple linear regression: independence of observations, linearity, homoscedasticity, multicollinearity, outliers, and multivariate normality (Laerd Statistics, 2015). There was independence of residuals, as assessed by Durbin-Watson statistics of 1.656 (ASRSV1.1 Total), 2.154 (ASRS-V1.1 Inattention), and 2.263 (ASRS-V1.1 Hyperactivity/Impulsivity).

The assumption of linearity is that a linear relationship exists between the criterion variable and both predictor variables, collectively and separately. This assumption was tested 
using scatterplots of studentized residuals by unstandardized predicted values and partial regression plots, respectively. The scatterplots revealed horizontal bands indicating that the relationships between ASRS-V1.1 Total, ASRS-V1.1 Inattention, ASRS-V1.1 Hyperactivity/Impulsivity, MRT, and SSRT are approximately linear. Partial regression plots also showed approximately linear relationships between these variables.

Homoscedasticity assumes that the variance of error terms is similar throughout levels of the predictor variables. This assumption was tested through visual examination of a scatterplot of studentized residuals versus unstandardized predicted values to determine whether residuals are randomly and equally distributed across all values of predictor variables. After inspection of the plots, it was concluded that the assumption of homoscedasticity was not violated.

The assumption of multicollinearity is that the two predictor variables are not highly correlated with each other at levels above .70 (Laerd Statistics, 2015). Inspection of correlation coefficients and Tolerance/Variance Inflation Factor (VIF) values revealed no multicollinearity problems, which arise with Tolerance values less than 0.1 and VIF values greater than 10 (Hair, Black, Babin, \& Anderson, 2014). The Tolerance value for this sample is .751 and the VIF value is 1.331 ; therefore, it is unlikely that problems with multicollinearity would have negatively impacted these results. Regarding unusual data points, no outliers were identified in the casewise diagnostics table.

Finally, multivariate normality assumes that the variables are normality distributed. This assumption was tested using a histogram and goodness-of-fit model to assess the shape of the distribution and identify outliers. The distribution was found to be approximately normal.

In addition to checking assumptions for hierarchical multiple linear regression, each measure was assessed for internal consistency reliability. Each measure demonstrated a high 
level of internal consistency, as determined by Cronbach's alpha, based on interpretation guidelines proposed by George and Mallery (2003). The ASRS-V1.1 Total scores were found to have a high reliability coefficient (18 items; $\alpha=.89$ ). Likewise, scores for the ASRS-V1.1 Inattention subscale demonstrated high internal consistency ( 9 items; $\alpha=.84$ ). Finally, the ASRS-V1.1 Hyperactivity/Impulsivity subscale scores also demonstrated high internal consistency ( 9 items; $\alpha=.86$ ). The sample Cronbach's alpha statistics are provided in Table 3. Table 3

Internal Consistency Reliability of Measures

\begin{tabular}{lcccc}
\hline \multicolumn{1}{c}{ Measure } & $\begin{array}{c}\text { Items } \\
\mathrm{N}\end{array}$ & $\begin{array}{c}\text { Participants } \\
\mathrm{N}\end{array}$ & $\begin{array}{c}\text { Cronbach's } \\
\text { Alpha }\end{array}$ & $\begin{array}{c}\text { Internal } \\
\text { Consistency }\end{array}$ \\
\hline ASRS-V1.1 Total & 18 & 48 & .89 & Good \\
ASRS-V1.1 (I) & 9 & 48 & .84 & Good \\
ASRS-V1.1 (H/I) & 9 & 48 & .86 & Good \\
\hline
\end{tabular}

\section{Hypothesis Testing}

\section{Hypothesis 1}

The first hypothesis stated that SSRT will significantly predict ASRS-V1.1 Inattention scores, over and above MRT alone. A hierarchical multiple regression was conducted to determine if the addition of SSRT improved the prediction of ASRS-V1.1 Inattention scores, over and above the proportion of the variance explained by MRT alone. The model included two continuous predictor variables (i.e., MRT and SSRT) and one continuous criterion variable (i.e., ASRS-V1.1 Inattention scores). The full model of MRT and SSRT was statistically significant, $R^{2}=.259, F(2,45)=7.88, p=.001$; adjusted $R^{2}=.226$. MRT accounted for $4.3 \%$ of the variance in ASRS-V1.1 Inattention scores, a small effect size according to Cohen's standards (Cohen, 1988). The addition of SSRT to the prediction of ASRS Inattention led to a statistically significant increase in $R^{2}$ of $.216, F(1,45)=13.149, p=.001$. SSRT accounted for an additional 
$21.6 \%$ of the variance in ASRS-V1.1 Inattention scores, which represents a medium effect size (Cohen, 1988). The results of this analysis are provided in Tables 4 and 5.

Table 4

Model Summary

\begin{tabular}{cccccccc}
\hline Model & $\mathrm{R}$ & $\mathrm{R}$ Square & $\begin{array}{c}\text { Adjusted } \\
\text { R Square }\end{array}$ & $\begin{array}{c}\text { Std. Error of } \\
\text { the Estimate }\end{array}$ & $\begin{array}{c}\text { R Square } \\
\text { Change }\end{array}$ & F Change & $\begin{array}{c}\text { Durbin- } \\
\text { Watson }\end{array}$ \\
\hline 1 & $.207^{\mathrm{a}}$ & .043 & .022 & 5.319 & .043 & 2.066 & \\
2 & $.509^{\mathrm{b}}$ & .259 & .226 & 4.731 & .216 & 13.149 & 2.154 \\
& & & & & & & \\
\hline $\begin{array}{l}\text { a. Predictors: (Constant), MRT } \\
\text { b. Predictors: (Constant), MRT, SSRT } \\
\text { c. Dependent Variable: ASRS-V1.1 Inattention }\end{array}$
\end{tabular}

Table 5 ANOVA

\begin{tabular}{|c|c|c|c|c|c|c|c|}
\hline \multirow[t]{2}{*}{ Model } & & & Sum of Squares & df & Mean Square & $\mathrm{F}$ & Sig. \\
\hline & \multirow[t]{3}{*}{1} & Regression & 58.445 & 1 & 58.445 & 2.066 & $.157^{b}$ \\
\hline & & Residual & 1301.471 & 46 & 28.293 & & \\
\hline & & Total & 1359.917 & 47 & & & \\
\hline \multirow{3}{*}{\multicolumn{2}{|c|}{2}} & Regression & 352.740 & 2 & 176.370 & 7.880 & $.001^{\mathrm{c}}$ \\
\hline & & Residual & 1007.177 & 45 & 22.382 & & \\
\hline & & Total & 1359.917 & 47 & & & \\
\hline
\end{tabular}

a. Dependent Variable: ASRS-V1.1 Inattention

b. Predictors: (Constant), MRT

c. Predictors: (Constant), MRT, SSRT

\section{Hypothesis 2}

The second hypothesis stated that SSRT will significantly predict ASRS-V1.1

Hyperactivity/Impulsivity scores, over and above MRT alone. A hierarchical multiple regression was conducted to determine if the addition of SSRT improved the prediction of ASRS Hyperactivity/Impulsivity, over and above the proportion of the variance explained by MRT alone. The model included two continuous predictor variables (i.e., MRT and SSRT) and one continuous criterion variable (i.e., ASRS-V1.1 Hyperactivity/Impulsivity scores). The full model of MRT and SSRT was statistically significant, $R^{2}=.132, F(2,45)=3.41, p=.042 ;$ adjusted $R^{2}$ 
$=.093$. MRT accounted for $7.7 \%$ of the variance in ASRS-V1.1 Hyperactivity/Impulsivity scores, which is considered a small effect (Cohen, 1988). The addition of SSRT to the prediction of ASRS Hyperactivity/Impulsivity led to a statistically significant increase in $R^{2}$ of .054 , $F(1,45)=2.814, p=.042$. SSRT accounted for an additional $5.4 \%$ of the variance in ASRS-V1.1 Hyperactivity/Impulsivity scores, which represents a small effect size (Cohen, 1988). The results of this analysis are provided in Tables 6 and 7.

Table 6

Model Summary

\begin{tabular}{cccccccc}
\hline Model & R & R Square & $\begin{array}{c}\text { Adjusted } \\
\text { R Square }\end{array}$ & $\begin{array}{c}\text { Std. Error of } \\
\text { the Estimate }\end{array}$ & $\begin{array}{c}\text { R Square } \\
\text { Change }\end{array}$ & F Change & $\begin{array}{c}\text { Durbin- } \\
\text { Watson }\end{array}$ \\
\hline 1 & $.278^{\mathrm{a}}$ & .077 & .057 & 6.003 & .077 & 3.853 & \\
2 & $.363^{\mathrm{b}}$ & .132 & .093 & 5.888 & .054 & 2.814 & 2.263
\end{tabular}

a. Predictors: (Constant), MRT

b. Predictors: (Constant), MRT, SSRT

c. Dependent Variable: ASRS-V1.1 Hyperactivity/Impulsivity

Table 7

ANOVA

\begin{tabular}{|c|c|c|c|c|c|c|c|}
\hline \multirow[t]{2}{*}{ Model } & & & Sum of Squares & df & Mean Square & $\mathrm{F}$ & Sig. \\
\hline & \multirow[t]{3}{*}{1} & Regression & 138.855 & 1 & 138.855 & 3.853 & $.056^{\mathrm{b}}$ \\
\hline & & Residual & 1657.624 & 46 & 36.035 & & \\
\hline & & Total & 1796.479 & 47 & & & \\
\hline \multirow{3}{*}{\multicolumn{2}{|c|}{2}} & Regression & 236.415 & 2 & 118.208 & 3.410 & $.042^{\mathrm{c}}$ \\
\hline & & Residual & 1560.064 & 45 & 34.668 & & \\
\hline & & Total & 1796.479 & 47 & & & \\
\hline
\end{tabular}

a. Dependent Variable: ASRS-V1.1 Hyperactivity/Impulsivity

b. Predictors: (Constant), MRT

c. Predictors: (Constant), MRT, SSRT

\section{Hypothesis 3}

The third hypothesis stated that SSRT will significantly predict ASRS-V1.1 Total scores (i.e., combined inattention and hyperactivity/impulsivity), over and above MRT alone. A hierarchical multiple regression was conducted to determine if the addition of SSRT improved 
the prediction of ASRS Total, over and above the proportion of the variance explained by MRT alone. The model included two continuous predictor variables (i.e., MRT and SSRT) and one continuous criterion variable (i.e., ASRS-V1.1 Total scores). The full model of MRT and SSRT was statistically significant, $R^{2}=.221, F(2,45)=6.376, p=.004$; adjusted $R^{2}=.186$. MRT accounted for $7.5 \%$ of the variance in ASRS-V1.1 Total scores, which is a small effect (Cohen, 1988). The addition of SSRT to the prediction of ASRS Total led to a statistically significant increase in $R^{2}$ of $.146, F(1,45)=8.408, p=.004$. SSRT accounted for an additional $14.6 \%$ of the variance in ASRS-V1.1 Total, which represents a small effect size (Cohen, 1988). The results of this analysis are provided in Tables 8 and 9.

Table 8

Model Summary

\begin{tabular}{cccccccc}
\hline Model & $\mathrm{R}$ & $\mathrm{R}$ Square & $\begin{array}{c}\text { Adjusted } \\
\mathrm{R} \text { Square }\end{array}$ & $\begin{array}{c}\text { Std. Error of } \\
\text { the Estimate }\end{array}$ & $\begin{array}{c}\text { R Square } \\
\text { Change }\end{array}$ & F Change & $\begin{array}{c}\text { Durbin- } \\
\text { Watson }\end{array}$ \\
\hline 1 & $.274^{\mathrm{a}}$ & .075 & .055 & 10.045 & .075 & 3.741 & \\
2 & $.470^{\mathrm{b}}$ & .221 & .186 & 9.322 & .146 & 8.4808 & 1.656 \\
\hline $\begin{array}{l}\text { a. Predictors: (Constant), MRT } \\
\text { b. Predictors: (Constant), MRT, SSRT } \\
\text { c. Pependent Variable: ASRS-V1.1 Total }\end{array}$ & & & & & & \\
\end{tabular}

Table 9

ANOVA

\begin{tabular}{|c|c|c|c|c|c|c|c|}
\hline Model & & & Sum of Squares & $\mathrm{df}$ & Mean Square & $\mathrm{F}$ & Sig. \\
\hline \multirow{3}{*}{\multicolumn{2}{|c|}{ 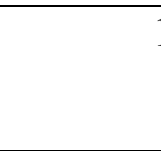 }} & Regression & 377.472 & 1 & 377.472 & 3.741 & $.059^{b}$ \\
\hline & & Residual & 4641.507 & 46 & 100.902 & & \\
\hline & & Total & 5018.979 & 47 & & & \\
\hline & 2 & Regression & 1108.215 & 2 & 554.108 & 6.376 & $.004^{\mathrm{c}}$ \\
\hline & & Residual & 3910.764 & 45 & 86.906 & & \\
\hline & & Total & 5018.979 & 47 & & & \\
\hline
\end{tabular}

a. Dependent Variable: ASRS-V1.1 Total

b. Predictors: (Constant), MRT

c. Predictors: (Constant), MRT, SSRT 


\section{CHAPTER 4: DISCUSSION}

\section{Summary of Findings}

In this study I evaluated the clinical utility of stop-signal reaction time (SSRT) in the assessment of attentional processing and response control based on performance on a continuous performance test (CPT) with central processing demands in a sample of 48 adults aged 19-68 years. The stop-signal task (SST) literature emphasizes CPT in basic “Go / No-Go" tasks (G/NG) formats without the additional cognitive complexity associated with interference control. Generally, these studies identify inattention as the predominate feature of ADHD, especially among children, and emphasize mean reaction time (MRT) and associated metrics as the CPT parameter of greatest clinical utility when differentiating ADHD and non-ADHD groups. The current study attempted to replicate and extend the SST literature by examining adults' performances on a CPT with interference stimuli, thereby demanding greater central processing. A previous study of adolescents with ADHD showed that, compared to controls, the clinical group made significantly more omission errors in the presence of distractor stimuli than when no distractors were presented (Berger \& Cassuto, 2014).

The predictor variables in this study were MRT and SSRT (as measured by the TDIA). The criterion variable(s) was self-reported symptoms of inattention, hyperactivity-impulsivity, and combined (as measured by the total score and subscales of the ASRS-V1.1). MRT and SSRT were assessed for their respective predictive significance with three ASRS-V1.1 scales, each of which corresponds to one of three ADHD diagnostic classifications. Because the literature on SST does not always indicate which type(s) of ADHD is represented in samples, it was necessary to assess the predictive significance of SSRT for each ADHD subtype. Three hypotheses were generated to examine the relationships among these variables. 
First, it was hypothesized that SSRT would significantly predict self-reported symptoms of inattention, over and above MRT alone. The analysis revealed that SSRT statistically significantly predicted self-reported symptoms of inattention, over and above MRT alone. The effect size of SSRT was medium (Cohen, 1988). Second, it was hypothesized that SSRT would significantly predict self-reported symptoms of hyperactivity/impulsivity, over and above MRT alone. The analysis revealed that SSRT statistically significantly predicted self-reported symptoms of hyperactivity/impulsivity, over and above MRT alone. The effect size was small (Cohen, 1988). Finally, it was hypothesized that SSRT would significantly predict self-reported combined ADHD symptoms, over and above MRT alone. The analysis revealed that SSRT statistically significantly predicted combined ADHD symptoms, over and above MRT alone. The effect size was small (Cohen, 1988).

Overall, these results are consistent with previous research showing the predictive significance of SSRT in identifying ADHD and non-clinical groups of adults. Lijffijt et al. (2005) reported a significant difference in SSRT between adults with ADHD and matched controls. In their study, adult ADHD patients and controls differed significantly on SSRT, and not MRT, leading researchers to conclude that adult ADHD may be characterized primarily by deficient inhibitory control, rather than general inattention. Although the current results do not show that SSRT differentiates between a clinical and control group, the data suggest that SSRT is significantly predictive of higher or lower ratings of self-reported ADHD symptoms. The medium effect size for SSRT and self-reported symptoms of inattention that was obtained in this study is comparable to the medium effect size reported in the Lijffijt et al. (2005) study.

The results of this analysis are consistent with a second study showing the clinical utility of SSRT in the adult population (Wodushek \& Neumann, 2003). A significant, large main effect 
for group (clinically significant versus subthreshold ADHD symptoms) was reported based on SSRT. Adults with clinically significant self-reported ADHD symptoms exhibited significantly slower SSRT than individuals with subthreshold symptoms. Although the current study did not compare between-group SSRT, self-reported ADHD symptoms were significantly predicted by SSRT. Larger SSRT values (i.e., slower reaction times) significantly predicted higher symptom ratings for inattentive, hyperactive-impulsive, and combined types of ADHD, whereas smaller SSRT values (i.e., faster reaction times) were related to lower symptom ratings, after controlling for MRT.

Second, it was hypothesized that SSRT would significantly predict self-reported symptoms of hyperactivity/impulsivity, over and above MRT alone. The analysis revealed that SSRT statistically significantly predicted self-reported symptoms of hyperactivity/impulsivity, over and above MRT alone. The effect size of SSRT for hyperactivity/impulsivity symptoms was small (Cohen, 1988). This finding is inconsistent with research by Dinn, Robbins, and Harris (2001) that examined the CPT performance of 25 adults with ADHD relative to controls. Their results indicated that performance between groups differed only for adults with Inattentive and Combined ADHD, not for adults with Hyperactive-Impulsive ADHD. However, because only four participants in their sample were diagnosed with hyperactive/impulsive ADHD, more research is needed to confirm whether CPT performance may differ relative to controls for certain ADHD subtypes and not others. It is important to note that the measure used by Dinn et al. (2001) involved G/NG tasks without SST and interference conditions. Taken together, these results indicate that different versions of CPT may vary in the level of sensitivity to specific ADHD subtypes. 
The ability of SSRT to significantly predict self-reported hyperactive-impulsive symptoms among adults is noteworthy considering the common course of ADHD throughout the lifespan. Symptoms of hyperactivity/impulsivity are known to diminish during late adolescence or early adulthood for most individuals, at which point inattention often becomes preeminent (APA, 2013). Although adults may still experience hyperactivity or impulsivity, the degree of functional impairment from these symptoms may decrease due to effective selection of environments or compensation (Craig, 2011; Jensen et al., 1997; Lasky et al., 2016). Accordingly, in this sample of adults, the mean score on the ASRS-V1.1 Hyperactive-Impulsive subscale (11.90) was lower than the mean score on subscales for Inattention (14.46) and Combined symptoms (26.35).

The composition of this sample of adults may also have contributed to the small, yet significant effect size of SSRT for hyperactive/impulsive symptoms. Only four participants were recruited in conjunction with a clinical assessment of ADHD compared to 44 participants who were recruited through other means. Therefore, only $0.08 \%$ of the sample represented clinical assessment, while $91.6 \%$ of the sample consisted of clinical analogues. Adults with hyperactiveimpulsive symptoms may have been largely underrepresented in this sample, both because of the reliance on analogue assessment and the relatively low prevalence of hyperactive-impulsive symptoms in the adult population, overall.

Regarding the third hypothesis, SSRT statistically significantly predicted combined ADHD symptoms, over and above MRT alone. This finding is consistent with previous research indicating slower SSRT relative to MRT in adults with ADHD combined type compared to controls (Aron et al., 2003; Bekker et al., 2005; Murphy, 2002). Of note, the effect size for SSRT 
in the current study is small compared to the large effect size reported by Aron et al. (2003). This is perhaps due to the small sample size included in the current study.

Overall, the results of this study contrasted with previous research on SST that identified inattention as the key deficit that differentiates ADHD and non-clinical groups among children and adolescents (Alderson et al., 2007; Oosterlaan et al., 1998). The diversity of results may be explained by the type of CPT represented in the analyses. Both meta-analyses examined SST based on $\mathrm{G} / \mathrm{NG}$ performance without distractors; therefore, there may have been insufficient cognitive demands to illuminate inhibitory control deficits that may have otherwise existed between groups. A study of CPT performance with environmental distractors among adolescents showed that incorporating distractor stimuli aids in identifying an ADHD group (Berger \& Cassuto, 2014). Another explanation for the discrepancy may be that the studies examined CPT performance among children and adolescents, whereas the current study involved an adult sample. A meta-analysis of adult patients showed significantly slower SSRT than MRT among adults, and not among children (Lijffijt et al., 2005).

Based on the predictive significance of SSRT relative to MRT, the current results provide initial evidence for key inhibitory control deficits among adults with self-reported impairment from ADHD symptoms. This finding also provides preliminary support for an inhibition deficit in ADHD (Lipszyc \& Schachar, 2010) and the assertion that this deficit is central to ADHD impairment (Barkley, 1997; Hart et al., 2014) as compared to an underlying attention deficit (Castellanos \& Tannock, 2002). Adults with ADHD may exhibit greater deficits in action cancellation based on stopping latencies than action initiation when engaged in central processing. This research also supports the identification of response inhibition deficiency as a 
key ADHD endopehnotype (Aron \& Poldrack, 2005; McAuley et al., 2013; Schachar et al., 2005).

\section{Limitations}

While this study may meaningfully contribute to the ADHD and SST literature, it should be considered preliminary given that there were several limitations. First, based on the current results, it cannot be confirmed whether all other executive dysfunction associated with ADHD is secondary to deficits in response inhibition, as Barkley (1997) proposed. While the results show a greater deficiency in response control (i.e., action cancellation) among adults with higher ratings of inattentive, hyperactive-impulsive, and combined ADHD symptoms, it remains unknown to what extent participants' self-reported impairment is attributable to this facet of executive dysfunction relative to others. Support for Barkley's (1997) model is therefore limited based on the results of this study.

Another limitation of this study is the methodology and the use of analogue assessment. It is unknown to what extent CPT performance exhibited in this sample represents an appropriate analogue of CPT performance in clinical settings. Because over $90 \%$ of participants in this sample did not present for clinical assessment, the extent to which these results may be comparable to studies that differentiate between clinical and non-clinical groups is limited. We are therefore unable to substantiate previous research suggesting that inhibitory control is significantly impaired in adults with ADHD relative to a control group (Epstein, Conners, Sitarenios, \& Erhardt, 1998; Lijffijt et al., 2005). In the current study we did not compare mean SSRT scores between a clinical and control group. Rather, our purpose was to examine the significance of the association between SSRT scores and self-reported ADHD symptoms, after controlling for MRT. It remains unknown whether SSRT scores in this sample would allow for 
differentiation between clinically significant and subthreshold impairment, which is essential for diagnostic purposes.

The generalizability of these results to clinical settings may be limited due to the relatively low number of participants who were recruited via clinical assessment. Furthermore, 37 of the 49 participants were graduate students, 20 of whom were doctoral students, which is an unlikely place to find significant signs and symptoms of ADHD given the assumed population prevalence. The external validity of these results is also limited because the sample was not randomly selected but rather was selected using convenience sampling methods.

A third limitation of this study is the use of self-reported data to measure ADHD symptoms. In general, the use of self-report measures presents a limitation because it relies on participants' self-report of their experience with and/or perception of the variables of interest, and therefore may be inaccurate (Heppner et al., 2008). Although self-report measures are often a core feature in ADHD evaluations (Taylor et al., 2011), research has shown that self-evaluation of ADHD is prone to underreporting of symptoms (Hoza et al., 2012). It cannot be determined whether elevations on the ASRS-V1.1 reflect true ADHD symptoms or are artifacts of other mental health or medical conditions.

A fourth limitation is the potential for the results to have been influenced by different demand characteristics across participants in the sample. Recall that participants recruited through MindFit were offered a reward directly, as opposed to a random drawing for other participants. Participants may have responded differentially depending on which pool they were in, as the incentive was not the same for all participants.

The use of an instrument that has not yet been empirically validated is another limitation of this study. The TDIA is a newly constructed G/NG CPT (Donders, 1969) that features three 
cognitive tasks: a modified Posner cuing task (Posner, 1980) that incorporates an Eriksen Flanker design (Eriksen \& Eriksen, 1974) and the classic stop signal paradigm (Logan, 1981; Logan \& Cowan, 1984). The TDIA is an amalgamation of these well-established neuropsychological tasks, however the current study is the first application of the TDIA to clinical research. Currently there is no normative sample with which to meaningfully interpret scores. Moreover, the psychometric properties of the TDIA are presently unknown, thus the results of this study are preliminary and warrant replication in future research. Despite these limitations, the metrics with which the TDIA was constructed are well-supported in the literature (Alderson et al., 2007; Epstein et al., 2001; Lijffijt et al., 2005; Oosterlaan et al., 1998; Wodushek \& Neumann, 2003).

\section{Implications}

Despite these limitations, the current study has several implications for assessment and conceptualization of adult ADHD. First, the current study provides initial evidence that inefficient processing due to generalized attention deficit may not be a predominate feature of individuals with ADHD, as has been suggested (Alderson et al., 2007; Castellanos \& Tannock, 2002; Epstein et al., 2010; Lifffijt et al., 2005; Oosterlaan et al., 1998). Research increasingly shows that CPT performance by adults with ADHD is distinctive from controls, with inhibitory control representing a key deficit in the adult clinical population (Aron et al., 2003; Bekker et al., 2005; Lijffijt et al., 2005; Murphy, 2002; Wodushek \& Neumann, 2003). Each of these studies show significantly slower SSRT among adult ADHD patients compared to controls. Likewise, the current study demonstrates that SSRT may be a useful metric in the clinical assessment of adult ADHD. The results are consistent with research showing that cognitive control deficits associated with motor response inhibition are a core feature of ADHD, with stop-signal inhibition being proposed as a key characteristic (Aron et al., 2003; Aron \& Poldrack, 2005; 
Berger \& Cassuto, 2014; Hart et al., 2014; Kofler et al., 2013; McAuley, Crosbie, Charach, \& Schachar, 2013; Schachar et al., 2005; Wodushek \& Neumann, 2003). The current study also supports Barkley's (1997) conceptual model of ADHD wherein response control deficits are primary to the executive dysfunction in ADHD.

Second, because this study did not examine CPT performances among children and adolescents, the data do not address a myriad of studies showing inattention as a primary characteristic of ADHD in this population (Alderson et al., 2007; Lijffijt et al., 2005; Oosterlaan et al., 1998). The implication is that impairment from ADHD symptoms, as measured by CPT performance, may evolve from childhood to adulthood, with greater indication of attention and response control deficits at different points throughout the lifespan.

Meta-analyses of SST performance among children with ADHD revealed deficits in response control and attention, as evidenced by significantly slower SSRT and MRT, respectively, compared to controls (Alderson et al., 2007; Lijffijt et al., 2005; Losier et al., 1996; Oosterlaan et al., 1998). A study of adults with ADHD reported similar performance profiles marked by greater errors of omission and commission relative to controls, suggesting deficits in both attention and inhibitory control (Epstein et al., 1998). However, it is important to consider that the studies by Losier et al. (1996) and Epstein et al. (1998) did not involve SST. It is possible that an alternative CPT, such as one that includes SST, may generate different results leading to alternate conclusions regarding the course of ADHD. Furthermore, none of the metaanalyses included environmental distractors, thus there were no increased demands for interference control.

A study by Epstein, Johnson, Varia, and Conners (2001) illustrates how the results of neuropsychological assessment may vary depending on the type of instrument that is employed. 
A sample of adult ADHD patients was compared to controls on different neuropsychological tests, one of which was a basic G/NG task while another was a CPT with SST. On the G/NG task without SST, adult ADHD patients exhibited impulsive responding as evidenced by significantly more commission errors compared to controls. This finding suggests that adults with ADHD experience impairment in action restraint, specifically, due to difficulty engaging in the "no-go" process. Conversely, on the CPT with SST, ADHD patients and controls performed similarly, suggesting that differentiation of ADHD patients cannot be made based on SST performance. The conclusion that follows is that action cancellation is not disproportionately impaired among adult ADHD patients relative to controls. Moreover, it may be concluded that SST is not a useful metric in the clinical assessment of ADHD in adults. However, the SST task employed in this study did not involve interference conditions, thus relatively low cognitive processing was necessary for successful performance. Performance of the clinical group may differ significantly from controls when greater cognitive processing demands are introduced. The inclusion of distractor stimuli may also illuminate deficits in action cancellation among adults with ADHD, whereas the CPT without distractors did not.

Third, due to diversity in measurement and methodology, the literature is mixed as to whether response inhibition or attention is central to ADHD dysfunction, and relatedly, which SST metric is most clinically useful in differentiating between ADHD and non-clinical groups. The current study contributes to the literature in two primary ways. It examined CPT performance with SST among adults, thereby measuring the action cancellation facet of motor response inhibition in adulthood (Schachar et al., 2007). This study also included distractor stimuli, thereby eliciting the need for interference control, which draws upon higher cognitive processing (Uno et al., 2006; van Velzen et al., 2014). Presently, no study has examined the 
clinical utility of SST in the adult population using a CPT with environmental distractors. The results of this study are in contrast with the findings of Epstein et al. (2001) by showing that SSRT is useful in predicting self-reported ADHD symptoms, and by extension, possibly predicting whose symptoms may reach a diagnostic threshold versus those whose symptoms do not warrant clinical diagnosis.

Finally, although CPT is commonly used in ADHD evaluations (Munkvold et al., 2014), numerous studies have shown questionable sensitivity and specificity for ADHD as low performance is characteristic of a variety of mental health disorders in addition to ADHD (Advokat et al., 2007; Baggio et al., 2019; Fuermaier et al., 2018; McGee et al., 2000; Tollander, 2011). Likewise, the performance of ADHD patients may not differ significantly from controls, which renders the instrument minimally useful in clinical settings (Epstein et al., 2001; McGee et al., 2000). CPT performance is also known to be differentially useful in identifying ADHD patients depending on examinee age and the type of CPT (Epstein et al., 2001; Lijffijt et al., 2005). For these reasons, advancement in clinical assessment and diagnosis of ADHD is contingent upon the development of tests that improve diagnostic accuracy. This study provides preliminary evidence for the inclusion of SST and environmental distractors in evaluations of adult ADHD using CPT. The results indicate that this combination of tasks yields greater predictive significance for identifying individuals with higher ratings of ADHD symptoms based on SSRT than with MRT alone. Diagnosticians may wish to consider whether a basic G/NG CPT without SST and environmental distractors is sufficient in identifying adult ADHD patients. Under these circumstances, clinicians have at their disposal only MRT, which based on the results of this study, has relatively low predictive power compared to SSRT. 


\section{Future Directions}

Several directions for future research on SST may enhance our understanding of adult ADHD and advance our assessment methods to improve diagnostic accuracy in clinical settings. Broadly, more research is needed to clarify whether we are defining the pathology of ADHD correctly. This is especially necessary in light of evidence that CPT scores vary at different points in the lifespan (Lijffijt et al., 2005). Additionally, future research is needed to replicate and extend existing studies of SST, many of which show inconsistency in results. The SST literature will benefit from operationalization of samples and greater consistency in instrumentation. First, studies have shown that SSRT is useful in differentiating between ADHD and control groups, yet the composition of clinical groups is often unknown with regard to ADHD subtype. Because CPT performance may differ by ADHD subtype (Marks et al., 1999), it is necessary for research on SST to indicate which subtypes are included in analyses of the clinical utility of SST metrics. Second, Epstein et al. (2001) demonstrated that profiles of CPT performance may vary between clinical and non-clinical groups when different CPT versions are used. Conclusions regarding the utility of specific SST metrics are therefore idiosyncratic and limited in generalizability to all assessment settings.

It will also be important for researchers to continue to validate the TDIA by developing a normative sample of clinical and non-clinical individuals to identify clinically significant and subthreshold ranges of performance. This will allow for diagnostic conclusions to be drawn by comparing an examinee's performance to the distribution of scores in the normative sample. The TDIA is presently a newly developed instrument, and this study is the first attempt at preliminary validation by comparing scores with an existing ADHD measure, albeit one that is self-report. The results of this study provide compelling evidence for further development of the TDIA for 
assessment of ADHD in the adult population. Future research may examine the utility of the TDIA in predicting self-reported impairment from ADHD symptoms among children and adolescents.

One area of future research is to assess the convergent validity of the TDIA and an existing CPT with satisfactory reliability and validity. The current study demonstrated that TDIA metrics are significantly correlated with three scales from an existing self-report measure of adult ADHD symptoms, the ASRS-V1.1 (Kessler et al., 2005). Due to the limitations associated with self-report measures, it befits TDIA developers to assess the TDIA's validity in comparison with a more objective measure of ADHD symptoms, such as the IVA+Plus (Sandford \& Turner, 2004). This research would allow for comparison of the TDIA and a CPT with a G/NG format, which would be useful in replicating the Epstein et al. (2001) results that showed that ADHD and control groups perform differentially on CPT with and without SST. Furthermore, it will be important for researchers to assess the clinical utility of the TDIA in comparison with other CPTs that involve SST, such as the Stop-Signal task (Logan, 1994), which was employed by Wodushek and Neumann (2003) in their assessment of adult ADHD. Replication and extension of this study will be necessary to demonstrate that SSRT is slower for adults with ADHD compared to controls, and to highlight response inhibitory deficits in adults with ADHD based on stopping latencies. Finally, the TDIA is the only known CPT that includes SST and a Flanker task (Eriksen \& Eriksen, 1974) to measure SSRT amid greater inhibitory control demands generated by environmental distractors. Research and development of the TDIA will necessitate that the test be validated alongside similar instruments, should such measures be introduced. 


\section{Conclusion}

ADHD is among the most common mental health disorders in adults (APA, 2013). The goal of the current study was to advance the stop-signal task literature by examining the relationships between mean reaction time, stop-signal reaction time, and three scales pertaining to self-reported ADHD symptoms. Examining the predictive significance of these variables contributed to the SST literature by highlighting the diagnostic utility of SSRT in an adult sample of clinical analogues and by analyzing a CPT that includes SST and environmental distractors. It was hypothesized that SSRT would significantly predict self-reported ADHD symptoms, after statistically controlling for MRT. The results supported this hypothesis for symptoms of inattention, hyperactivity/impulsivity, and combined symptoms. Future research examining the clinical utility of SST with more complex CPT methodology may improve clinical assessment and advance our understanding of ADHD in the adult population. 


\section{REFERENCES}

Adler, L. A., Faraone, S. V., Spencer, T. J., Berglund, P., Alperin, S., \& Kessler, R. C. (2017). The structure of adult ADHD. International Journal of Methods in Psychiatric Research, 26(1), 1-23. doi:10.1002/mpr.1555

Adler, L. A., Spencer, T., Faraone, S. V., Kessler, R. C., Howes, M. J., Biederman, J., \& Secnik, K. (2006). Validity of pilot adult ADHD self-report scale (ASRS) to rate adult ADHD symptoms. Annals of Clinical Psychiatry, 18(3), 145-148. doi:

$10.1080 / 1040123060081077$

Advokat, C. D., Guidry, D., \& Martino, L. (2008). Licit and illicit use of medications for attention-deficit hyperactivity disorder in undergraduate college students. Journal of American College Health, 56(6), 601-606. doi: 10.3200/jach.56.6.601-606

Advokat, C. D., Martino, L., Hill, B. D., \& Gouvier, W. (2007). Continuous performance test (CPT) of college students with ADHD, psychiatric disorders, cognitive deficits, or no diagnosis. Journal of Attention Disorders, 10(3), 253-256. doi:

$10.1177 / 1087054706292106$

Agnew-Blais, J. C., Polanczyk, G. V., Danese, A., Wertz, J., Moffitt, T. E., Arseneault, L. (2016). Evaluation of the persistence, remission, and emergence of attentiondeficit/hyperactivity disorder in young adulthood. Jama Psychiatry, 73(7), 713-20. doi: 10.1001/jamapsychiatry.2016.0465

Alderson, R. M., Rapport, M. D., \& Kofler, M. J. (2007). Attention-deficit/hyperactivity disorder and behavioral inhibition: A meta-analytic review of the stop-signal paradigm. Journal of Abnormal Child Psychology, 35(5), 745-758. doi: 10.1007/s10802-007-9131-6 
American Psychiatric Association. (1968). Diagnostic and Statistical Manual of Mental Disorders (2 ${ }^{\text {nd }}$ ed.). Washington, DC: American Psychiatric Publishing. American Psychiatric Association. (1980). Diagnostic and Statistical Manual of Mental Disorders ( $3^{\text {rd }}$ ed.). Washington, DC: American Psychiatric Publishing. American Psychiatric Association. (1987). Diagnostic and Statistical Manual of Mental Disorders ( $3^{\text {rd }}$ ed., text revision). Washington, DC: American Psychiatric Publishing. American Psychiatric Association. (1994). Diagnostic and Statistical Manual of Mental Disorders $\left(4^{\text {th }}\right.$ ed.). Washington, DC: American Psychiatric Publishing. American Psychiatric Association. (2013). Diagnostic and statistical manual of mental disorders ( $5^{\text {th }}$ ed.). Washington, DC.

Anastopoulos, A. D., DuPaul, G. J., Weyandt, L. L., Morrissey-Kane, E., Sommer, J. L., Rhoads, L. H., ... Gudmundsdottir, B. G. (2018). Rates and patterns of comorbidity among firstyear college students with ADHD. Journal of Clinical Child \& Adolescent Psychology, 47(2), 236-247. doi: 10.1080/15374416.2015.1105137

Arnett, A. B., Pennington, B. F., Willcutt, E. G., DeFries, J. C., \& Olson, R. K. (2014). Sex differences in ADHD symptom severity. Journal of Child Psychology and Psychiatry, 56(6), 632-639. doi: 10.1111/jcpp.12337

Arnsten, A. F. T. (2009). Toward a new understanding of attention-deficit hyperactivity disorder pathophysiology. CNS Drugs, 23(1), 33-41. doi: 10.2165/00023210-200923000-00005

Arnsten, A. F. T., \& Li, B. M. (2005). Neurobiology of executive functions: Catecholamine influences on prefrontal cortical functions. Biological Psychiatry, 57(11), 1377-1384. doi: 10.1016/j.biopsych.2004.08.019 
Aron, A. R., Downson, J. H., Sahakian, B. J., \& Robbins, T. W. (2003). Methylphenidate improves response inhibition in adults with attention-deficit/hyperactivity disorder. Biological Psychiatry, 54(12), 1465-1468. doi: 10.1016/S0006-3223(03)00609-7

Aron, A. R., Fletcher, P. C., Bullmore, E. T., Sahakian, B. J., \& Robbins, T. W. (2003). Erratum: Stop-signal inhibition disrupted by damage to right inferior frontal gyrus in humans. Nature Neuroscience, 6(12), 1329-1329. doi: 10.1038/nn1203-1329a

Aron, A. R., \& Poldrack, R. A. (2005). The cognitive neuroscience of response inhibition: Revelance for genetic research in attention-deficit/hyperactivity disorder. Biological Psychiatry, 57(11), 1285-1292. doi: 10.1016/j.biopsych.2004.10.026

Asherson, P. (2016). ADHD across the lifespan. Medicine, 44(11), 683-686. doi: 10.1016/j.mpmed.2016.08.012

Aston-Jones, G., \& Cohen, J. D. (2005). An integrative theory of locus-coeruleus-norepinephrine function: Adaptive gain and optimal performance. Annual Review of Neuroscience, 28, 403-450. doi: 10.1146/annurev.neuro.28.061604.135709

Baggio, S., Hasler, R., Giacomini, V., El-Masri, H., Weibel, S., Perroud, N., \& Deiber, M. (2019). Does the continuous performance test predict ADHD symptoms severity and ADHD presentation in Adults? Journal of Attention Disorders. doi: $10.1177 / 1087054718822060$

Balint, S., Czobor, P., Komlosi, S., Meszaros, A. (2009). Attention deficit hyperactivity disorder (ADHD): Gender- and age-related differences in neurocognition. Psychological Medicine, 39(8), 1337-1345. doi: 10.1017/S0033291708004236 
Bari, A., \& Robbins, T. W. (2013). Inhibition and impulsivity: Behavioral and neural basis of response control. Progress in Neurobiology, 108, 44-79. doi:

10.1016/j.pneurobio.2013.06.005

Barkley, R. A. (1997). Behavioral inhibition, sustained attention, and executive functions:

Constructing a unifying theory of ADHD. Psychological Bulletin, 121(1), 65-94. doi:10.1037/0033-2909.121.1.65

Barkley, R. A., \& Biederman, J. (1997). Toward a broader definition of the age-of-onset criterion for attention-deficit hyperactivity disorder. Journal of the American Academy of Child \& Adolescent Psychiatry, 36(9), 1204-1210. doi:10.1097/00004583-199709000-00012

Barkley, R. A., Fischer, M., Smallish, L., \& Fletcher, K. (2002). The persistence of attentiondeficit/hyperactivity disorder into young adulthood as a function of reporting source and definition of disorder. Journal of Abnormal Psychology, 111(2), 279-289. doi:10.1037/0021-843x.111.2.279

Barkley, R. A., Fischer, M., Smallish, L., \& Fletcher, K. (2004). Young adult follow-up of hyperactive children: Antisocial activities and drug use. Journal of Child Psychology and Psychiatry, 45(2), 195-211. doi:10.1111/j.1469-7610.2004.00214.x

Bekker, E. M., Overtoom, C. C., Kenemans, J. L., Kooij, J. J., De Noord, I., Buitelaar, J. K., \& Verbaten, M. N. (2005). Stopping and changing in adults with ADHD. Psychological Medicine, 35(6), 807-816. doi: 10.1017/S0033291704003459

Benotsch, E. G., Koester, S., Luckman, D., Martin, A. M., \& Cejka, A. (2011). Non-medical use of prescription drugs and sexual risk behavior in young adults. Addictive Behaviors, 36(1), 152-155. doi:10.1016/j.addbeh.2010.08.027 
Ben-Porath, Y. S. (2013). Self-report inventories: Assessing personality and psychopathology. In J. R. Graham \& J. Naglieri (Eds.), Handbook of psychology (2nd ed. Assessment psychology (2 ${ }^{\text {nd }}$ ed.) (Vol. 10, pp. 622-644). New York, NY: Wiley.

Benson, K., Flory, K., Humphreys, K. L., \& Lee, S. S. (2015). Misuse of stimulant medication among college students: A comprehensive review and meta-analysis. Clinical Child and Family Psychology Review, 18(1), 50-76. doi:10.1007/s10567-014-0177-z

Berger, I., \& Cassuto, H. (2014). The effect of environmental distractors incorporation into a CPT on sustained attention and ADHD diagnosis among adolescents. Journal of Neuroscience Methods, 222, 62-68. doi:10.1016/j.jneumeth.2013.10.012

Beiderman J., \& Faraone, S. V. (2005). Attention-deficit hyperactivity disorder. Lancet, 366, 237-248. doi:10.1016/s0140-6736(05)66915-2

Biederman, J., Faraone, S. V., Milberger, S., Guite, J., Mick, E., Chen, L. ... Perrin, J. (1996). A prospective 4-year follow-up study of attention-deficit hyperactivity and related disorders. Archives of General Psychiatry, 53(5), 437-446. doi:10.1001/archpsyc.1996.01830050073012

Biederman, J., Faraone, S. V., Monuteaux, M. C., Bober, M., \& Cadogen, E. (2004). Gender effects on attention-deficit/hyperactivity disorder in adults, revisited. Biological Psychiatry, 55(7), 692-700. doi:10.1016/j.biopsych.2003.12.003

Biederman, J., Kwon, A., Aleardi, M., Chouinard, V.-A., Marino, T., Cole, H., ... Faraone, S. V. (2005). Absence of gender effects on attention deficit hyperactivity disorder: Findings in nonreferred subjects. American Journal of Psychiatry, 162(6), 1083-1089. doi:10.1176/appi.ajp.162.6.1083 
Biederman, J., Mick, E., \& Faraone, S. V. (2000). Age-dependent decline of symptoms of attention deficit hyperactivity disorder: Impact of remission definition and symptom type. The American Journal of Psychiatry, 157(5), 816-818. doi:10.1176/appi.ajp.157.5.816

Biederman, J., Petty, C. R., Evans, M., Small, J., \& Faraone, S. (2010). How persistent is ADHD? A controlled 10-year follow-up study of boys with ADHD. Psychiatry Research, 177(3), 299-304. doi:10.1016/j.psychres.2009.12.010

Biederman, J., Petty, C. R., Woodworth, Y., Lomedico, A., Hyder, L. L., \& Faraone, S. V. (2012). Adult outcome of attention-deficit/hyperactivity disorder: A controlled 16-year follow-up study. Journal of Clinical Psychiatry, 73(7), 941-950. doi:10.4088/jcp.11m07529

Bleck, J., \& DeBate, R. D. (2013). Exploring the co-morbidity of attention-deficit/hyperactivity disorder with eating disorders and disordered eating behaviors in a nationally representative community-based sample. Eating Behaviors, 14(3), 390-393. doi:10.1016/j.eatbeh.2013.05.009

Blue Cross Blue Shield Association. (2019). The impact of attention deficit hyperactivity disorder on the health of America's children [webpage]. Retrieved from https://www.bcbs.com/the-health-of-america/reports/impact-of-adhd-attention-deficithyperactivity-disorder-on-health-of-americas-children

Bolino, M. C., Kacmar, K. M., Turnley, W. H., \& Gilstrap, J. B. (2008). A multi-level review of impression management motives and behaviors. Journal of Management, 34(6), 10801109. doi:10.1177/0149206308324325

Borgaro, S., Pogge, D. L., DeLuca, V. A., Bilginer, L., Stokes, J., \& Harvey, P. D. (2003). Convergence of different versions of the continuous performance test: Clinical and 
scientific implications. Journal of Clinical and Experimental Neuropsychology, 25(2), 283-292. doi:10.1076/jcen.25.2.283.13646

Borland, B. L., \& Heckman, H. K. (1976). Hyperactive boys and their brothers: A 25-year follow-up study. Archives of General Psychiatry, 33(6), 669-675. doi:10.1001/archpsyc.1976.01770060013002

Bornstein, M. H., Jager, J., \& Putnick, D. L. (2013). Sampling in developmental science: Situations, shortcomings, solutions, and standards. Developmental Review, 33(4), 357370. doi: 10.1016/j.dr.2013.08.003

Bron, T. I., Bijlenga, D., Verduijn, J., Penninx, B. W. J. H., Beekman, A. T. F., \& Kooij, J. J. S. (2016). Prevalence of ADHD symptoms across clinical stages of major depressive disorder. Journal of Affective Disorders, 197, 29-35. doi:10.1016/j.jad.2016.02.053

Bruchmüller, K., Margraf, J., \& Schneider, S. (2012). Is ADHD diagnosed in accord with diagnostic criteria? Overdiagnosis and influence of client gender on diagnosis. Journal of Consulting and Clinical Psychology, 80(1), 128-138. doi:10.1037/a0026582

Bruner, M. R., Kuryluk, A. D., \& Whitton, S. W. (2015). Attention-deficit/hyperactivity disorder symptom levels and romantic relationship quality in college students. Journal of American College Health, 63(2), 98-108. doi:10.1080/07448481.2014.975717

Bryant, A. M., Lee, E., Howell, A., Morgan, B., Cook, C. M., Patel, K., ... Suhr, J. A. (2018). The vulnerability of self-reported disability measures to malingering: A simulated ADHD study. The Clinical Neuropsychologist, 32(1), 1-10. doi:10.1080/13854046.2017.1346145

Bush, G., Valera, E. M., \& Seidman, L. J. (2005). Functional neuroimaging of attentiondeficit/hyperactivity disorder: A review and suggested future directions. Biological Psychiatry, 57(11), 1273-1284. doi:10.1016/j.biopsych.2005.01.034 
Cadman, T., Findon, J., Eklund, H., Hayward, H., Howley, D., Cheung, C., ... Asherson, P. (2016). Six-year follow-up study of combined type ADHD from childhood to young adulthood: Predictors of functional impairment and comorbid symptoms. European Psychiatry, 35, 47-54. doi:10.1016/j.eurpsy.2015.08.007

Campbell, D. T., \& Fiske, D. W. (1959). Convergent and discriminant validation by the multitrait-multimethod matrix. Psychological Bulletin, 56(2), 81-105.

Castellanos, F. X., Sonuga-Barke, E. J. S., Milham, M. P., \& Tannock, R. (2006). Characterizing cognition in ADHD: Beyond executive dysfunction. Trends in Cognitive Sciences, 10(3), 117-123. doi: 10.1016/j.tics.2006.01.011

Castellanos, F. X., \& Tannock, R. (2002). Neuroscience of attention-deficit/hyperactivity disorder: The search for endophenotypes. Nature Review Neuroscience, 3, 617-628. doi: $10.1038 / \mathrm{nrn} 896$

Caye, A., Rocha, T. B.-M., Anselmi, L., Murray, J., Menezes, A. M. B., Barros, F. C., ... Rohde, L. A. (2016). Attention-deficit/hyperactivity disorder trajectories from childhood to young adulthood. JAMA Psychiatry, 73(7), 705-712. doi:10.1001/jamapsychiatry.2016.0383

Chen, M. H., Pan, T. L., Hsu, J. W., Huang, K. L., Su, T. P., Li, C. T., .. Bai, Y. M. (2016). Attention-deficit hyperactivity disorder comorbidity and antidepressant resistance among patients with major depression: A nationwide longitudinal study. European Neuropsychopharmacology, 26(11), 1760-1767. doi:10.1016/j.euroneuro.2016.09.369

Christakis, D. A., Zimmerman, F. J., DiGiuseppe, D. L., \& McCarty, C. A. (2004). Early television exposure and subsequent attentional problems in children. Pediatrics, 113, 708-713. doi:10.1542/peds.113.4.708 
Cohen, J. (1988). Statistical Power Analysis for the Behavioral Sciences, $2^{\text {nd }}$ Edition. Erlbaum, Hillsdale, NJ.

Conners, C. K. (1995). Conners' Continuous Performance Test. Toronto: Multi-Health Systems.

Conners, C. K. (2000). CPT-II: Continuous Performance Test II: Computer program for Windows technical guide and software manual. Toronto, ON: Multi-Health Systems.

Connor, D. F., Steeber, J., \& McBurnett, K. (2010). A review of attention-deficit/hyperactivity disorder complicated by symptoms of oppositional defiant disorder or conduct disorder. Journal of Developmental and Behavioral Pediatrics, 31, 427-440. doi: 10.1097/DBP.0b013e3181e121bd

Constantinou, M., Bauer, L., Ashendorf, L., Fisher, J. M., \& McCaffrey, R. J. (2005). Is poor performance on recognition memory effort measures indicative of generalized poor performance on neuropsychological tests? Archives of Clinical Neuropsychology, 20(2), 191-198. doi:10.1016/j.acn.2004.06.002

Craig, W. S. (2011). Adult attention deficit hyperactivity disorder. Journal of Men's Health, 8(4), 299-305. doi:10.1016/j.jomh.2011.08.001

Crowne, D. P., \& Marlowe, D. (1960). A new scale of social desirability independent of psychopathology. Journal of Consulting Psychology, 24(4), 349-354. doi: $10.1037 / \mathrm{h} 0047358$

Cruz, S., Sumstine, S., Mendez, J., \& Bavarian, N. (2017). Health-compromising practices of undergraduate college students: Examining racial/ethnic and gender differences in characteristics of prescription stimulant misuse. Addictive Behaviors, 68, 59-65. doi:10.1016/j.addbeh.2017.01.016 
Cubillo, A., \& Rubia, K. (2010). Structural and functional brain imaging in adult attentiondeficit/hyperactivity disorder. Expert Review of Neurotherapeutics, 10(4), 603-620. doi:10.1586/ern. 10.4

Cuffe, S. P., Moore, C. G., \& McKeown, R. E. (2005). Prevalence and correlates of ADHD symptoms in the national health interview survey. Journal of Attention Disorders, 9(2), 392-401. doi:10.1177/1087054705280413

Dalsgaard, S., Østergaard, S. D., Leckman, J. F., Mortensen, P. B., \& Pedersen, M. G. (2015). Mortality in children, adolescents, and adults with attention deficit hyperactivity disorder: A nationwide cohort study. The Lancet, 385(9983), 2190-2196. doi:10.1016/s01406736(14)61684-6

Dambacher, F., Sack, A. T., Lobbestael, J., Arntz, A., Brugman, S., \& Schuhmann, T. (2014). A network approach to response inhibition: Dissociating functional connectivity of neural components involved in action restraint and action cancellation. European Journal of Neuroscience, 39(5), 821-831. doi:10.1111/ejn.12425

Davidson, M. C., \& Marrocco, R. T. (2000). Local infusion of scopolamine into intraparietal cortex slows covert orienting in rhesus monkeys. Journal of Neurophysiology, 83(3), 1536-1549. doi: 10.1152/jn.2000.83.3.1536

DeGutis, J. M., \& Van Vleet, T. M. (2010). Tonic and phasic alertness training: A novel behavioral therapy to improve spatial and non-spatial attention in patients with hemispatial neglect. Frontiers in Human Neuroscience, 4(60), 1-17. doi:

10.3389/fnhum.2010.00060

Demontis, D., Walters, R. K., Martin, J., Mattheisen, M., Als, T. D., Agerbo, E., ... \& Neale, B. M. (2019). Discovery of the first genome-wide significant risk loci for attention 
deficit/hyperactivity disorder. Cardiff University. Nature Genetics, 51(1), 63-75. doi: $10.1038 / \mathrm{s} 41588-018-0269-7$

Diener, M. B., \& Milich, R. (1997). Effects of positive feedback on the social interactions of boys with attention deficit hyperactivity disorder: A test of the self-protective hypothesis. Journal of Clinical Child Psychology, 26(3), 256-265. doi:10.1207/s15374424jccp2603_4

Dinn, W. M., Robbins, N. C., \& Harris, C. L. (2001). Adult attention-deficit/hyperactivity disorder: Neuropsychological correlates and clinical presentation. Brain and Cognition, 46(1-2), 114-121. doi: 10.1016/S0278-2626(01)80046-4

Donders, F. C. (1969). On the speed of mental processes. Acta psychologica, 30, 412-431. doi:10.1016/0001-6918(69)90065-1

Dosenbach, N. U. F., Fair, D. A., Cohen, A. L., Schlaggar, B. L., \& Petersen, S. E. (2008). A dual-networks architecture of top-down control. Trends in Cognitive Neuroscience, 12(3), 99-105. doi: 10.1016/j.tics.2008.01.001

Doshi, J. A., Hodgkins, P., Kahle, J., Sikirica, V., Cangelosi, M. J., Setyawan, J., ... \& Neumann, P. J. (2012). Economic impact of childhood and adult attentiondeficit/hyperactivity disorder in the United States. Journal of the American Academy of Child \& Adolescent Psychiatry, 51(10), 990-1002. doi:10.1016/j.jaac.2012.07.008

Douglas, V. I. (1972). Stop, look and listen: The problem of sustained attention and impulse control in hyperactive and normal children. Canadian Journal of Behavioural Science, 4(4), 259-282. doi:10.1037/h0082313 
DuPaul, G. J., Gormley, M. J., \& Laracy, S. D. (2013). Comorbidity of LD and ADHD: Implications of DSM-5 for assessment and treatment. Journal of Learning Disabilities, 46(1), 43-51. doi:10.1177/0022219412464351

DuPaul, G. J., Power, T. J., Anastopoulos, A. D. \& Reid, R. (1998). ADHD rating scale-IV: Checklists, norms, and clinical Interpretation. New York, NY: Guilford.

DuPont, R. L., Coleman, J. J., Bucher, R. H., \& Wilford, B. B. (2008). Characteristics and motives of college students who engage in nonmedical use of methylphenidate. The American Journal on Addictions, 17(3), 167-171. doi:10.1080/10550490802019642

Edwards, M. C., Gardner, E. S., Chelonis, J. J., Schulz, E. G., Flake, R. A., \& Diaz, P. F. (2007). Estimates of the validity and utility of the Conners' continuous performance test in the assessment of inattentive and/or hyperactive-impulsive behaviors in children. Journal of Abnormal Child Psychology, 35(3), 393-404. doi:10.1007/s10802-007-9098-3

Efron, D. (2015). Attention-deficit/hyperactivity disorder: The past 50 years. Journal of Pediatrics and Child Health, 51(1), 69-73. doi:10.1111/jpc.12809

Egan, K. L., Reboussin, B. A., Blocker, J. N., Wolfson, M., \& Sutfin, E. L. (2013). Simultaneous use of non-medical ADHD prescription stimulants and alcohol among undergraduate students. Drug and Alcohol Dependence, 131(1), 71-77. doi:10.1016/j.drugalcdep.2012.12.004

Egeland, J., Johansen, S. N., \& Ueland, T. (2009). Differentiating between ADHD sub-types on CCPT measures of sustained attention and vigilance. Scandinavian Journal of Psychology, 50(4), 347-354. doi:10.1111/j.1467-9450.2009.00717.x 
Elder, T. (2010). The importance of relative standards in ADHD diagnoses: Evidence based on exact birth dates. Journal of Health Economics, 29(5), 641-641. doi:10.1016/j.jhealeco.2010.06.003

Elder, T., \& Lubotsky, D. (2009). Kindergarten entrance age and children's achievement: Impacts of state policies, family background, and peers. Journal of Human Resources, 44(3), 641-683. doi:10.3368/jhr.44.3.641

Epstein, J. N., Conners, C. K., Sitarenios, G., \& Erhardt, D. (1998). Continuous performance test results of adults with attention deficit hyperactivity disorder. The Clinical Neuropsychologist, 12(2), 155-168. doi: 10.1076/clin.12.2.155.2000

Epstein, J. N., Erkanli, A., Conners, C. K., Klaric, J., Costello, J. E., \& Angold, A. (2003). Relations between continuous performance test performance measures and ADHD behaviors. Journal of Abnormal Child Psychology, 31(5), 543-554.

doi:10.1023/a:1025405216339

Epstein, J. N., Hwang, M. E., Antonini, T., Langberg, J. M., Altaye, M., \& Arnold, L. E. (2010). Examining predictors of reaction times in children with ADHD and normal controls. Journal of the International Neuropsychological Society, 16(1), 138-147. doi: $10.1017 / \mathrm{s} 1355617709991111$

Epstein, J. N., Johnson, D. E., Varia, I. M., \& Conners, C. K. (2001). Neuropsychological assessment of response inhibition in adults with ADHD. Journal of Clinical and Experimental Neuropsychology, 23(3), 362-371. doi: 10.1076/jcen.23.3.362.1186

Eriksen, B. A., \& Eriksen, C. W. (1974). Effects of noise letters upon the identification of a target letter in a nonsearch task. Perception \& Psychophysics, 16(1), 143-149. doi: $10.3758 / \mathrm{bf03203267}$ 
Estévez, N., Dey, M., Eich-Höchli, D., Foster, S., Gmel, G., \& Mohler-Kuo, M. (2016). Adult attention-deficit/hyperactivity disorder and its association with substance use and substance use disorders in young men. Epidemiology and Psychiatric Sciences, 25(03), 255-266. doi:10.1017/s2045796015000360

Etikan, I., Musa, S. A., \& Alkassim, R. S. (2016). Comparison of convenience sampling and purposive sampling. The American Journal of Theoretical and Applied Statistics, 5(1), 14. doi: 10.11648/j.ajtas.2016-9006

Evans, W., Morrill, M., \& Parente, S. (2010). Measuring inappropriate medical diagnosis and treatment in survey data: The case of ADHD among school-age children. Journal of Health Economics, 29(5), 657-657. doi:10.1016/j.jhealeco.2010.07.005

Faraone, S. V., Biederman, J., \& Mick, E. (2006). The age-dependent decline of attention deficit hyperactivity disorder: A meta-analysis of follow-up studies. Psychological Medicine, 36, 159-165. doi:10.1017/s003329170500471x

Faraone, S. V., Biederman, J., Spencer, T., Wilens, T., Seidman, L. J., Mick, E., \& Doyle, A. E. (2000). Attention-deficit/hyperactivity disorder in adults: An overview. Biological Psychiatry, 48(1), 9-20. doi:10.1016/s0006-3223(00)00889-1

Faraone, S. V., \& Mick, E. (2010). Molecular genetics of attention deficit hyperactivity disorder. Psychiatric Clinics of North America, 33(1), 159-180. doi:10.1016/j.psc.2009.12.004

Faraone, S. V., Perlis, R. H., Doyle, A. E., Smoller, J. W., Goralnick, J. J., Holmgren, M. A., \& Sklar, P. (2005). Molecular genetics of attention-deficit/hyperactivity disorder. Biological Psychiatry, 57, 1313-1323. doi:10.1016/j.biopsych.2004.11.024 
Faul, F., Erdfelder, E., Buchner, A., \& Lang, A. G. (2009). Statistical power analyses using G* Power 3.1: Tests for correlation and regression analyses. Behavior Research Methods, 41(4), 1149-1160. doi:10.3758/brm.41.4.1149

Fayyad, J., De Graaf, R., Kessler, R., Alonso, J., Angermeyer, M., Demyttenaere, K., ... Jin, R. (2007). Cross-national prevalence and correlates of adult attention-deficit hyperactivity disorder. British Journal of Psychiatry, 190, 402-409. doi:10.1192/bjp.bp.106.034389

Fisher, A. B., \& Watkins, M. W. (2008). ADHD rating scales' susceptibility to faking in a college student sample. Journal of Postsecondary Education and Disability, 20(2), 8192.

Flory, K., Molina, B. S., Pelham, W. E., Gnagy, E., \& Smith, B. (2006). Childhood ADHD predicts risky sexual behavior in young adulthood. Journal of Clinical Child and Adolescent Psychology, 35(4), 571-577. doi: 10.1207/s15374424jccp3504

Frances, A. J., \& Widiger, T. (2012). Psychiatric diagnosis: Lessons from the DSM-IV past and cautions for the DSM-5 future. Annual Review of Clinical Psychology, 8, 109-130. doi:10.1146/annurev-clinpsy-032511-143102

Froehlich, T. E., Anixt, J. S., Loe, I. M., Chirdkiatgumchai, V., Kuan, L., \& Gilman, R. C. (2011). Update on environmental risk factors for attention-deficit/hyperactivity disorder. Current Psychiatry Reports, 13, 333-344. doi:10.1007/s11920-011-0221-3

Fuermaier, A. B., Fricke, J. A., de Vries, S. M., Tucha, L., \& Tucha, O. (2018). Neuropsychological assessment of adults with ADHD: A delphi consensus study. Applied Neuropsychology: Adult, 1-15. doi:10.1080/23279095.2018.1429441 
Gallucci, A. R., Martin, R. J., \& Usdan, S. L. (2015). The diversion of stimulant medications among a convenience sample of college students with current prescriptions. Psychology of Addictive Behaviors, 29(1), 154-161. doi:10.1037/adb0000012

Garfield, C. F., Dorsey, E. R., Zhu, S., Huskamp, H. A., Conti, R., Dusetzina, S. B., .. \& Alexander, C. G. (2012). Trends in attention deficit hyperactivity disorder ambulatory diagnosis and medical treatment in the United States, 2000-2010. Academic Pediatrics, 12(2), 110-116. doi:10.1016/j.acap.2012.01.003

Genro, J. P., Kieling, C., Rohde, L. A., \& Hutz, M. H. (2010). Attention-deficit/hyperactivity disorder and the dopaminergic hypotheses. Expert Review of Neurotherapeutics, 10(4), 587-601. doi:10.1586/ern.10.17

George, D., \& Mallery, P. (2003). SPSS for Windows step by step: A simple guide and reference ( $4^{\text {th }}$ ed.). Boston, MA: Allyn \& Bacon.

Gilberg, C., Gilberg, I. C., Rasmussen, P., Kadesjo, B., Soderstrom, H., Rastam, M., ... Niklasson, L. (2004). Co-existing disorders in ADHD - implications for diagnosis and intervention. European Child and Adolescent Psychiatry, 13, 80-92. doi: $10.1007 / \mathrm{s} 00787-0041008-4$

Ginsberg, Y., Quintero, J., Anand, E., Casillas, M., \& Upadhyaya, H. P. (2014). Underdiagnosis of attention-deficit/hyperactivity disorder in adult patients: A review of the literature. The Primary Care Companion for CNS Disorders, 16(3). doi:10.4088/pcc.13r01600

Gizer, I. R., Ficks, C., \& Waldman, I. D. (2009). Candidate gene studies of ADHD: A metaanalytic review. Human Genetics, 126, 51-90. doi:10.1007/s00439-009-0694-x

Gray, J. A. (1987). The psychology of fear and stress (2nd ed.). Cambridge: Cambridge University Press. 
Gray, S., Woltering, S., Mawjee, K., \& Tannock, R. (2014). The adult ADHD self-report scale (ASRS): Utility in college students with attention-deficit/hyperactivity disorder. PeerJ, 2(324), 1-17. doi:10.7717/peerj.324

Green, P. (2008). Medical symptom validity test for windows: User's manual and program. Edmonton, Canada: Green's Publishing.

Greenberg, L. M., \& Waldman, I. D. (1993). Developmental normative data on the test of variables of attention (TOVA). Child Psychology \& Psychiatry \& Allied Disciplines, 34 (6), 1019-1030. doi:10.1111/j.1469-7610.1993.tb01105.x

Guelzow, B., Loya, F., \& Hinshaw, S. (2017). How persistent is ADHD into adulthood? Informant report and diagnostic thresholds in a female sample. Journal of Abnormal Child Psychology, 45(2), 301-312. doi:10.1007/s10802-016-0174-4

Guo, Y., Schmitz, T. W., Mur, M., Ferreira, C. S., \& Anderson, M. C. (2018). A supramodal role of the basal ganglia in memory and motor inhibition: Meta-analytic evidence. Neuropsychologia, 108, 117-134. doi: 10.1016/j.neuropsychologia.2017.11.033

Hair, J. F., Black, W. C., Babin, B. J., \& Anderson, R. E. (2014). Multivariate data analysis (7th ed.). Essex, UK: Pearson.

Harrison, A. G., Edwards, M. J., \& Parker, K. C. (2007). Identifying students faking ADHD: Preliminary findings and strategies for detection. Archives of Clinical Neuropsychology, 22(5), 577-588. doi:10.1016/j.acn.2007.03.008

Hart, H., Chantiluke, K., Cubillo, A. I., Smith, A. B., Simmons, A., Brammer, M. J., ... \& Rubia, K. (2014). Pattern classification of response inhibition in ADHD: Toward the development of neurobiological markers for ADHD. Human Brain Mapping, 35, 30833094. doi:10.1002/hbm. 22386 
Hassan, E. (2006). Recall bias can be a threat to retrospective and prospective research designs. The Internet Journal of Epidemiology, 3(2), 339-412. doi:10.5580/2732

Hedges, L. V. (1982). Estimation of effect sizes from a series of independent experiments. Psychological Bulletin, 92, 490-499. doi: 10.1037/0033-2909.92.2.490

Henry, B., Moffitt, T. E., Caspi, A., Langley, J., \& Silva, P. A. (1994). On the "remembrance of things past": A longitudinal evaluation of the retrospective method. Psychological Assessment, 6(2), 92-101. doi:10.1037/1040-3590.6.2.92

Heppner, P. P., Wampold, B. E., \& Kivlighan, D. M. (2008). Quantitative descriptive designs. Research Designs in Counseling, 3, 224-255.

Hoza, B., Vaughn, A., Waschbusch, D. A., Murray-Close, D., \& McCabe, G. (2012). Can children with ADHD be motivated to reduce bias in self-reports of competence? Journal of Consulting and Clinical Psychology, 80(2), 245-254. doi:10.1037/a0027299

Huang, C. Y., Liao, H. Y., \& Chang, S. H. (1998). Social desirability and the clinical self-report inventory: Methodological reconsideration. Journal of Clinical Psychology, 54(4), 517528. doi: 10.1002/(SICI)1097-4679(199806)54:4<517::AID-JCLP13>3.0.CO;2-I

Huang-Pollock, C. L., Karalunas, S. L., Tam, H., \& Moore, A. N. (2012). Evaluating vigilance deficits in ADHD: A meta-analysis of CPT performance. Journal of Abnormal Psychology, 121(2), 360-371. doi:10.1037/a0027205

Instanes, J. T., Klungsøyr, K., Halmøy, A., Fasmer, O. B., \& Haavik, J. (2016). Adult ADHD and comorbid somatic disease: A systematic literature review. Journal of Attention Disorders, 22(3), 203-228. doi:10.1177/1087054716669589 
Jachimowicz, G., \& Geiselman, R. E. (2004). Comparison of ease of falsification of attention deficit hyperactivity disorder diagnosis using standard behavioral rating scales. Cognitive Science Online, 2(1), 6-20.

Jensen, P. S., Mrazek, D., Knapp, P. K., Steinberg, L., Pfeffer, C., Schowalter, J., \& Shapiro, T. (1997). Evolution and revolution in child psychiatry: ADHD as a disorder of adaptation. Journal of the American Academy of Child \& Adolescent Psychiatry, 36(12), 1672-1681. doi:10.1097/00004583-199712000-00015

Kaisari, P., Dourish, C. T., \& Higgs, S. (2017). Attention deficit hyperactivity disorder (ADHD) and disordered eating behavior: A systematic review and a framework for future research. Clinical Psychology Review, 53, 109-121. doi:10.1016/j.cpr.2017.03.002

Kessler, R. C., Adler, L., Ames, M., Demler, O., Faraone, S., Hiripi, E. V. A., ... \& Ustun, T. B. (2005). The world health organization adult ADHD self-report scale (ASRS): A short screening scale for use in the general population. Psychological Medicine, 35(2), 245256. doi:10.1017/s0033291704002892

Kessler, R. C., Adler, L., Barkley, R., Biederman, J., Conners, C. K., Demler, O., ... \& Spencer, T. (2006). The prevalence and correlates of adult ADHD in the United States: Results from the national comorbidity survey replication. American Journal of Psychiatry, 163(4), 716-723. doi:10.1176/ajp.2006.163.4.716

King, M. F., \& Bruner, G. C. (2000). Social desirability bias: A neglected aspect of validity testing. Psychology \& Marketing, 17(2), 79-103. doi: 10.1002/(SICI)15206793(200002)17:2<79::AID-MAR2>3.0.CO;2-0

Klein, R. G., Mannuzza, S., Olazagasti, M. A. R., Roizen, E., Hutchison, J. A., Lashua, E. C., \& Castellanos, F. X. (2012). Clinical and functional outcome of childhood attention- 
deficit/hyperactivity disorder 33 years later. Archives of General Psychiatry, 69(12), 1295-1303. doi:10.1001/archgenpsychiatry.2012.271

Knouse, L. E., Bagwell, C. L., Barkley, R. A., \& Murphy, K. R. (2005). Accuracy of selfevaluation in adults with ADHD: Evidence from a driving study. Journal of Attention Disorders, 8(4), 221-234. doi:10.1177/1087054705280159

Kofler, M. J., Rapport, M. D., Sarver, D. E., Raiker, J. S., Orban, S. A., Friedman, L. M., \& Kolomeyer, E. G. (2013). Reaction time variability in ADHD: A meta-analytic review of 319 studies. Clinical Psychology Review, 33(6), 795-811. doi:10.1016/j.cpr.2013.06.001

Kofman, O., Larson, J. G., \& Mostofsky, S. H. (2008). A novel task for examining strategic planning: Evidence for impairment in children with ADHD. Journal of Clinical and Experimental Neuropsychology, 30(3), 261-271. doi:10.1080/13803390701380583

Kooij, J. J. S., Boonstra, A. M., Swinkels, S.H.N., Bekker, E. M., de Noord, I., \& Buitelaar, K. (2008). Reliability, validity, and utility of instruments of self-report and informant report concerning symptoms of ADHD in adult patients. Journal of Attention Disorders, 11(4), 445-458. doi:10.1177/1087054707299367

Laerd Statistics. (2015). Hierarchical multiple regression using SPSS Statistics [webpage]. Retrieved from https://statistics.laerd.com/

LaLonde Jr, D. G. (2013). Effects of media exposure on intention to seek mental health treatment in college students. (Doctoral dissertation, Indiana University of Pennsylvania).

Landis, J. R., \& Koch, G. G. (1977). The measurement of observer agreement for categorical data. Biometrics, 159-174. doi:10.2307/2529310

Langley, K., Fowler, T., Ford, T., Thapar, A. K., van den Bree, M., Harold, G., ... Thapar, A. (2010). Adolescent clinical outcomes for young people with attention-deficit 
hyperactivity disorder. The British Journal of Psychiatry, 196, 235-240. doi:

10.1192/bjp.bp.109.066274

Lasky, A. K., Weisner, T. S., Jensen, P. S., Hinshaw, S. P., Hechtman, L., Arnold, L. E., ... Swanson, J. M. (2016). ADHD in context: Young adults' reports of the impact of occupational environment on the manifestation of ADHD. Social Science \& Medicine, 161, 160-168. doi:10.1016/j.socscimed.2016.06.003

Layton, T. J., Barnett, M. L., Hicks, T. R., \& Jena, A. B. (2018). Attention deficit-hyperactivity disorder and month of school enrollment. New England Journal of Medicine, 379, 21222130. doi: 10.1056/NEJMoa1806828

Leber, A. B., Turk-Browne, N. B., \& Chun, M. M. (2008). Neural predictors of moment-tomoment fluctuations in cognitive flexibility. PNAS, 105(36), 13592-13597. doi: 10.1073/pnas.0805423105

Lee, S. S., Humphreys, K. L., Flory, K., Liu, R., \& Glass, K. (2011). Prospective association of childhood attention-deficit/hyperactivity disorder (ADHD) and substance use and abuse/dependence: A meta analytic review. Clinical Psychology Review, 31, 328-341. doi: 10.1016/j.cpr.2011.01.006

Lenzi, F., Cortese, S., Harris, J., \& Masi, G. (2018). Pharmacotherapy of emotional dysregulation in adults with ADHD: A systematic review and meta-analysis. Neuroscience \& Biobehavioral Reviews, 84, 359-367. doi:10.1016/j.neubiorev.2017.08.010

Leppma, M., Long, D., Smith, M., \& Lassiter, C. (2017). Detecting symptom exaggeration in college students seeking ADHD treatment: Performance validity assessment using the 
NV-MSVT and IVA-Plus. Applied Neuropsychology: Adult, 25(3), 210-218. doi:10.1080/23279095.2016.1277723

Levin, R. L., \& Rawana, J. S. (2016). Attention-deficit/hyperactivity disorder and eating disorders across the lifespan: A systematic review of the literature. Clinical Psychology Review, 50, 22-36. doi:10.1016/j.cpr.2016.09.010

Levy, F. (1991). The dopamine theory of attention deficit hyperactivity disorder (ADHD). Australian \& New Zealand Journal of Psychiatry, 25(2), 277-283. doi: $10.3109 / 00048679109077746$

Lijffijt, M., Kenemans, J. L., Verbaten, M. N., \& van Engeland, H. (2005). A meta-analytic review of stopping performance in attention-deficit/hyperactivity disorder: Deficient inhibitory motor control? Journal of Abnormal Psychology, 114(2), 216-222. doi:10.1037/0021-843x.114.2.216

Lipsey, M. W., \& Wilson, D. B. (2000). Practical meta-analysis. Thousand Oaks, CA: Sage. Lipszyc, J., \& Schachar, R. (2010). Inhibitory control and psychopathology: A meta-analysis of studies using the stop signal task. Journal of the International Neuropsychological Society, 16(6), 1064-1076. doi: 10.1017/S135561770000895

Logan, G. D. (1981). Attention, automaticity, and the ability to stop a speeded choice response. Attention and Performance, 4, 205-222.

Logan, G. D. (1994). On the ability to inhibit thought and action: A users' guide to the stop signal paradigm. In D. Dagenbach \& T. H. Carr (Eds.), Inhibitory processes in attention, memory, and language (pp. 189-239). San Diego, CA: Academic Press.

Logan, G. D., \& Cowan, W. B. (1984). On the ability to inhibit thought and action: A theory of an act of control. Psychological Review, 91(3), 295-327. doi:10.1037/0033-295x.91.3.295 
Logan, G. D., Schachar, R. J., \& Tannock, R. (1997). Impulsivity and inhibitory control. Psychological Science, 8(1), 60-64. doi:10.1111/j.1467-9280.1997.tb00545.x

London, A. S., \& Landes, S. D. (2016). Attention deficit hyperactivity disorder and adult mortality. Preventive Medicine, 90, 8-10. doi:10.1016/j.ypmed.2016.06.021

Long, D. G. (2018). Test of differential inhibition and attention. Manuscript in preparation.

Lopez, R., Micoulaud-Franchi, J.-A., Galera, C., \& Dauvilliers, Y. (2017). Is adult-onset attention deficit/hyperactivity disorder frequent in clinical practice? Psychiatry Research, 257, 238-241. doi:10.1016/j.psychres.2017.07.080

Losier, B. J., McGrath, P. J., \& Klein, R. M. (1996). Error patterns on the continuous performance test in non-medicated and medicated samples of children with and without ADHD: A meta-analytic review. Journal of Child Psychology and Psychiatry, 37(8), 971-987. doi:10.1111/j.1469-7610.1996.tb01494.x

Mackworth, J. F., \& Taylor, M. M. (1963). The d'measure of signal detectability in vigilance like situations. Canadian Journal of Psychology/Revue Canadienne de Psychologie, 17(3), 302-325. doi: 10.1037/h0092885

MacLeod, C. M. (1992). The Stroop task: The "gold standard" of attentional measures. Journal of Experimental Psychology: General, 121(1), 12-14. doi:10.1037/0096-3445.121.1.12

Magnin, E., \& Maurs, C. (2017). Attention-deficit/hyperactivity disorder during adulthood. Revue Neurologique, 173(7), 506-515. doi:10.1016/j.neurol.2017.07.008

Mallett, C. A., Natarajan, A., \& Hoy, J. (2014). Attention deficit/hyperactivity disorder: A DSM timeline review. International Journal of Mental Health, 43, 36-60.

doi:10.1080/00207411.2015.1009310 
Mannuzza, S., Klein, R. G., Bessler, A., Malloy, P., \& LaPadula, M. (1998). Adult outcome of hyperactive boys. Archives of General Psychiatry, 50(7), 565-576. doi:10.1176/ajp.155.4.493

Marks, D. J., Himelstein, J., Newcorn, J. H., \& Halperin, J. M. (1999). Identification of AD/HD subtypes using laboratory-based measures: A cluster analysis. Journal of Abnormal Child Psychology, 27(2), 167-175.

Martinuessen, R., Hayden, J., Hogg-Johnson, S., \& Tannock, R. (2005). A meta-analysis of working memory impairments in children with attention-deficit/hyperactivity disorder. Journal of the American Academic of Child \& Adolescent Psychiatry, 44(4), 377-384. doi:10.1097/01.chi.0000153228.72591.73

Matte, B., Rohde, L. A., Turner, J. B., Fisher, P. W., Shen, S., Bau, C., ... \& Grevet, E. H. (2015). Reliability and validity of proposed DSM-5 ADHD symptoms in a clinical sample of adults. The Journal of Neuropsychiatry and Clinical Neurosciences, 27(3), 228-236. doi:10.1176/appi.neuropsych.13060137

McAuley, T., Crosbie, J., Charach, A., \& Schachar, R. (2013). The persistence of cognitive deficits in remitted and unremitted ADHD: A case for the state-independence of response inhibition. Journal of Child Psychology and Psychiatry, 55(3), 292-300. doi: 10.1111/jcpp. 12160

McCluskey, D. L. (2017). Examining the efficacy of a 1-session brief behavioral activation intervention with university students with mild to moderate depressive symptoms. (Doctoral dissertation, West Virginia University).

McGee, R. A., Clark, S. E., \& Symons, D. K. (2000). Does the Conners' continuous performance test aid in ADHD diagnosis? Journal of Abnormal Child Psychology, 28(5), 415-424. 
McGough, J. J., \& McCracken, J. T. (2006). Adult attention deficit hyperactivity disorder: Moving beyond DSM-IV. The American Journal of Psychiatry, 163(10), 1673-1675. doi:10.1176/appi.ajp.163.10.1673

Meyer, J. S., \& Quenzer, L. F. (2013). Psychopharmacology: Drugs, the brain, and behavior. Sunderland, MA: Sinauer Associates, Inc.

Michielsen, M., Comijs, H. C., Semeijn, E. J., Beekman, A. T. F., Deeg, D. J. H., \& Sandra Kooij, J. J. (2013). The comorbidity of anxiety and depressive symptoms in older adults with attention-deficit/hyperactivity disorder: A longitudinal study. Journal of Affective Disorders, 148(2), 220-227. doi:10.1016/j.jad.2012.11.063

Miller, C. J., Newcorn, J. H., \& Halperin, J. M. (2010). Fading memories: Retrospective recall inaccuracies in ADHD. Journal of Attention Disorders, 14(1), 7-14. doi: $10.1177 / 1087054709347189$

Moffitt, T. E., Caspi, A., Taylor, A., Kokaua, J., Milne, B. J., Polanczyk, G., \& Poulton, R. (2010). How common are common mental disorders? Evidence that lifetime prevalence rates are doubled by prospective versus retrospective ascertainment. Psychological Medicine, 40(6), 899-909. doi:10.1017/s0033291709991036

Moffitt, T. E., Houts, R., Asherson, P., Belsky, D. W., Corcoran, D. L., Hammerle, M., ... \& Caspi, A. (2015). Is adult ADHD a childhood-onset neurodevelopmental disorder? Evidence from a four-decade longitudinal cohort study. The American Journal of Psychiatry, 172(10), 967-77. doi:10.1176/appi.ajp.2015.14101266

Mordre, M., Groholt, B., Sandstad, B., \& Myhre, A. M. (2012). The impact of ADHD symptoms and global impairment in childhood on working disability in mid-adulthood: A 28-year 
follow-up study using official disability pension records in a high-risk in-patient population. BMC Psychiatry, 12, 174-183. doi: 10.1186/1471-244X-12-174

Munkvold, L. H., Manger, T., \& Lundervold, A. J. (2014). Conners' continuous performance test (CCPT-II) in children with ADHD, ODD, or a combined ADHD/ODD diagnosis. Child Neuropsychology, 20(1), 106-126. doi:10.1080/09297049.2012.753997

Murphy, P. (2002). Inhibitory control in adults with attention-deficit/hyperactivity disorder. Journal of Attention Disorders, 6(1), 1-4. doi: 10.1177/108705470200600101

Murphy, K., \& Barkley, R. A. (1996). Attention deficit hyperactivity disorder adults: Comorbidities and adaptive impairments. Comprehensive Psychiatry, 37(6), 393-401. doi:10.1016/s0010-440x(96)90022-x

Murphy, P., \& Schachar, R. (2000). Use of self-ratings in the assessment of symptoms of attention deficit hyperactivity disorder in adults. American Journal of Psychiatry, 157(7), 1156-1159. doi:10.1176/appi.ajp.157.7.1156

National Institute of Mental Health. (2010). ADHD: Signs, symptoms, research [webpage]. Retrieved from https://www.nimh.nih.gov/news/media/2010/adhd.shtml

National Institute of Mental Health. (2017). Attention-Deficit/Hyperactivity Disorder [webpage]. Retrieved from https://www.nimh.nih.gov/health/statistics/attention-deficit-hyperactivitydisorder-adhd.shtml

Nigg, J. T. (2001). Is ADHD a disinhibitory disorder? Psychological Bulletin, 127(5), 571-598. doi:10.1037/0033-2909.127.5.571

Nigg, J. T., Johnstone, J. M., Musser, E. D., Long, H. G., Willoughby, M. T., \& Shannon, J. (2016). Attention-deficit/hyperactivity disorder (ADHD) and being overweight/obesity: New data and meta-analysis. Clinical Psychology Review, 43, 67-79. 
doi:10.1016/j.cpr.2015.11.005

O'dougherty, M., Neuchterlein, K. H., \& Drew, B. (1984). Hyperactive and hypoxic children: Signal detection, sustained attention, and behavior. Journal of Abnormal Psychology, 93(2), 178-191. doi:10.1037/0021-843x.93.2.178

Ogundele, M. O., Ayyash, H. F., \& Banerjee, S. (2011). Role of computerized continuous performance task tests in ADHD. Progress in Neurology and Psychiatry, 15(3), 8-13. doi:10.1002/pnp. 198

Oosterlaan, J., Logan, G. D., \& Sergeant, J. A. (1998). Response inhibition in AD/HD, CD, comorbid $\mathrm{AD} / \mathrm{HD}+\mathrm{CD}$, anxious, and control children: A meta-analysis of studies with the stop task. The Journal of Child Psychology and Psychiatry and Allied Disciplines, 39(3), 411-425. doi:10.1111/1469-7610.00336

Owens, J. S., Goldfine, M. E., Evangelista, N. M., Hoza, B., \& Kaiser, N. M. (2007). A critical review of self-perceptions and the positive illusory bias in children with ADHD. Clinical Child and Family Psychology Review, 10(4), 335-351. doi:10.1007/s10567-007-0027-3

Owens, J. S., \& Hoza, B. (2003). The role of inattention and hyperactivity/impulsivity in the positive illusory bias. Journal of Consulting and Clinical Psychology, 71(4), 680-691. doi:10.1037/0022-006x.71.4.680

Pauls, C. A., \& Crost, N. W. (2004). Effects of faking on self-deception and impression management scales. Personality and Individual Differences, 37(6), 1137-1151. doi:10.1016/j.paid.2003.11.018

Pennington, B. F., \& Ozonoff, S. (1996). Executive functions and developmental psychopathology. Journal of Child Psychology and Psychiatry, 37, 51-87. doi:10.1111/j.1469-7610.1996.tb01380.x 
Peterson, S. E., \& Posner, M. I. (2012). The attention system of the human brain: 20 years after. Annual Review of Neuroscience, 35, 73-89. doi: 10.1146/annurev-neuro-062111-150525

Pliszka, S. (2005). The neuropsychopharmacology of Attention-Deficit/Hyperactivity Disorder. Biological Psychiatry, 57, 1385-1390. doi: 10.1016/j.biopsych.2004.08.026

Posner, M. I. (1980). Orienting of attention. Quarterly Journal of Experimental Psychology, 32, 3-25. doi: 10.1080/00335558008248231

Posner, M. I., \& Petersen, S. E. (1990). The attention system of the human brain. Annual Review of Neuroscience, 13(1), 25-42. doi:10.1146/annurev.neuro.13.1.25

Prevatt, F., \& Young, J. L. (2014). Recognizing and treating attention-deficit/hyperactivity disorder in college students. Journal of College Student Psychotherapy, 28(3), 182-200. doi:10.1080/87568225.2014.914825

Ptacek, R., Kuzelova, H., \& Stefano, G. B. (2011). Dopamine D4 receptor gene DRD4 and its association with psychiatric disorders. Medical Science Monitor, 17(9), 215-220. doi: $10.12659 / \mathrm{msm} .881925$

Quay, H.C. (1988). The behavioral reward and inhibition system in childhood behavior disorder. In L. M. Bloomingdale (Ed.), Attention deficit disorder, Vol. 3 (pp. 176-185). Oxford: Pergamon Press.

Quinn, C. (2003). Detection of malingering in assessment of adult ADHD. Archives of Clinical Neuropsychology, 18, 379-395. doi:10.1093/arclin/18.4.379

Rapport, M. D., Chung, K., Shore, G., \& Isaacs, P. (2001). A conceptual model of child psychopathology: Implications for understanding attention deficit hyperactivity disorder and treatment efficacy. Journal of Clinical Child Psychology, 30, 48-58. doi:10.1207/s15374424jccp3001_6 
Reid, A. M., Graziano, P. A., Balkhi, A. M., McNamara, J. P., Cottler, L. B., Meneses, E., \& Geffken, G. R. (2015). Frequent nonprescription stimulant use and risky behaviors in college students: The role of effortful control. Journal of American College Health, 63(1), 23-30. doi:10.1080/07448481.2014.960422

Rigler, T., Manor, I., Kalansky, A., Shorer, Z., Noyman, I., \& Sadaka, Y. (2016). New DSM-5 criteria for ADHD — Does it matter? Comprehensive Psychiatry, 68, 56-59. doi:10.1016/j.comppsych.2016.03.008

Rossi, A. F., Bichot, N. P., Desimone, R., \& Ungerleider, L. G. (2007). Top-down attentional deficits in macaques with lesions of lateral prefrontal cortex. Journal of Neuroscience, 27(42), 11306-11314. doi: 10.1523/jneurosci.2939-07.2007

Rosvold, H. E., Mirsky, A. F., Sarason, I., Bransome Jr, E. D., \& Beck, L. H. (1956). A continuous performance test of brain damage. Journal of Consulting Psychology, 20(5), 343-350. doi:10.1037/h0043220

Rubia, K., Cubillo, A., Woolley, J., Brammer, M. J., \& Smith, A. (2011). Disorder-specific dysfunctions in patients with attention-deficit/hyperactivity disorder compared to patients with obsessive-compulsive disorder during interference inhibition and attention allocation. Human Brain Mapping, 32(4), 601-611. doi:10.1002/hbm.21048

Sandford, J. A., \& Turner, A. (1995). Intermediate visual and auditory continuous performance test interpretation manual. Richmond, VA: Braintrain.

Sandford, J. A., \& Turner, A. (2004). IVA+ Plus: Integrated visual and auditory performance test. Toronto, Canada: Brain Train.

Schachar, R. J., Chin, S., Logan, G. D., Ornstein, T. J., Crosbie, J., Ickowicz, A., \& Pakulak, A. (2004). Evidence for an error monitoring deficit in attention deficit hyperactivity 
disorder. Journal of Abnormal Child Psychology, 32(3), 285-293.

doi:10.1023/b:jacp.0000026142.11217.f2

Schachar, R. J., Crosbie, J., Barr, C. L., Ornstein, T. J., Kennedy, J., Malone, M., ... \& Pathare, T. (2005). Inhibition of motor responses in siblings concordant and discordant for attention deficit hyperactivity disorder. The American Journal of Psychiatry, 162(6), 1076-1082. doi: 10.1176/appi.ajp.162.6.1076

Schachar, R. J., Logan, G. D., Robaey, P., Chen, S., Ickowicz, A., \& Barr, C. (2007). Restraint and cancellation: Multiple inhibition deficits in attention deficit hyperactivity disorder. Journal of Abnormal Child Psychology, 35(2), 229-238. doi:10.1007/s10802-006-9075-2

Schultz, N. R., Silvestri, M. M., \& Correia, C. J. (2017). Diversion of prescription stimulants among college students: An initial investigation of injunctive norms. Addictive Behaviors, 65, 264-268. doi:10.1016/j.addbeh.2016.08.022

Sebastian, A., Pohl, M. F., Klöppel, S., Feige, B., Lange, T., Stahl, C., ... \& Tüscher, O. (2013). Disentangling common and specific neural subprocesses of response inhibition. Neuroimage, 64, 601-615. doi:10.1016/j.neuroimage.2012.09.020

Seidman, L., Valera, E., \& Makris, N. (2005). Structural brain imaging of attentiondeficit/hyperactivity disorder. Biological Psychiatry, 57(11), 1263-1272. doi:10.1016/j.biopsych.2004.11.019

Sexton, C.C., Gelhorn, H. L., Bell, J. A., \& Classi, P. M. (2012). The co-occurrence of reading disorder and ADHD: Epidemiology, treatment, psychosocial impact, and economic burden. Journal of Learning Disabilities, 45, 538-564. doi: 10.1177/0022219411407772 
Shalev, L., Ben-Simon, A., Mevorach, C., Cohen, Y., \& Tsal, Y. (2011). Conjunctive continuous performance task (CCPT) - a pure measure of sustained attention. Neuropsychologia, 49(25), 84-91. doi: 10.1016/j.neuropsychologia.2011.05.006

Shaw, P., De Rossi, P., Watson, B., Wharton, A., Greenstein, D., Raznahan, A., ... \& Chakravarty, M. M. (2014). Mapping the development of the basal ganglia in children with attention-deficit/hyperactivity disorder. Journal of the American Academy of Child \& Adolescent Psychiatry, 53(7), 780-789. doi:10.1016/j.jaac.2014.05.003

Sibley, M. H., Mitchell, J. T., \& Becker, S. P. (2016). Method of adult diagnosis influences estimated persistence of childhood ADHD: A systematic review of longitudinal studies. The Lancet Psychiatry, 3(12), 1157-1165. doi:10.1016/s2215-0366(16)30190-0

Sibley, M. H., Pelham Jr, W. E., Molina, B. S., Gnagy, E. M., Waxmonsky, J. G., Waschbusch, D. A., ... \& Kuriyan, A. B. (2012). When diagnosing ADHD in young adults emphasize informant reports, DSM items, and impairment. Journal of Consulting and Clinical Psychology, 80(6), 1052-1061. doi:10.1037/a0029098

Simon, V., Czobor, P., Bálint, S., Mészáros, A., \& Bitter, I. (2009). Prevalence and correlates of adult attention-deficit hyperactivity disorder: meta-analysis. The British Journal of Psychiatry, 194(3), 204-211. doi:10.1192/bjp.bp.107.048827

Simon, V., Czobor, P., \& Bitter, I. (2013). Is ADHD severity in adults associated with the lifetime prevalence of comorbid depressive episodes and anxiety disorders? European Psychiatry, 28(5), 308-314. doi:10.1016/j.eurpsy.2012.05.002

Skirrow, C., \& Asherson, P. (2013). Emotional lability, comorbidity and impairment in adults with attention-deficit hyperactivity disorder. Journal of Affective Disorders, 147(1-3), 80-86. doi:10.1016/j.jad.2012.10.011 
Sollman, M. J., Ranseen, J. D., \& Berry, D. T. (2010). Detection of feigned ADHD in college students. Psychological Assessment, 22(2), 325-335. doi:10.1037/a0018857

Sonuga-Barke, E. J., Sergeant, J. A., Nigg, J., \& Willcutt, E. (2008). Executive dysfunction and delay aversion in attention deficit hyperactivity disorder: Nosologic and diagnostic implications. Child and Adolescent Psychiatric Clinics of North America, 17(2), 367-384. doi:10.1016/j.chc.2007.11.008

Spencer, T. J., Biederman, J., \& Mick, E. (2007). Attention-deficit/hyperactivity disorder: Diagnosis, lifespan, comorbidities, and neurobiology. Ambulatory Pediatrics 7(1), 73-81. doi:10.1016/j.ambp.2006.07.006

Spencer, T. J., Biederman, J., Wilens, T. E., \& Faraone, S. V. (2002). Overview and neurobiology of attention-deficit/hyperactivity disorder. Journal of Clinical Psychiatry, 63(12), 3-9.

Stevens, M. C., Pearlson, G. D., Calhoun, V. D., \& Besette, K. L. (2018). Functional neuroimaging evidence for distinct neurobiological pathways in attentiondeficit/hyperactivity disorder. Biological Psychiatry: Cognitive Neuroscience and Neuroimaging, 3(8), 675-685. doi: 10.1016/j.bpsc.2017.09.005

Stickley, A., Koyanagi, A., Takahashi, H., Ruchkin, V., \& Kamio, Y. (2016). Attentiondeficit/hyperactivity disorder symptoms and suicide ideation and attempts: Findings from the adult psychiatric morbidity survey 2007. Journal of Affective Disorders, 189(1), 321328. doi:10.1016/j.jad.2015.09.061

Stickley, A., Koyanagi, A., Takahashi, H., Ruchkin, V., \& Kamio, Y. (2017). Attentiondeficit/hyperactivity disorder symptoms and loneliness among adults in the general 
population. Research in Developmental Disabilities, 62, 115-123.

doi:10.1016/j.ridd.2017.01.007

Sullivan, B. K., May, K., \& Galbally, L. (2007). Symptom exaggeration by college adults in attention-deficit hyperactivity disorder and learning disorder assessments. Applied Neuropsychology, 14(3), 189-207. doi:10.1080/09084280701509083

Swick, D., Ashley, V., \& Turken, A. U. (2008). Left inferior frontal gyrus is critical for response inhibition. BMC Neuroscience, 9(102), 1-11. doi: 10.1186/1471-2202-9-102

Taylor, A., Deb, S., \& Unwin, G. (2011). Scales for the identification of adults with attention deficit hyperactivity disorder (ADHD): A systematic review. Research in Developmental Disabilities, 32(3), 924-938. doi:10.1016/j.ridd.2010.12.036

Tamana, S. K., Ezeugwu, V., Chikuma, J., Lefebvre, D. L., Azad, M. B., Moraes, T. J., ... \& Mandhane, P. J. (2019). Screen-time is associated with inattention problems in preschoolers: Results from the CHILD birth cohort study. PLoS ONE, 14(4), 1-15. doi: 10.1371/journal.pone.0213995

Teichert, T., \& Ferrera, V. P. (2015). A new paradigm and computational framework to estimate stop-signal reaction time distributions from the inhibition of complex motor sequences. Frontiers in Computational Neuroscience, 9(87), 1-17. doi: 10.3389/fncom.2015.00087

Thomas, R., Sanders, S., Doust, J., Beller, E., \& Glasziou, P. (2015). Prevalence of attentiondeficit/hyperactivity disorder: A systematic review and meta-analysis. Pediatrics, 135(4), 994-1001. doi:10.1542/peds.2014-3482

Tollander, H. (2011). The integrated visual and auditory continuous performance test: Does the comprehension scale discriminate ADHD? (Doctoral dissertation, Pacific University). 
Uno, M., Abe, J., Sawai, C., Sakaue, Y., Nishitani, A., Yasuda, Y., ... \& Takeuchi, Y. (2006). Effect of additional auditory and visual stimuli on continuous performance test (noisegenerated CPT) in AD/HD children-usefulness of noise-generated CPT. Brain and Development, 28(3), 162-169. doi:10.1016/j.braindev.2005.06.007

Van de Mortel, T. F. (2008). Faking it: social desirability response bias in self-report research. The Australian Journal of Advanced Nursing, 25(4), 40-48.

Van Mourik, R., Oosterlaan, J., \& Sergeant, J. A. (2005). The stroop revisited: A meta-analysis of interference control in AD/HD. Journal of Child Psychology and Psychiatry, 46(2), 150-165. doi:10.1111/j.1469-7610.2004.00345.x

van Velzen, L. S., Vriend, C., de Wit, S. J., \& van den Heuvel, O. A. (2014). Response inhibition and interference control in obsessive-compulsive spectrum disorders. Frontiers in Human Neuroscience, 8(419), 1-22. doi:10.3389/fnhum.2014.00419

VanVoorhis, C. W., \& Morgan, B. L. (2007). Understanding power and rules of thumb for determining sample sizes. Tutorials in Quantitative Methods for Psychology, 3(2), 43-50. doi:10.20982/tqmp.03.2.p043

Verbruggen, F., \& Logan, G. D. (2008). Response inhibition in the stop-signal paradigm. Trends in Cognitive Sciences, 12(11), 418-424. doi: 10.1016/j.tics.2008.07.005

Wakefield, J. C. (2015). DSM-5, psychiatric epidemiology and the false positives problem. Epidemiology and Psychiatric Sciences, 24(3), 188-196. doi: $10.1017 /$ s2045796015000116

Waldman, I. D., \& Gizer, I. R. (2006). The genetics of attention deficit hyperactivity disorder. Clinical Psychology Review, 26, 396-432. doi:10.1016/j.cpr.2006.01.007 
Weinberg, W. A., \& Brumback, R. A. (1992). The myth of attention deficit-hyperactivity disorder: Symptoms resulting from multiple causes. Journal of Child Neurology, 7(4), 431-445. doi:10.1177/088307389200700420

Weiss, W. U., Weiss, P. A., Cain, S., \& Manley, B. (2009). Impression management in police officer candidacy on the MMPI-2. Journal of Police and Criminal Psychology, 24(2), 120-125. doi:10.1007/s11896-009-9044-0

Westover, A. N., \& Halm, E. A. (2012). Do prescription stimulants increase the risk of adverse cardiovascular events?: A systematic review. BMC Cardiovascular Disorders, 12(1), 4151. doi:10.1186/1471-2261-12-41

Wilens, T. E., Biederman, J., Faraone, S. V., Martelon, M., Westerberg, D., \& Spencer, T. J. (2009). Presenting ADHD symptoms, subtypes, and comorbid disorders in clinically referred adults with ADHD. The Journal of Clinical Psychiatry, 70(11), 1557-1562. doi:10.4088/jcp.08m04785pur

Willcutt, E. G. (2012). The prevalence of DSM-IV attention-deficit/hyperactivity disorder: A meta-analytic review. Neurotherapeutics, 9(3), 490-499. doi:10.1007/s13311-012-0135-8

Willcutt, E. G., Doyle, A. E., Nigg, J. T., Faraone, S. V., \& Pennington, B. F. (2005). Validity of the executive function theory of attention-deficit/hyperactivity disorder: A meta-analytic review. Biological psychiatry, 57(11), 1336-1346. doi:10.1016/j.biopsych.2005.02.006

Williamson, D., \& Johnston, C. (2015). Gender differences in adults with attentiondeficit/hyperactivity disorder: A narrative review. Clinical Psychology Review, 40, 1527. doi:10.1016/j.cpr.2015.05.005 
Wodushek, T. R., \& Neumann, C. S. (2003). Inhibitory capacity in adults with symptoms of attention deficit/hyperactivity disorder (ADHD). Archives of Clinical Neuropsychology, 18, 317-330. doi: 10.1016/S0887-6177(02)00152-X

Wood, D., Reimherr, F. W., Wender, P. H., \& Johnson, G. E. (1976). Diagnosis and treatment of minimal brain dysfunction in adults. Archives of General Psychiatry, 33(12), 1453-1453. doi:10.1001/archpsyc.1976.01770120057005

Wright, L., Lipszyc, J., Dupuis, A., Thayapararajah, S. W., \& Schachar, R. (2014). Response inhibition and psychopathology: A meta-analysis of go/no-go task performance. Journal of Abnormal Psychology, 123(2), 429-439. doi:10.1037/a0036295

Young, J. L., \& Goodman, D. W. (2016). Adult attention-deficit/hyperactivity disorder diagnosis, management, and treatment in the DSM-5 era. The Primary Care Companion for CNS Disorders, 18(6), 1-18. doi:10.4088/pcc.16r02000

Young, J. T., Carruthers, S., Kaye, S., Allsop, S., Gilsenan, J., Degenhardt, L., ... Preen, D. (2015). Comorbid attention deficit hyperactivity disorder and substance use disorder complexity and chronicity in treatment-seeking adults. Drug and Alcohol Review, 34(6), 683-693. doi:10.1111/dar.12249

Zetterqvist, J., Asherson, P., Halldner, L., Långström, N., \& Larsson, H. (2013). Stimulant and non-stimulant attention deficit/hyperactivity disorder drug use: Total population study of trends and discontinuation patterns 2006-2009. Acta Psychiatrica Scandinavica, 128(1), 70-77. doi:10.1111/acps.12004

Zhao, X., Page, T. F., Altszuler, A. R., Pelham III, W. E., Kipp, H., Gnagy, E. M., ... \& Pelham, Jr., W. E. (2019). Family burden of raising a child with ADHD. Journal of Abnormal Child Psychology, 1-12. doi: 10.1007/s10802-019-00518-5 
Ziobrowski, H., Brewerton, T. D., \& Duncan, A. E. (2018). Associations between ADHD and eating disorders in relation to comorbid psychiatric disorders in a nationally representative sample. Psychiatry Research, 260, 53-59. doi:10.1016/j.psychres.2017.11.026 


\section{APPENDICES}

\section{Appendix A: Informational Cover Letter - Form A}

\section{Dear Participant,}

My name is Ben Darling and I am a doctoral candidate in Counseling Psychology at West Virginia University (WVU). I kindly request your participation in a research study titled: "Associations between the Adult ADHD Self-Report Rating Scale and the Test of Differential Inhibition and Attention." The primary aim of this study is to assess the validity of a newly developed measure of attentional processing and response control in adulthood. The study involves completing a basic demographics questionnaire, one self-report survey of attention and hyperactivity/impulsivity, and one computerized continuous performance test.

This project has been acknowledged by the Institutional Review Board at WVU and is being conducted under the guidance of Dr. Monica Leppma, Associate Professor. Your participation is completely voluntary and you may withdraw from the study at any time without penalty. Your involvement will be kept as confidential as legally possible and no identifying information will be collected. You will have the option of providing your email address to enter an anonymous, random drawing to win one of ten $\$ 10$ Amazon gift cards. This information will be kept separate from your individual responses to the survey questions.

Your participation in this study is highly valued and will require no more than 35 minutes of your time. This study will be conducted on WVU's Evansdale Campus at a designated time and location. Please send an email to abdarling@mix.wvu.edu for more information on how to participate in this study.

Thank you for your consideration. Please do not hesitate to contact Ben Darling (abdarling@mix.wvu.edu) or Dr. Monica Leppma (monica.leppma@mail.wvu.edu) should you have questions or need additional information.

Sincerely,

\section{Ben Darling, M.A.}

Counseling Psychology Doctoral Candidate

Department of Counseling, Rehabilitation

Counseling, and Counseling Psychology

West Virginia University | Morgantown, WV 


\section{Appendix B: Informational Cover Letter - Form B}

\section{Dear Participant,}

My name is Ben Darling and I am a doctoral candidate in Counseling Psychology at West Virginia University (WVU). I kindly request your participation in a research study titled: "Associations between the Adult ADHD Self-Report Rating Scale and the Test of Differential Inhibition and Attention." The primary aim of this study is to assess the validity of a newly developed measure of attentional processing and response control in adulthood. The study involves completing a basic demographics questionnaire, one self-report survey of attention and hyperactivity/impulsivity, and one computerized continuous performance test.

This project has been acknowledged by the Institutional Review Board at WVU and is being conducted under the guidance of Dr. Monica Leppma, Associate Professor. Your participation is completely voluntary and you may withdraw from the study at any time without penalty. Your involvement will be kept as confidential as legally possible and no identifying information will be collected.

Your participation in this study is highly valued and will require no more than 35 minutes of your time. As a thank you, you will be provided with one \$10 Amazon gift card for participating in this study. This study will be conducted in the MindFit Clinic at the WVU Carruth Center for Psychological and Psychiatric Services (MindFit) by trained personnel. Please contact your MindFit representative if you have questions or need additional information about this study.

Thank you for your consideration. Please do not hesitate to contact Ben Darling (abdarling@mix.wvu.edu) or Dr. Monica Leppma (monica.leppma@mail.wvu.edu) should you have questions or need additional information.

Sincerely,

Ben Darling, M.A.

Counseling Psychology Doctoral Candidate

Department of Counseling, Rehabilitation

Counseling, and Counseling Psychology

West Virginia University | Morgantown, WV 


\section{Appendix C: Informed Consent}

\section{Only Minimal Risk}

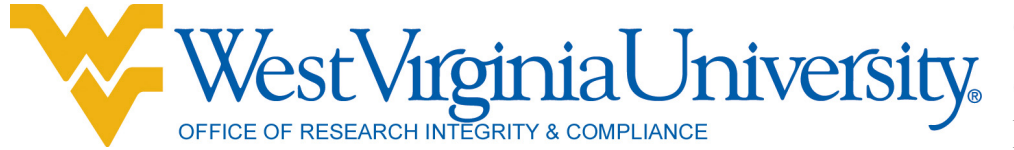

\section{Consent Information Form (without HIPAA)}

Principal Investigator Monica

Leppma, Ph.D.

Department

Protocol Number

Study Title

the Test of Differential Inhibition and Attention (TDIA)

Co-Investigator(s)

Sponsor (if any)
Counseling, Rehabilitation Counseling, and Counseling Psychology

1901443696

Associations between the Adult ADHD Self-Report Rating Scale (ASRS) and

\section{Contact Persons}

In the event you experience any side effects or injury related to this research, you should contact the Carruth Center for Psychological and Psychiatric Services at (304) 293-4431. If you have any questions, concerns, or complaints about this research, you can contact Dr. Monica Leppma at (304) 293-0540.

For information regarding your rights as a research subject, to discuss problems, concerns, or suggestions related to the research, to obtain information or offer input about the research, contact the Office of Research Integrity and Compliance at (304) 293-7073.

\section{Introduction}

You, , have been asked to participate in this research study, which has been explained to you by This study is being conducted by Ben Darling, M.A. and Monica Leppma, Ph.D., in the

Department of Counseling, Rehabilitation Counseling, and Counseling Psychology at West Virginia University.

\section{Purpose(s) of the Study}

The purpose of this study is to examine the relationship between scores on a self-report measure of adult ADHD symptomatology and CPT performance to aid in the validation of a newly developed computerized assessment of ADHD symptoms. The primary aim is to determine whether SSRT may distinguish between individuals with self-reported impairment from ADHD symptoms and those who report no such impairment on a CPT with greater central processing demands.

\section{Description of Procedures}

This study involves analysis of self-report and objective measures of attentional processing and response control. Participation in this study will take approximately 30 minutes. You do not have to answer every question. You are being invited to allow your anonymous scores to be included in the analyses.

\section{Discomforts}

There are no known or expected risks from participating in this study, except for the mild frustration associated with answering the questions. Should you experience any form or degree of distress related to your participation in this study, resources are available at the WVU Carruth Center for Psychological and Psychiatric Services (304-293-4431), WVU Quin Curtis Center (304-293-1824), and WVU Student Health Center (855-WVUCARE).

\section{Alternatives}

You do not have to participate in this study. 


\section{Benefits}

You may not receive any direct benefit from this study. The knowledge gained from this study may eventually benefit others.

\section{Financial Considerations}

There are no special fees for participating in this study.

\section{Confidentiality}

Any information about you that is obtained through your participation in this research will be kept as confidential as legally possible. Your research records and test results, just like hospital records, may be subpoenaed by court order or may be inspected by the study sponsor or federal regulatory authorities (including the FDA if applicable) without your additional consent.

In any publications that result from this research, neither your name nor any information from which you might be identified will be published without your consent.

\section{Voluntary Participation}

Participation in this study is voluntary. You are free to withdraw your consent to participate in this study at any time.

Refusal to participate or withdrawal will not affect your class standing or grades, as appropriate, and will involve no penalty to you. Refusal to participate or withdrawal will not affect your future care, or your employee status, as appropriate, at West Virginia University.

In the event new information becomes available that may affect your willingness to participate in this study, this information will be given to you so that you can make an informed decision about whether or not to continue your participation.

You have been given the opportunity to ask questions about the research, and you have received answers concerning areas you did not understand.

Upon signing this form, you will receive a copy.

I willingly consent to participate in this research.

\begin{tabular}{llll}
\hline Printed Name & Signature & Date & Time
\end{tabular}

The participant has had the opportunity to have questions addressed. The participant willingly agrees to be in the study.

Signature of Investigator or Co-Investigator 


\section{Appendix D: Demographics Questionnaire}

Please complete the following information.

\begin{tabular}{|c|c|c|c|}
\hline Item & Text & Answers & Type \\
\hline 1 & Age: & & $\begin{array}{l}\text { Text } \\
\text { Entry }\end{array}$ \\
\hline 2 & Sex: & $\begin{array}{ll}\circ & \text { Male } \\
\circ & \text { Female } \\
\circ & \text { Self-Identify: }\end{array}$ & $\begin{array}{l}\text { Multiple } \\
\text { Choice }\end{array}$ \\
\hline 3 & $\begin{array}{l}\text { Have you ever been clinically diagnosed } \\
\text { with Attention-Deficit Hyperactivity } \\
\text { Disorder? }\end{array}$ & $\begin{array}{ll}\text { O } & \text { Yes } \\
\text { O } & \text { No }\end{array}$ & $\begin{array}{l}\text { Multiple } \\
\text { Choice }\end{array}$ \\
\hline 4 & $\begin{array}{l}\text { If you answered "Yes" on Item } 3 \text {, how } \\
\text { old were you (in years) when you were } \\
\text { diagnosed? If you answered "No" on } \\
\text { Item } 3 \text {, proceed to Item } 5 \text {. }\end{array}$ & $\begin{array}{ll} & \text { Between } 0 \text { and } 12 \\
& \text { years } \\
\circ & \text { Between } 12 \text { and } 18 \\
& \text { years } \\
\circ & 18 \text { or older }\end{array}$ & $\begin{array}{l}\text { Multiple } \\
\text { Choice }\end{array}$ \\
\hline 5 & $\begin{array}{l}\text { Which of the following best describes } \\
\text { you? }\end{array}$ & $\begin{array}{l}\text { Currently prescribed } \\
\text { psychostimulant } \\
\text { medication }\end{array}$ & $\begin{array}{l}\text { Multiple } \\
\text { Choice }\end{array}$ \\
\hline
\end{tabular}




\section{Appendix E: Adult ADHD Self-Report Scale (ASRS-V1.1) Symptom Checklist}

Please answer the questions below, rating yourself on each of the criteria shown using the scale provided. Please select the answer that best describes how you have felt and conducted yourself over the past 6 months.

1. How often do you have trouble wrapping up the final details of a project, once the challenging parts have been done?

$\begin{array}{ccccc}\text { Never } & \text { Rarely } & \text { Sometimes } & \text { Often } & \text { Very Often } \\ 0 & 1 & 2 & 3 & 4\end{array}$

2. How often do you have difficulty getting things in order when you have to do a task that requires organization?

$\begin{array}{ccccc}\text { Never } & \text { Rarely } & \text { Sometimes } & \text { Often } & \text { Very Often } \\ 0 & 1 & 2 & 3 & 4\end{array}$

3. How often do you have problems remembering appointments or obligations?

$\begin{array}{ccccc}\text { Never } & \text { Rarely } & \text { Sometimes } & \text { Often } & \text { Very Often } \\ 0 & 1 & 2 & 3 & 4\end{array}$

4. When you have a task that requires a lot of thought, how often do you avoid or delay getting started?
Never
0
Rarely
1
Sometimes
2
Often
3
Very Often

5. How often do you fidget or squirm with your hands or feet when you have to sit down for a long time?

$\begin{array}{ccccc}\text { Never } & \text { Rarely } & \text { Sometimes } & \text { Often } & \text { Very Often } \\ 0 & 1 & 2 & 3 & 4\end{array}$

6. How often do you feel overly active and compelled to do things, like you were driven by a motor?

$\begin{array}{ccccc}\text { Never } & \text { Rarely } & \text { Sometimes } & \text { Often } & \text { Very Often } \\ 0 & 1 & 2 & 3 & 4\end{array}$

7. How often do you make careless mistakes when you have to work on a boring or difficult project?

$\begin{array}{ccccc}\text { Never } & \text { Rarely } & \text { Sometimes } & \text { Often } & \text { Very Often } \\ 0 & 1 & 2 & 3 & 4\end{array}$

8. How often do you have difficulty keeping your attention when you are doing boring repetitive work?

$\begin{array}{ccccc}\text { Never } & \text { Rarely } & \text { Sometimes } & \text { Often } & \text { Very Often } \\ 0 & 1 & 2 & 3 & 4\end{array}$


9. How often do you have difficulty concetrating on what people say to you, even when they are speaking to you directly?

$\begin{array}{ccccc}\text { Never } & \text { Rarely } & \text { Sometimes } & \text { Often } & \text { Very Often } \\ 0 & 1 & 2 & 3 & 4\end{array}$

10. How often do you misplace or have difficulty finding things at home or at work?

$\begin{array}{ccccc}\text { Never } & \text { Rarely } & \text { Sometimes } & \text { Often } & \text { Very Often } \\ 0 & 1 & 2 & 3 & 4\end{array}$

11. How often are you distracted by activity or noise around you?

$\begin{array}{ccccc}\text { Never } & \text { Rarely } & \text { Sometimes } & \text { Often } & \text { Very Often } \\ 0 & 1 & 2 & 3 & 4\end{array}$

12. How often do you leave your seat in meetings or other situations in which you are expected to remain seated?

$\begin{array}{ccccc}\text { Never } & \text { Rarely } & \text { Sometimes } & \text { Often } & \text { Very Often } \\ 0 & 1 & 2 & 3 & 4\end{array}$

13. How often do you feel restless or fidgety?

$\begin{array}{ccccc}\text { Never } & \text { Rarely } & \text { Sometimes } & \text { Often } & \text { Very Often } \\ 0 & 1 & 2 & 3 & 4\end{array}$

14. How often do you have difficulty unwinding and relaxing when you have time to yourself?

$\begin{array}{ccccc}\text { Never } & \text { Rarely } & \text { Sometimes } & \text { Often } & \text { Very Often } \\ 0 & 1 & 2 & 3 & 4\end{array}$

15. How often do you find yourself talking too much when you are in social situations?

$\begin{array}{ccccc}\text { Never } & \text { Rarely } & \text { Sometimes } & \text { Often } & \text { Very Often } \\ 0 & 1 & 2 & 3 & 4\end{array}$

16. When you're in conversation, how often do you find yourself finishing the sentences of the people you're talking to, before they can finish them themselves?
Never
0
Rarely
Sometimes
Often
3
Very Often

17. How often do you have difficulty waiting your turn in situations when turn-taking is required?

$\begin{array}{ccccc}\text { Never } & \text { Rarely } & \text { Sometimes } & \text { Often } & \text { Very Often } \\ 0 & 1 & 2 & 3 & 4\end{array}$

18. How often do you interrupt others when they are busy?

Never

0
Rarely

1
Sometimes

2
Often

3
Very Often

4 


\section{Appendix F: Closing Statement and Resources}

Thank you for your participation!

If you are currently experiencing any form or level of distress, and wish to seek professional assistance, mental health services are available at the following locations:

Carruth Center for Psychological and Psychiatric Services | West Virginia University http://well.wvu.edu/ccpps

(304)293-4431

Quin Curtis Center | West Virginia University

https://psychology.wvu.edu/about/quin-curtis-center

(304) 293-1824

Student Health Center | West Virginia University

https:/wvumedicine.org/ruby-memorial-hospital/services/wvu-specialty-clinics/student-health/ (855) WVU-CARE 


\section{Appendix G: IRB Acknowledgement of Exemption}

\section{W. WestVirginiaUniversity. \\ Office of Research Integrity and Compliance \\ 886 Chestnut Ridge Road Morgantown, WV 26506}

\section{Acknowledgement of Exemption}

$02 / 11 / 2019$

To: Monica Leppma

From: WVU Office of Research Integrity \& Compliance

Protocol Type: Exempt

Submission Type: Initial

Funding: N/A

WVU Protocol \#: 1901443696

Protocol Title: Associations between the Adult ADHD Self-Report Rating Scale (ASRS) and the Test of Differential Inhibition and Attention (TDLA)
Approval Date: 02/11/2019

Expir ation Date: $02 / 10 / 2022$

The West Virginia University Institutional Review Board has rev iewed your submission of Exempt protocol 1901443696. Additional details regarding the review are below:

- This research study was granted an exemption because the Research inv olves educational tests, survey procedures, interv iew procedures or observation of public behavior and (i) information obtained is recorded in such a manner that human subjects cannot be identified, directly or through identifiers linked to the subjects; and (ii) any disclosure of the human subjects responses outside the research could not reasonably place the subjects at risk of criminal or civ il liability or be damaging to the subjects financial standing, employability, or reputation [45 CFR 46.101(2)]. All exemptions are only good for three years. If this research extends more than three years beyond the approved date, then the researcher will have to request another exemption. The following documents have been acknowledged for use in this study and are available in the WVU+kc system:

The following documents were reviewed and approved for use as part of this submission. Only the documents listed below may be used in the research. Please access and print the files in the Notes \& Attachments section of your approved protocol.

- Closing Statement and Resources.pdf

$$
\begin{array}{rr}
\text { Protocol \#: } 1901443696 & \text { Phone: } 304293-7073 \\
\text { FWA: } 00005078 & \text { Fax: } 304293-3098 \\
\text { IORG: } 0000194 & \text { Email: IRB@mail.ww.edu }
\end{array}
$$


- Demographics Questionmaire.pdf

- Test of Differential Inlubition and Attention.pdf

- Cover Letter Form A.pdf

- Cover Letter Form B.pdf

- Adult ADHD Self-Report Rating Scale.pdf

\section{WVU IRB acknowledgement of protocol 1901443696 willexpire on 02/10/2022.}

If the study is to contirue beyond the expiration date, a renewal application rnus tbe sub rritted no later than two (2) weeks prior to expiration date. It is your responsib ility to sub nit your protocol for renewal.

Once you begin your human subjects research, the following regulations apply.

1. Unartic ipated or serious adverse events amdior side effects encoumtered in this research study must be reporte d to the IRB withinf ive (5) days, using the Hotify IRB action in the electronis protocol.

2. Ary modic ications to the study protocol should be submitted only if there will be an ince ase in risk to subjects ac comparying the proposed change(s).

3. You may not use a modif ie information sheet until it has beenreviewe d and ackonowle dged by the WVU IRB prior to implementation.

The Office of Research Integrity and Cormpliance will be glad to provide assistance to you throughout the research process. Please feel free to contact us by phone, at 304.293 .7073 or by email at IRBOmailumedu.

Sincerely,

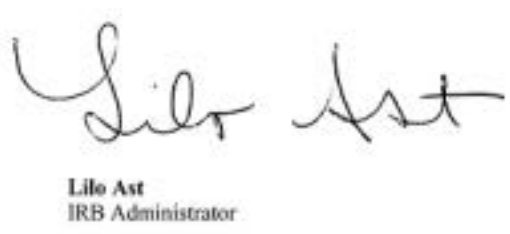

